\title{
Reinforcement of Flowable Dental Composites with Titanium Dioxide Nanotubes
}

Manal Dafar, The University of Western Ontario

Supervisor: Dr. Amin Rizkalla, The University of Western Ontario

A thesis submitted in partial fulfillment of the requirements for the Master of Science degree in Medical Biophysics

(C) Manal Dafar 2014

Follow this and additional works at: https://ir.lib.uwo.ca/etd

Part of the Dental Materials Commons

\section{Recommended Citation}

Dafar, Manal, "Reinforcement of Flowable Dental Composites with Titanium Dioxide Nanotubes" (2014). Electronic Thesis and Dissertation Repository. 2061.

https://ir.lib.uwo.ca/etd/2061

This Dissertation/Thesis is brought to you for free and open access by Scholarship@Western. It has been accepted for inclusion in Electronic Thesis and Dissertation Repository by an authorized administrator of Scholarship@Western. For more information, please contact wlswadmin@uwo.ca. 


\section{REINFORCEMENT OF FLOWABLE DENTAL COMPOSITES WITH TITANIUM DIOXIDE NANOTUBES}

(Thesis format: Monograph)

by

Manal Dafar

Graduate Program in Medical Biophysics

A thesis submitted in partial fulfillment of the requirements for the degree of Master of Science

The School of Graduate and Postdoctoral Studies

The University of Western Ontario

London, Ontario, Canada

(C) Manal Dafar 2014 


\begin{abstract}
Flowable composites are widely used in dentistry. However, they suffer from poor mechanical properties. The aim of this study was to reinforce a flowable composite with $\mathrm{TiO}_{2}$ nanotubes $\left(\mathrm{n}-\mathrm{TiO}_{2}\right)$, which were synthesized using an alkaline hydrothermal technique then functionalized with silane or methacrylic acid (MA). The synthesized n$\mathrm{TiO}_{2}$ was characterized using X-ray diffraction, energy-dispersive X-ray spectroscopy and Fourier transform infrared spectroscopy. Electron microscopy revealed a tubular morphology of $n-\mathrm{TiO}_{2}$. Commercially available flowable composite was reinforced with varying amounts of nanotubes (0-5\%). Dynamic Young's moduli (E) and fracture toughness $\left(\mathrm{K}_{\mathrm{IC}}\right)$ of composites reinforced with $3 \% \mathrm{n}-\mathrm{TiO}_{2}$ functionalized with $\mathrm{MA}$ exhibited the highest values. Cytotoxicity assays, performed on NIH/3T3 fibroblasts revealed excellent biocompatibility. We conclude that flowable composites reinforced with $3 \% \mathrm{n}-\mathrm{TiO}_{2}$ exhibited superior mechanical properties to those of control, with a minimum effect on flowability and radiopacity. Thus, these reinforced composites represent promising materials for use in dental restorations.
\end{abstract}

\title{
Key words:
}

Flowable dental composites, $\mathrm{TiO}_{2}$ nanotubes, flowability, dynamic Young's modulus, fracture toughness, radiopacity, MTT cytotoxicity. 


\section{Dedication}

I dedicate my thesis to my loving parents, Osama and Salwa, my supporting husband, Faris, my precious daughters, Leen and Dana, my sisters, Amal and Walaa, and my brothers, Tamer, Ahmed and Rayan. 


\section{Acknowledgments}

In the name of ALLAH, the most Gracious and the most Merciful. First, All praises to Allah who granted me with all blessings and guidance to proceed successfully. I would like to acknowledge my supervisor, Dr. Amin Rizkalla, not only for giving me an opportunity to work with him, but for his invaluable guidance, encouragement and support throughout my Masters journey. I am deeply grateful to my advisory committee, Dr. Peter Canham and Dr. S. Jeffrey Dixon for their support, help and constructive advice during my research. Special thanks to Dr. Peter Canham who spent a long time editing and proofreading this thesis.

I extend my appreciation to people at Western for their assistance and allowing me to use their facilities. Many thanks to Grace C. Yau for helping with XRD and FTIR, Tim Goldhawk for his assistance with SEM, Dr. Richard Gardiner and Karen Nygard at the Biotron Research Centre for helping with TEM, Matthew Grol for the help with cell studies, and Dr. Richard Bohay who helped with X-ray radiography.

Special thanks go to my colleagues in the lab Dr. Selma Saadaldin and Barry Lai for their friendship and help.

I would like to express my heartfelt gratitude to my parents, Osama and Salwa for their unconditional love, care and sacrifices throughout my learning journey. I would not have achieved anything in my education and my career without their support.

My sincere appreciation also goes to my loving husband, Faris. Without his endless support and encouragement, I would not have been able to proceed in my graduate program. Having you by my side gave me the strength and inspiration needed to succeed. Thanks also to the joy of my life, my precious children, Leen and Dana, whom I 
spent long hours away from especially in the last few months to get this thesis done. Your presence in my life has blessed me with happiness.

Special appreciation is given to my sisters and brothers especially my twin sister, Amal who shared everything with me starting from my happiness and sadness to editing my thesis while she is overseas.

Many thanks to my best friends, Khadija, Dalia and Waad for their continuous support. Finally, I could not have succeeded without the support of a Graduate Scholarship from the Ministry of Health in Saudi Arabia. As well, these studies were supported by an operating grant to Dr. Amin Rizkalla from the Natural Sciences and Engineering Research Council of Canada (NSERC). 


\section{Table of Contents}

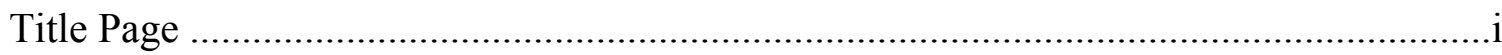

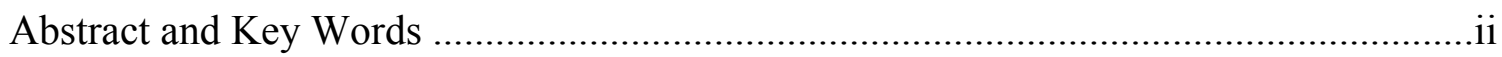

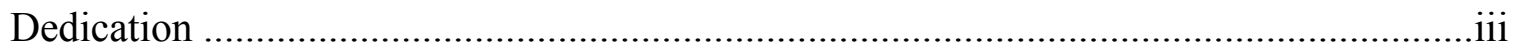

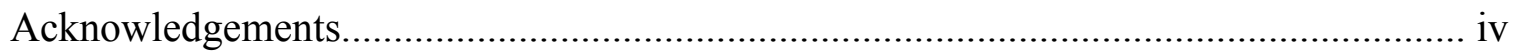

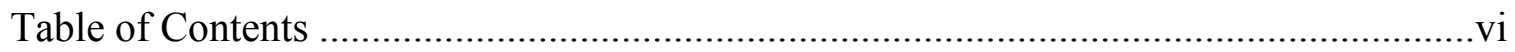

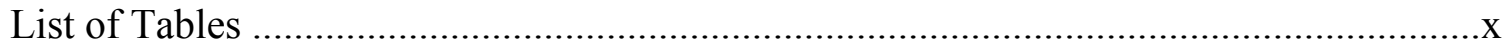

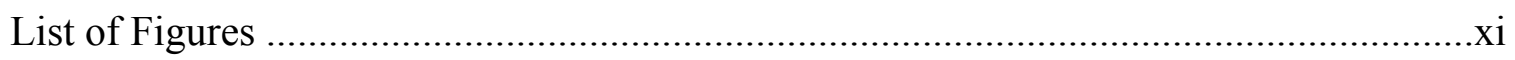

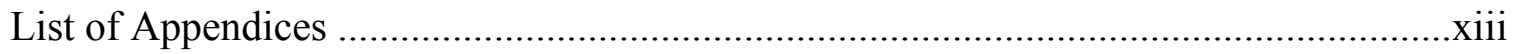

List of Abbreviations and Symbols.....................................................................

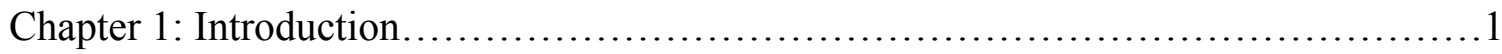

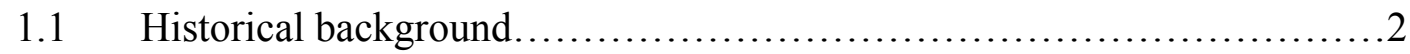

1.2 Composition of dental composites.....................................

1.3 Classification of dental composites..................................

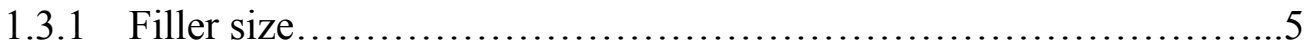

1.3.2 Handling properties........................................... 8

$1.4 \quad$ Clinical failure of dental composites..................................

$1.5 \quad$ Composite reinforcement trials .......................................

1.6 Nanofiller structures and fabrication methods..........................10

$1.7 \quad$ Biomedical applications of titania nanofillers...........................11

1.8 Nanofiller surface modifications (functionalization).....................12

$1.9 \quad$ Characterization of nanotubes........................................ 13 


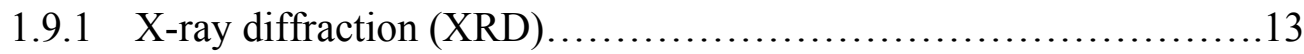

1.9.2 Energy dispersive X-ray spectroscopy (EDX)....................14

1.9.3 Fourier transform infrared spectroscopy (FTIR) .................14

$1.10 \quad$ Flowability of dental composites.................................... 15

1.11 Mechanical properties of dental composites............................16

1.11.1 Factors affecting mechanical properties..........................16

1.11.2 Dynamic Young's modulus (E) ................................17

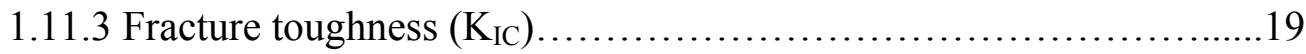

1.12 Radiopacity of dental composites...................................23

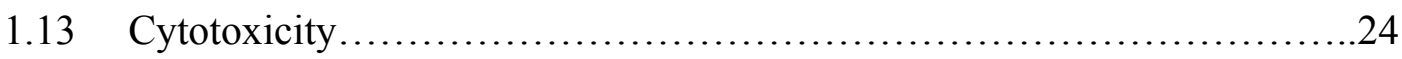

1.14 Thesis motivation, objectives and hypothesis..........................26

Chapter 2: Materials and Methods.................................................27

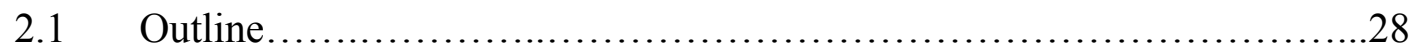

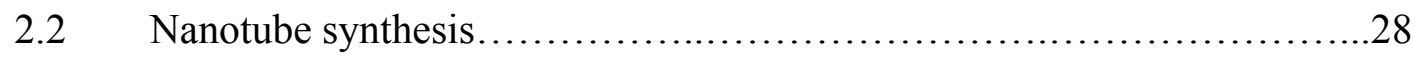

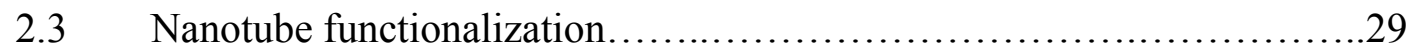

2.3.1 Silane functionalization...........................................29

2.3.2 Methacrylic acid (MA) functionalization.........................30

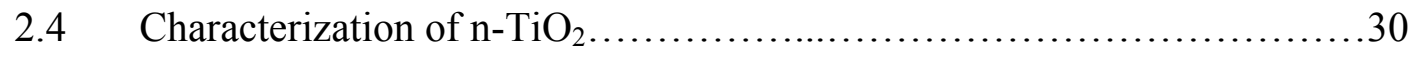

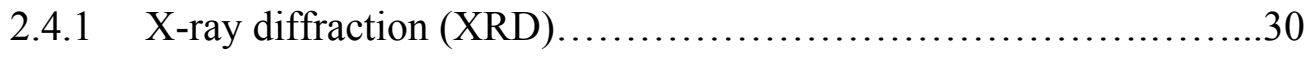

2.4.2 Energy dispersive X-ray spectroscopy (EDX).....................30

2.4.3 Fourier transform infrared spectroscopy (FTIR) ..................31

2.4.4 Scanning (SEM) and transmission (TEM) electron microscopy......31 
2.5 Preparation of composite specimens................................. 32

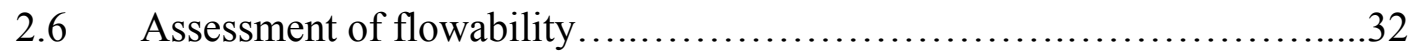

2.7 Mechanical testing of composites.................................. 34

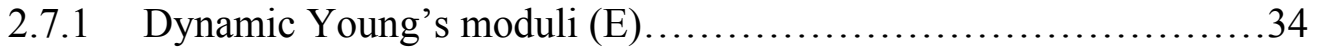

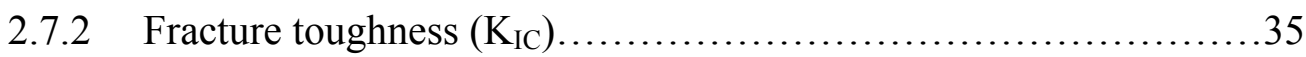

$2.8 \quad$ Radiopacity...................................................... 36

2.9 In vitro cytotoxicity.............................................

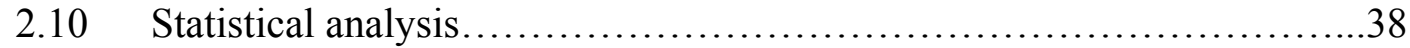

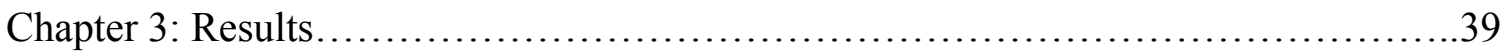

3.1 Chemical characterization of titanium dioxide nanotubes...............40

3.2 Morphological characterization of titanium dioxide nanotubes............42

3.3 Flowability of reinforced and control composites....................43

3.4 Mechanical characterization of reinforced and control composites........45

3.4.1 Dynamic Young's moduli (E) ..............................45

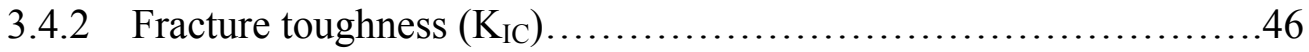

3.5 Radiopacity of reinforced and control composites....................47

3.6 Biocompatibility of reinforced and control composites..................49

Chapter 4: Discussion.................................................... 51

4.1 Nanocomposite fillers.........................................52

4.2 Synthesis of $\mathrm{n}-\mathrm{TiO}_{2}$ using the alkaline hydrothermal reaction.............53

$4.3 \quad$ Filler functionalization........................................... 55 
4.3.1 Purpose of functionalization...............................55

4.3.2 Functionalization with silane...................................55

4.3.3 Functionalization with MA................................57

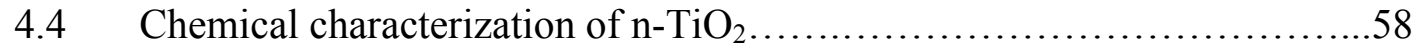

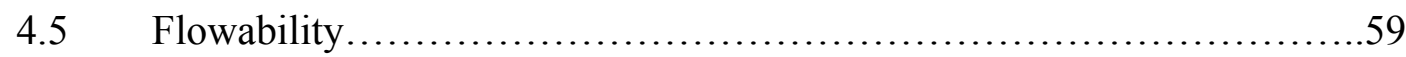

4.6 Mechanical properties of composites..............................60

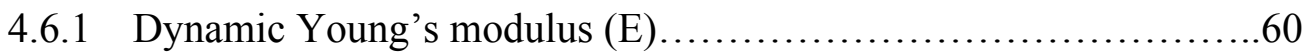

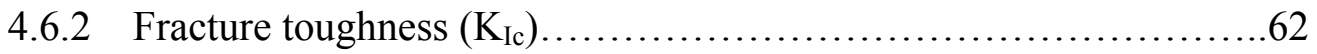

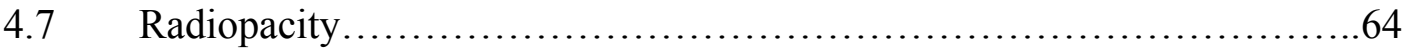

$4.8 \quad$ Biocompatibility ............................................66

Chapter 5: Conclusions and future directions................................67

$5.1 \quad$ Conclusions...................................................... 68

$5.2 \quad$ Future directions.............................................. 70

Chapter 6: References................................................... 72

Appendices:............................................................. 83

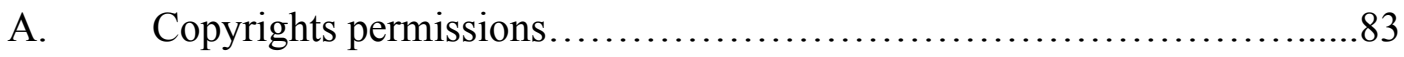

B. Composition of Filtek ${ }^{\mathrm{TM}}$ Supreme Ultra Flowable Restorative, 3M ESPE as supplied by manufacturer.................................. 97

Curriculum Vitae......................................................... 98 


\section{List of Tables}

Table 1.1: Chemical composition of resin dental materials...........................5

Table 1.2: Classification of dental composites depending on the size of fillers...........6

Table 1.3: Summary of three commercial nanocomposites...........................8

Table 1.4: Comparison between different $\mathrm{n}-\mathrm{TiO}_{2}$ fabrication techniques................11

Table 3.1: Elemental analysis of $\mathrm{n}-\mathrm{TiO}_{2}$ sample using EDX......................41

Table 3.2: Fracture toughness $\left(\mathrm{K}_{\mathrm{IC}}\right)$ of control and reinforced flowable composites.....46

Table 4.1: Summary for $\mathrm{E}$ and $\mathrm{K}_{\mathrm{IC}}$ values for enamel, dentin and different dental materials................................................................63

Table 4.2: Radiopacity of enamel, dentin and restorative materials...................65 


\section{List of Figures}

Figure 1.1: Nanostructures morphologies; nanowires, nanorods, nanotubes, and

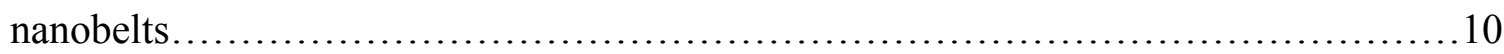

Figure 1.2: Fracture modes due to crack propagation...............................20

Figure 1.3: (a) Notchless triangular prism (NTP) used for fracture toughness test, (b) Diagram of NTP specimen mounted in holder..................................22

Figure 1.4: (a) Holder for the NTP specimen, (b) Mounting block with specimen holder,

(c) Mounting block with specimen holder, NTP sample, and spacer blade, and (d) Custom-designed grips securing the holder and an NTP specimen...................23

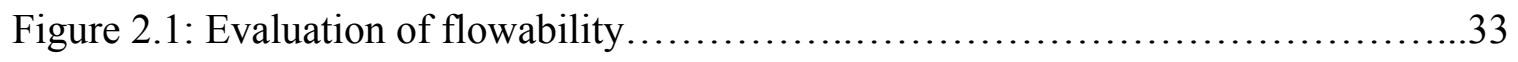

Figure 2.2: Ultrasonic method setup....................................... 34

Figure 2.3: Linear regression curve for $\log \% \mathrm{cRGB}$ versus $\log \mathrm{Al}$ thickness............37

Figure 3.1: XRD signal intensity (arbitrary units) versus diffraction angle $2 \theta$

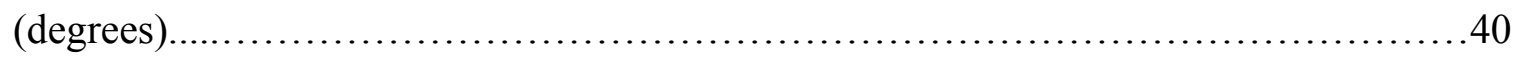

Figure 3.2: FTIR for (a) $\mathrm{TiO}_{2}$ nanotubes functionalized with silane, (b) $\mathrm{TiO}_{2}$ nanotubes functionalized with MA...................................................42

Figure 3.3: (a) SEM, (b) TEM of $\mathrm{n}-\mathrm{TiO}_{2}$ following alkaline hydrothermal reaction and calcination................................................................. 43

Figure 3.4: Changes in composite discs diameters with different amounts of $\mathrm{NF}$ n- $\mathrm{TiO}_{2}$ fillers. 
Figure 3.5: Flowability of composites evaluated by measuring the composite discs diameters corresponding to the filler content...................................44

Figure 3.6: Dynamic Young's moduli of reinforced composites as compared to control..............................................................45

Figure 3.7: SEM images for composites fracture surfaces........................................47

Figure 3.8: Radiograph shows the flowable composite specimens, leads and Al step

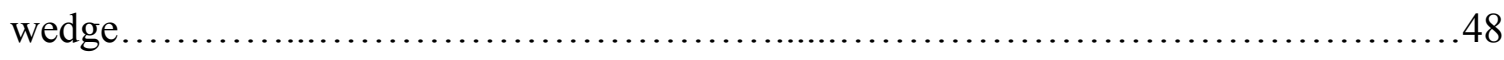

Figure 3.9: Radiopacity of flowable composites.............................49

Figure $3.10:$ MTT cytotoxicity test........................................... 50

Figure 4.1: $\mathrm{TiO}_{2}$ nanotube formation scheme.................................54

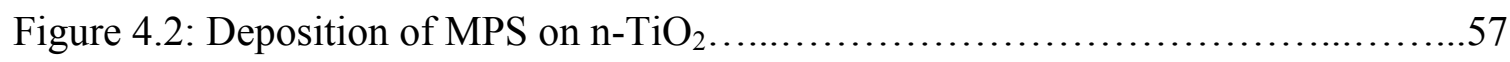

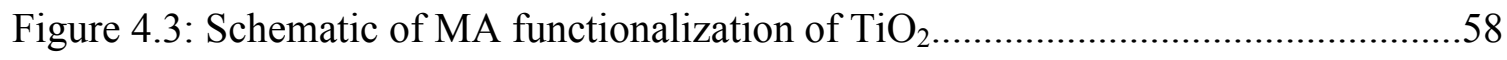




\section{List of Appendices}

Appendix A: Copyrights permissions......................................... 83 Appendix B: Composition of Filtek ${ }^{\mathrm{TM}}$ Supreme Ultra Flowable Restorative, 3M ESPE as

Supplied by Manufacturer......................................................97 


\title{
List of Abbreviations and Symbols
}

\author{
Abbreviations: \\ \% RGB: percentage of red, green and blue \\ ADA: $\quad$ American Dental Association \\ ATES: allyltriethoxysilane \\ Bis-EMA: ethoxylated bisphenol-A-dimethacrylate \\ Bis-GMA: bisphenol A-glycidyl methacrylate \\ C-factor: configuration factor \\ CF: $\quad$ correction factor \\ CNSR: $\quad$ chevron-notched short rod \\ $\mathrm{D}_{3} \mathrm{MA}: \quad$ decanediol dimethacrylate \\ DMEM: $\quad$ Dulbecco's Modified Eagle Medium \\ E: Dynamic Young's modulus \\ EDX: $\quad$ Energy dispersive $\mathrm{x}$-ray spectroscopy \\ FBS: $\quad$ Fetal bovine serum \\ FTIR: $\quad$ Fourier transform infrared spectroscopy \\ GPS: $\quad$ glycidoxypropyltrimethoxy-silane \\ ISO: International Standards Organization \\ $\mathrm{K}_{\mathrm{IC}}: \quad$ fracture toughness \\ LDH: $\quad$ lactate dehydrogenase \\ MA: methacrylic acid \\ MPS: $\quad 3$-(trimethoxysilyl) propyl methacrylate \\ MPTMS: 3-methacryloxypropyltrimethoxysilane
}




$\begin{array}{ll}\text { MTT: } & \text { 3-(4,5-dimethylthiazol-2-yl)-2,5-diphenyl tetrazolium bromide } \\ \text { n-TiO }: & \text { titania nanotubes } \\ \text { NF n-TiO }_{2}: & \text { nonfunctionalized titania nanotubes } \\ \text { NTP: } & \text { notchless triangular prism } \\ \text { OD: } & \text { optical density of the X-ray image } \\ \text { OTMS: } & \text { trimethoxy (octyl) silane } \\ \text { PDF: } & \text { powder diffraction file } \\ \text { PMMA: } & \text { poly(methyl methacrylate) } \\ \text { SEM: } & \text { scanning electron microscopy } \\ \text { TEGDM: } & \text { triethyleneglycol dimethacrylate } \\ \text { TEM: } & \text { transmission electron microscopy } \\ \text { UDMA: } & \text { urethane dimethacrylate } \\ \text { UDMS: } & \text { urethane dimethacrylate silane } \\ \text { UTMA: } & \text { urethane tetramethacrylate } \\ \text { X-ray diffraction }\end{array}$




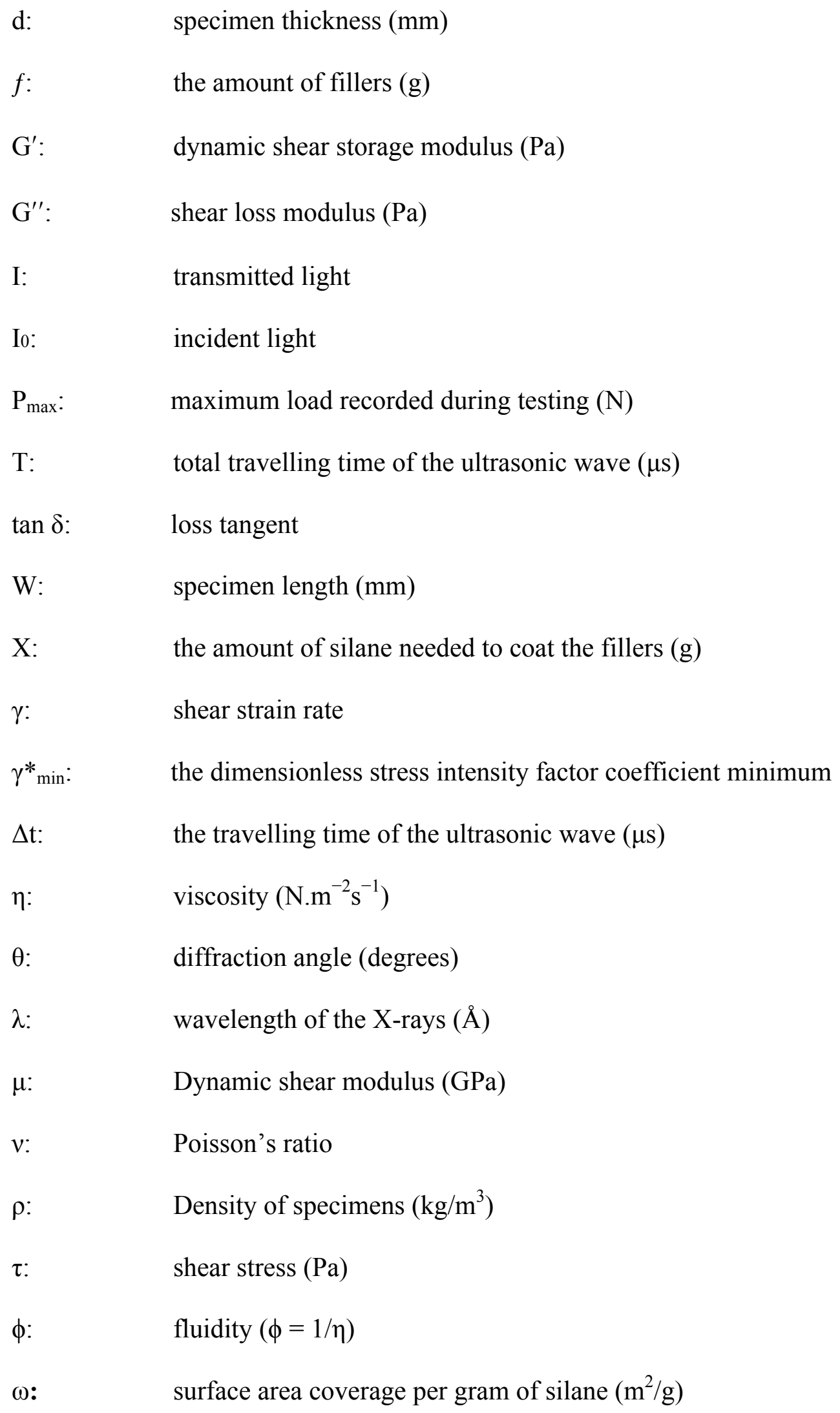


Chapter 1

Introduction 


\subsection{Historical background}

Esthetic restorations that have the properties for matching natural color of teeth are in demand by patients and dentists. Thus, many trials have been done to find the best tooth colored restorations. The first attempt was using silicate cement as a white tooth filling material in 1873 by Thomas Fletcher [1]. These materials were supplied in a form of a powder and a liquid of alumino silicate glass and aqueous phosphoric acid respectively. The setting of this material occurred as a result of acid-base reaction that caused the material to be highly acidic. Due to its acidic nature, pulpal injury and dentin sensitivity were associated with silicate cements [2]. Resin-based dental materials were introduced at the end of the 1940's. Although these composites had much better esthetics than amalgam, the widely used restorative material at that time, their clinical use was not satisfactory. These early resins had very high polymerization shrinkage, low stiffness and unstable color. Subsequently, in 1951, Knock and Glenn [3] introduced a new material which had inorganic fillers incorporated with the resin to avoid polymerization shrinkage. However, discoloration and wear were problems encountered with these newer materials. Recently used dental composites were discovered in 1963 when Rafael Bowen discovered that chemical treatment of silica particles resulted in bonding with organic polymers. He used tris(2-methoxyethoxy) vinyl silane to coat the silica surfaces and referred to it as a coupling agent. Bowen was able to bind coated silica into bisphenol Aglycidyl methacrylate (bis-GMA) producing a material with very promising properties in the area of dental biomaterials [4]. This was a materials revolution in dentistry and the first stage in introducing dental composites - now so widely used in the practice of dentistry. Earlier, dental composites were composed of a continuous organic phase 
formed by a fluid monomer and inorganic fillers of silica coated with a silane coupling agent. These composites were self-cured. They were prepared by mixing two pastes immediately before use. One paste contains an activator (e.g., tertiary amine) and the second paste contains an initiator (e.g., benzoyl peroxide) [5].

In the early 1970s, ultraviolet (UV) light-activated resin composites were introduced. It utilized UV light with an average wavelength $365 \mathrm{~nm}$ that can split benzoin methyl ether into free radicals (no tertiary amines) to start composite polymerization. Using UV light was not convenient because of its disadvantages including eye damage, possible soft tissue burns and shallow polymerization [6]. Within very few years Dart et al. [7] reported the use of visible light to cure composites by converting a photoinitiator into free radicals when exposed to the blue range wavelength. Flowable composites were introduced in 1996. Initially, the development of flowable composites was based on their higher fluidity but there was no clinical evidence of their success in clinical use. However, these composites were more subjected to wear due to their lower fillers content.

\subsection{Composition of dental composites}

Currently, dental composites consist of two phases: the synthetic polymer matrix and inorganic fillers. They are linked together via a coupling agent (such as silane). In addition, initiators and activators are added [8]. Bis-GMA is the most commonly used organic matrix in commercially available dental composites. Other monomers including triethyleneglycol dimethacrylate (TEGDMA), urethane dimethacrylate (UDMA), ethoxylated bisphenol-A-dimethacrylate (Bis-EMA), decanediol dimethacrylate ( $\left.{ }_{3} M A\right)$, 
bis(methacryloyloxymethyl) tricyclodecane, and urethane tetramethacrylate (UTMA) can be used to reduce the viscosity of Bis-GMA [9].

Inorganic fillers such as quartz, colloidal silica, and silica glass containing small amounts of zirconium, strontium and barium are the most commonly used fillers. The inorganic fillers play an important role in improving the strength and elastic stiffness. On the other hand, they reduce water absorption, polymerization shrinkage and coefficient of thermal expansion. Bonding of organic and inorganic phases by coating the fillers with a coupling agent results in the formation of a strong covalent bond. This is a key factor in terms of good mechanical properties of dental composite. Coupling agents have two functional groups in order to link the matrix and the fillers chemically [8]. Polymerization of light-activated composites takes place due to irradiation through blue light curing with the wavelength ranges between $410-500 \mathrm{~nm}$. Photoinitiators are incorporated into dental composites to absorb that blue light [10]. Tertiary amine is used as a photoactivator [11]. Table 1.1 summarizes the composition of dental composites and the purpose of each ingredient [12]. 


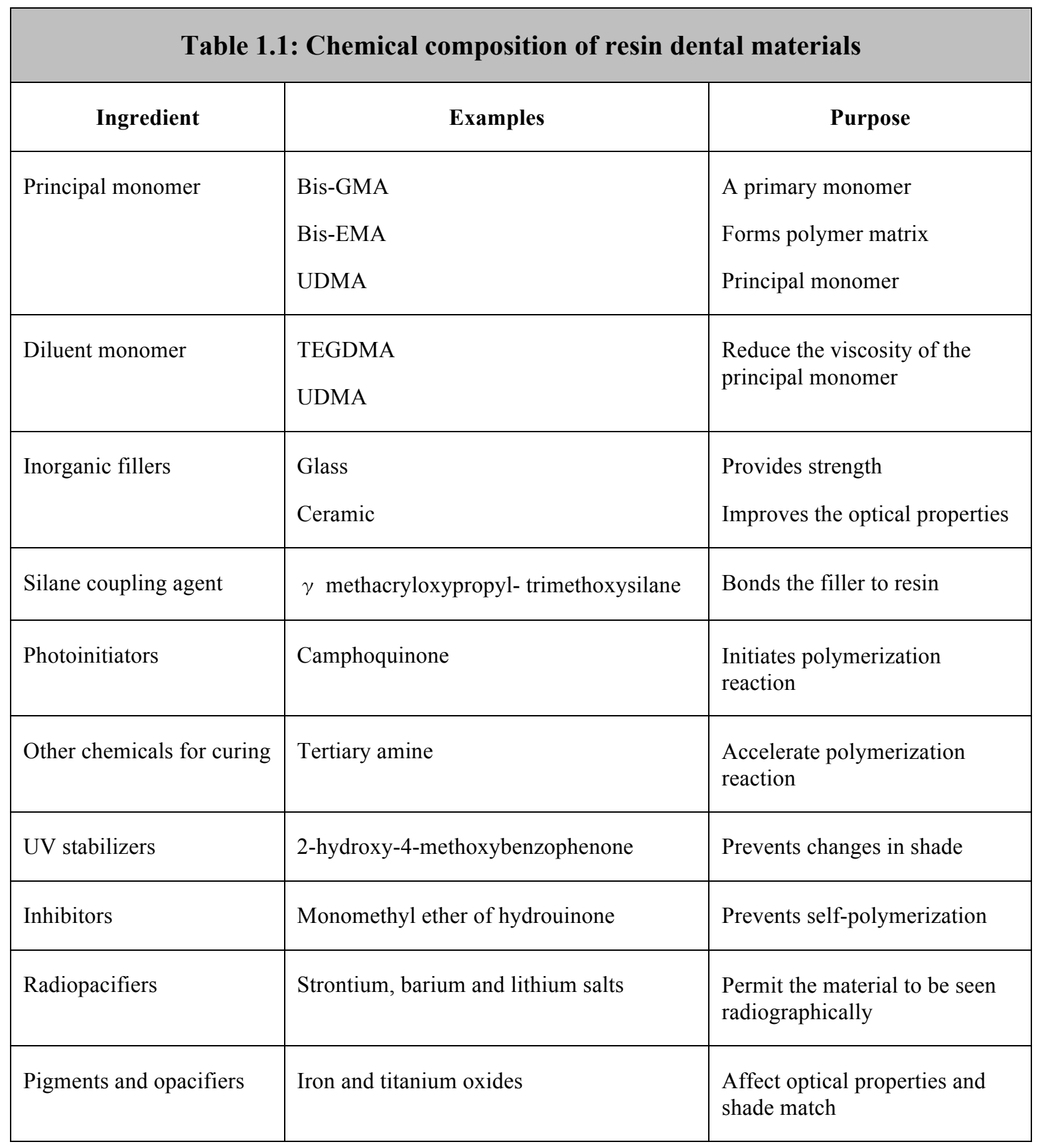

\subsection{Classification of dental composites}

\subsubsection{Filler size}

According to the size of fillers, dental composites can be classified into macrofilled (conventional), microfilled, hybrid and nanofilled, Table 1.2 [5]. Composites with nanofillers are so called nanocomposites [8]. Different nanofillers have been introduced 
to dental composites. However, in this thesis, we are introducing a novel flowable nanocomposites reinforced with $\mathrm{TiO}_{2}$ nanotubes. Nanofillers do not scatter visible light as they shrink to a fraction of this light wavelength $(0.4-0.8 \mu \mathrm{m})$. So, they are invisible and they can improve the optical properties of composites [13]. Theoretically, nanofiller content could be increased up to $90-95 \%$ by weight due to their small size. In fact, adding a high percentage of nanofillers affects their dispersion in the resin matrix and the viscosity of the nanocomposites because of their high surface area. Incorporating small weight fractions of nanofillers will result in significant reduction of polymerization shrinkage and further improvement in both physical and mechanical properties of nanocomposites [8].

\begin{tabular}{|c|c|c|c|c|}
\hline $\begin{array}{l}\text { Type of } \\
\text { composite }\end{array}$ & $\begin{array}{l}\text { Size of filler } \\
\quad(\mu \mathrm{m})\end{array}$ & Type of filler & Advantages & Disadvantages \\
\hline Macrofilled & $10-40$ & Quartz or glass & $\begin{array}{l}\text { Can withstand occlusal } \\
\text { forces }\end{array}$ & $\begin{array}{l}\text { 1- Poor finish } \\
\& \text { high wear } \\
\text { 2- Inadequate } \\
\text { radiopacity of } \\
\text { quartz }\end{array}$ \\
\hline Microfilled & $.01-0.1$ & Colloidal silica & $\begin{array}{l}\text { 1- Easier to polish. } \\
\text { 2- Good surface finish }\end{array}$ & $\begin{array}{l}\text { Lower } \\
\text { mechanical } \\
\text { properties than } \\
\text { the macrofilled. }\end{array}$ \\
\hline Hybrid & $\begin{array}{c}15-20 \\
0.01-0.05\end{array}$ & Glass and colloidal silica & $\begin{array}{l}\text { Less polymerization } \\
\text { shrinkage }\end{array}$ & $\begin{array}{l}\text { Surface finish is } \\
\text { less than } \\
\text { microfilled }\end{array}$ \\
\hline $\begin{array}{l}\text { Modern } \\
\text { hybrid }\end{array}$ & $\begin{array}{c}0.5-1 \\
0.01-0.05\end{array}$ & $\begin{array}{c}\text { Glass, Zirconia and } \\
\text { colloidal silica }\end{array}$ & $\begin{array}{l}\text { Combine advantages of } \\
\text { macro and microfilled }\end{array}$ & Less translucent \\
\hline Nanofilled & $\begin{array}{c}<0.01 \\
(10 \mathrm{~nm})\end{array}$ & Silica or Zirconia & $\begin{array}{l}\text { Improved strength and } \\
\text { esthetic }\end{array}$ & $\begin{array}{l}\text { Agglomeration } \\
\text { of nanofillers }\end{array}$ \\
\hline
\end{tabular}


Studies reported that the smaller filler size has the ability to change the organic matrix between fillers resulting in better mechanical properties. This is due to reducing interparticle distances (at interfacial region) resulting in smooth transition between the stiff inorganic fillers to smooth organic polymer matrix $[14,15]$. In contrast, nanofilled composites are characterized by larger interface between the small filler and organic matrix. Consequently, they could be more susceptible to hydrolytic degradation and a faster degradation of mechanical properties as compared to micro-hybrid composites [16].

Several types of dental nanocomposites are available commercially. Three examples are mentioned here. Filtek Supreme (3M ESPE, St. Paul, MN, USA) contains nanoclusters (silica or zirconia-silica particles, 2-75 nm) and nanomers (20-75 nm nonagglomerated, non-aggregated silica particles). Nanoclusters tend to form spherical agglomerates with average size of $0.6 \mu \mathrm{m}$. Another type of commercially available nanocomposite is Premise (Kerr/Sybron, Orange, CA, USA). It is a nanohybrid composite combining 3 different kinds of fillers: non-agglomerated $20 \mathrm{~nm}$ spherical silica nanoparticles, prepolymerized fillers $(30-50 \mu \mathrm{m})$ and barium glass fillers $(0.4 \mu \mathrm{m})$. The third example of nanocomposite is Ceram-X (Dentsply DeTrey, Konstanz, Germany). It contains glass fillers $(1.1-1.5 \mu \mathrm{m})$, silicon-dioxide nanofiller $(10 \mathrm{~nm})$ and polysiloxane particles $(2-3 \mathrm{~nm})$ [8]. Table 1.3 summarizes these three nanocomposites. 


\begin{tabular}{|c|l|c|l|}
\hline \multicolumn{4}{|c|}{ Table 1.3: Summary of three commercial nanocomposites } \\
\hline Nanocomposite & \multicolumn{1}{|c|}{ Type of filler } & Size of filler & \multicolumn{1}{|c|}{ Manufacturer } \\
\hline Filtek Supreme & 1-Nanoclusters & $2-75 \mathrm{~nm}$ & 3M ESPE, St. Paul, MN, USA \\
& 2-Nanomers & $20-75 \mathrm{~nm}$ & \\
\hline \multirow{2}{*}{ Premise } & 1-Nonagglomerated silica & $20 \mathrm{~nm}$ & Kerr/Sybron, Orange, \\
& nanoparticles & $30-50 \mu \mathrm{m}$ & CA, USA \\
& 2- Prepolymerized fillers & $0.4 \mu \mathrm{m}$ & \\
\hline 3eram-X & 3- Barium glass fillers & $1.1-1.5 \mu \mathrm{m}$ & $\begin{array}{l}\text { Dentsply DeTrey, Konstanz, } \\
\text { 1-Glass fillers }\end{array}$ \\
& 2-Silicon-dioxide nanofiller & $10 \mathrm{~nm}$ & \\
& 3- Polysiloxane particles & $2-3 \mathrm{~nm}$ & \\
\hline
\end{tabular}

\subsubsection{Handling properties}

Based on their handling properties, dental composites can be classified into universal, packable and flowable [12]. Universal composites can be used for almost all applications. Packable (condensable) composites are considered to be alternatives to dental amalgam. They are characterized by good physical and mechanical properties that enable them to withstand occlusal forces in posterior restorations.

Flowable composites are characterized by their greater fluidity due to either lower filler content or more diluent monomers. They offer the advantages of greater fluidity, easier placement and better adaptation to the walls of the cavity. They are indicated as liners, fissure sealants, preventive resin restorations (PRR), class $\mathrm{V}$ restorations and repair of fractured restorations [17]. Moreover, previous studies suggested the use of flowable composite with low modulus of elasticity as an intermediate layer under the hybrid composite. This may result in reducing the interfacial stress between the tooth and restoration [18]. However, the mechanical properties of flowable composites are inferior 
to those of packable ones. Bayne et al. [19] reported that flowable composites have 20$25 \%$ lower filler content and subsequently lower rigidity and 20-30\% lower modulus of elasticity [18]. Packable composites can be placed using a syringe or other dental instrument while flowable composites are formulated to be dispensed from a syringe with very fine disposable tips [11].

\subsection{Clinical failure of dental composites}

Researchers are trying to understand the factors leading to failure of composite restorations. Recurrent caries found to be the most common cause of failure especially with posterior restorations [20]. However, other studies showed evidence for restoration failure after 5 years due to bulk fracture [21].

\subsection{Composite reinforcement trials}

With respect to the inferior mechanical properties of flowable composites, many attempts were made to reinforce resin-based composites. Fiber reinforcements with ceramic and metal fibers are the most common approaches to improve the mechanical properties of dental and orthopedic composites $[22,23]$. The success of such reinforcements was not ideal due to the large fillers size, poor filler-matrix bonding, unequal distribution of fillers, and the presence of stress concentration areas [24]. Until now, no fillers are defined as ideal for dental composites. However, $\mathrm{TiO}_{2}$ nanotubes incorporated into flowable resin composites could improve the fracture and flexural properties without significant alteration in their fluidity [25]. 


\subsection{Nanofiller structures and fabrication methods}

Nanofiller morphology varies depending on the preparation method. Different nanostructure morphology may influence their reinforcing effect on composites. Ding et al. [26] defined four different groups of nanostructures. Nanowires are linear structures, but their sides or cross sections may not be uniform; nanorods are similar to nanowires, but shorter; nanoribbons/nanobelts have well-defined and uniform walls; and nanotubes have a characteristic hollow interior channel (Fig. 1.1).

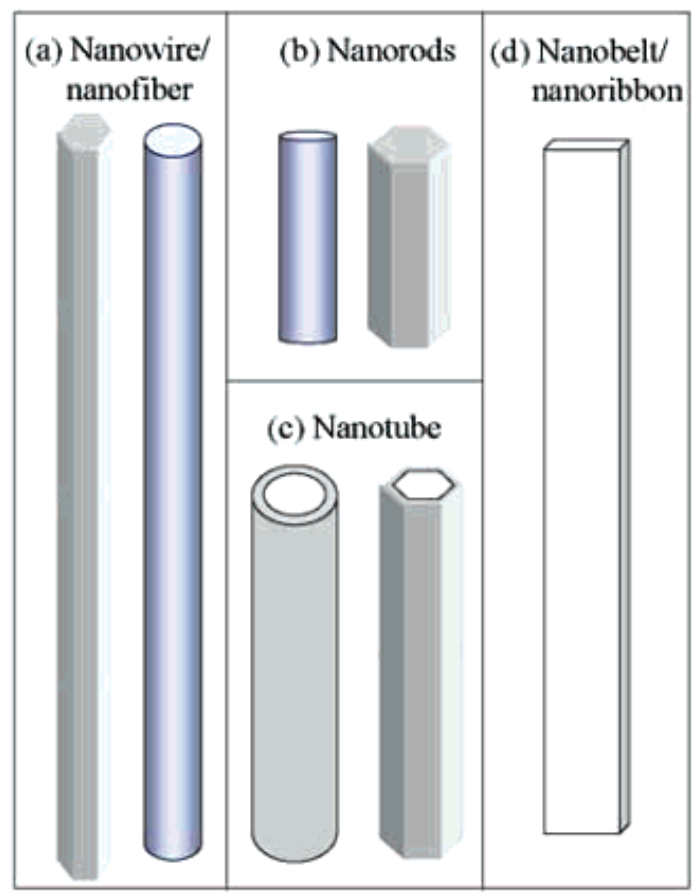

Fig.1.1: Nanostructure morphologies; nanowires, nanorods, nanotubes, and nanobelts. Adapted with permission (Appendix A) from the journal of physical chemistry B. 2004;108(33): 12280-91 [26].

Titania nanotubes $\left(\mathrm{n}-\mathrm{TiO}_{2}\right)$ can be fabricated using several techniques, including the assisted-template method [27], sol-gel method [28], electrochemical anodic oxidation method [29] and hydrothermal treatment [30]. Ou et al. [31] compared different n- $\mathrm{TiO}_{2}$ 
preparation techniques (Table 1.4). In the work presented in this thesis, we used the alkaline hydrothermal method at $160^{\circ} \mathrm{C}$ followed by washing with deionized water and $0.1 \mathrm{~N} \mathrm{HCl}$ to fabricate $\mathrm{n}-\mathrm{TiO}_{2}$.

\begin{tabular}{|l|l|l|l|}
\hline \multicolumn{2}{|c|}{ Table 1.4: Comparison between different n-TiO fabrication techniques } \\
\hline \multicolumn{1}{|c|}{ Fabrication method } & \multicolumn{1}{|c|}{ Advantages } & \multicolumn{1}{c|}{ Disadvantages } & \multicolumn{1}{c|}{ n-TiO features } \\
\hline $\begin{array}{l}\text { Template-assisted } \\
\text { method }\end{array}$ & $\begin{array}{l}\text { 1- The scale of nanotube } \\
\text { can be moderately } \\
\text { controlled by applied } \\
\text { template }\end{array}$ & $\begin{array}{l}\text { 1- Complicated } \\
\text { fabrication process } \\
\text { 2- Tube morphology may } \\
\text { be destroyed during } \\
\text { fabrication process. }\end{array}$ & $\begin{array}{l}\text { Ordered arrays } \\
\text { (powder form) }\end{array}$ \\
\hline $\begin{array}{l}\text { Electrochemical anodic } \\
\text { oxidation method }\end{array}$ & $\begin{array}{l}\text { 1-More desirable for } \\
\text { practical applications } \\
\text { 2-Ordered alignment } \\
\text { with high aspect ratio } \\
\text { 3-Feasible for extensive } \\
\text { applications }\end{array}$ & $\begin{array}{l}\text { 1-Mass production is } \\
\text { limited } \\
\text { 2-Rapid formation } \\
\text { kinetics is subjected to the } \\
\text { utilization of HF } \\
\text { 3-Highly expense of } \\
\text { fabrication apparatus }\end{array}$ & $\begin{array}{l}\text { Oriented arrays (thin } \\
\text { film) }\end{array}$ \\
\hline Hydrothermal treatment & $\begin{array}{l}\text { 1-Easy route to obtain } \\
\text { nanotube morphology } \\
\text { 2-A number of } \\
\text { modifications can be } \\
\text { used to enhance the } \\
\text { attributes of titanium } \\
\text { nanotubes } \\
\text { 3-Feasible for extensive } \\
\text { applications }\end{array}$ & $\begin{array}{l}\text { 1-Long reaction duration } \\
\text { is needed } \\
\text { 2-Highly concentrated } \\
\text { NaOH must be added. } \\
\text { 3-Difficult in achieving } \\
\text { uniform size }\end{array}$ & $\begin{array}{l}\text { Random alignment } \\
\text { (powder form) }\end{array}$ \\
\hline
\end{tabular}

\subsection{Biomedical applications of titania nanofillers}

$\mathrm{n}-\mathrm{TiO}_{2}$ have been found to have excellent biocompatibility [25]. As reported by Swami et al. [32], $\mathrm{n}-\mathrm{TiO}_{2}$ with modified surfaces have been used in orthopedics and dental implants. Also, $\mathrm{n}-\mathrm{TiO}_{2}$ were a suitable substrate for bone regeneration using stem cells. In addition, these nanotubes could be used as drug delivery vehicles for local antibiotics. 
Yoshikawa et al. [33] reported that calcium phosphate cement containing anatase phase of $\mathrm{TiO}_{2}$ contributes to apatite formation in vitro. This led to the application of titaniabased cements in endodontics as root canal sealers. These cements exhibited excellent sealing ability and controlled setting times [33]. n- $\mathrm{TiO}_{2}$ were successfully incorporated into resin-based bone cements as reinforcing fillers [25].

\subsection{Nanofiller surface modifications (functionalization)}

Functionalization can be defined as the chemical reaction to treat/modify the inorganic fillers surface in order to be compatible with the organic polymer matrix of the composite. Surface modification of $\mathrm{n}-\mathrm{TiO}_{2}$ particles is required because these nanoparticles are very fine and can easily agglomerate. On the other hand, they are difficult to disperse in organic solvents. Organosilanes are commonly used to coat inorganic fillers of dental materials to improve their dispersion and bonding to the resin matrix [34].

For functionalization with silane, two main methods have been proposed. Hydrolysis and direct condensation mechanisms. As described by Pluedeman [35], hydrolysis mechanism involves hydrolysis of $\left(-\mathrm{OCH}_{3}\right)$ groups on silane results in formation of silanol groups. The silanol groups condense with hydroxyl groups on the surface of inorganic fillers to form a covalent bond. This method needs to be done in a water-containing organic solvent such as cyclohexane. The second mechanism is direct condensation in which silane binds to the filler surface chemically through direct condensation of alkyloxy groups of the silane with hydroxyl groups on the fillers surface. This method is carried out in an anhydrous environment [36]. Amines can also be used as 
catalysts to promote adsorption of silane. According to Chen et al. [37], 2\% npropylamine used with 3-methacryloxypropyltrimethoxysilane (MPS) forms a more stable silane bond.

The interphase between organic matrix and fillers has a significant role in nanocomposites as the nanosized fillers have high surface area to volume ratio. Wilson et al. [38] studied the effect of organosilanes on nanocomposites. Two types of silane were used, a reactive and non-reactive silanes (dual silanization). The reactive silane; 3methacryloxypropyltrimethoxysilane (MPTMS) has the ability to copolymerize with the polymer network while the nonreactive silane; n-octyltrimethoxysilane (OTMS) does not copolymerize but it is hydrophobic which may prevent water sorption and hydrolytic degradation of composite. Methacrylic acid (MA) was found to be able to bind with n$\mathrm{TiO}_{2}$ via a Ti-carboxylic coordination bond. Also, copolymerization of the vinyl double bond in MA results in formation of $\mathrm{nTiO}_{2}$-PMMA composite [39]. Nanosized $\mathrm{TiO}_{2}$ reinforcing fillers were introduced to dental composites by Xia et al. [40] in form of nanoparticles. Allyltriethoxysilane, (ATES) was used for functionalization of these nanoparticles. ATES functionalized nanoparticles have a limited improvement in the mechanical properties of dental composites because of their agglomeration.

\subsection{Characterization of nanotubes}

\subsubsection{X-ray diffraction (XRD)}

X-ray diffraction (XRD) is used to characterize the structure and composition of materials. Each material has its own XRD pattern caused by diffraction of an incident Xray beam when it interferes with the atomic planes of a crystal. XRD can be used to 
identify crystal structures of elements or to identify unknown materials or mixtures by comparing the experimental data with databases [41]. XRD pattern for $\mathrm{TiO}_{2}$ varies according to its different crystal structures. Each pattern results due to interaction between the incident X-rays and the sample creating diffraction beams. These diffracted beams are related to interplanar spacing (d-space) in the crystalline powder. According to Bragg's Law: $\lambda=2 \mathrm{~d} \sin \theta$ where $\lambda$ is the wavelength of the X-rays $(\AA), \mathrm{d}$ is the interplanar spacing $(\AA)$ and $\theta$ is the diffraction angle (degrees). In case of $\mathrm{Cu} K \alpha, \lambda=1.54(\AA)$. Lin et al. [42] reported diffraction peaks for anatase $\mathrm{TiO}_{2}$ matched with Powder Diffraction File (PDF\#21-1272) in databases.

\subsubsection{Energy dispersive x-ray spectroscopy (EDX)}

Energy-dispersive X-ray spectroscopy (EDX) is a common analytical technique used for elements analysis. It depends on the interaction between X-rays and a sample. Each element has a characteristic atomic structure that results in a unique set of peaks. To stimulate X-rays emission from a sample, a high-energy beam with charged particles (either electrons or protons) or X-ray beam is directed to the sample of interest. This beam leads to electron excitation in the inner shell of the sample's atoms followed by electron ejection leaving a hole in the inner shell. This hole will be filled with an electron from the outer shell of the atom. The difference in energy between the inner and outer shells may be released as X-ray that can be measured by an energy-dispersive spectrometer [43].

\subsubsection{Fourier transform infrared spectroscopy (FTIR)}

To confirm bonding between $\mathrm{n}-\mathrm{TiO}_{2}$ and coupling agents via different functional groups, 
Fourier transform infrared spectroscopy (FTIR) can be done. FTIR can be used to determine the presence of functional groups in molecules by comparing the experimental FTIR absorbance or transmission peaks with databases. When new fillers are introduced to composite, FTIR is a valuable method in evaluating the functional groups that bind the fillers with the polymer matrix. In the literature, many studies were conducted to understand bonding between functionalized fillers and resin matrix. Yang et al. [44] studied the bonds formed between $\mathrm{TiO}_{2}$ particles and poly (methyl methacrylate) (PMMA). FTIR showed an evidence of presence of vinyl groups causing PMMA grafting from the surface of $\mathrm{TiO}_{2}$ particles. FTIR absorption band at $1700 \mathrm{~cm}^{-1}$ corresponds to carbonyl group stretching in silane confirming that vinyl groups were successfully grafted into $\mathrm{TiO}_{2}$ surfaces. Khaled et al. [25] reported FTIR absorbance peaks between $1413-1547 \mathrm{~cm}^{-1}$ due to the presence of carboxylic group and another peak at $1630 \mathrm{~cm}^{-1}$ due to coordination of vinyl bond of $\mathrm{MA}$ with $\mathrm{TiO}_{2}$ nanotubes.

\subsection{Flowability of dental composites}

Improving the strength of flowable composites was the main target of this study. However, maintaining their fluidity was essential. It is important here to clarify that flow is the fluidity $(\phi)$ of the material and it is the reciprocal of viscosity $(\phi=1 / \eta)$. Flow is a function of shear rate and temperature. It is a term used to describe how quickly materials flow in a certain period of time, whereas viscosity is the material's resistance to flow. Viscosity $(\eta)$ is the shear stress $(\tau)$ divided by the shear strain rate $(\gamma)$ under the same temperature. Dental composites are viscoelastic materials. They share criteria of both viscous materials (e.g., oils) and elastic materials (e.g., metals). 
The dynamic oscillatory shear test is commonly used to study the viscoelastic behavior of a material. Lee et al. [45] investigated the viscoelastic properties of different composites including flowable ones. A vibratory shear signal of frequency $(\omega)$ was applied to the composite specimens. Afterwards, the dynamic shear storage modulus $\left(\mathrm{G}^{\prime}\right)$, the shear loss modulus $\left(\mathrm{G}^{\prime \prime}\right)$, the loss tangent $(\tan \delta)$ and the viscosity $(\eta)$ were measured. Evaluation of flowability can be done by using different methods other than those that are used to evaluate viscosity. Bayne et al. [19] compared the flowability of different commercial flowable composites. They combined the American Dental Association (ADA) flow test for dental cements [46] with a suggested flow test for composites [19, 47]. A standard volume of material was dispensed and sandwiched between two glass slides and permitted to flow for $30 \mathrm{~s}$ then light cured. The diameters of resulted composite discs were measured and compared. A similar technique was used by Attar et al. [17] who also compared the flowability of different composites. In the study reported in this thesis, we modified the ADA flow test for dental cements and combined it with previously published methods to evaluate the flowability.

\subsection{Mechanical properties of dental composites}

\subsubsection{Factors affecting mechanical properties}

Mechanical properties of composites are greatly affected by inorganic fillers. There is a direct relation between filler content and mechanical properties. In terms of modulus of elasticity, the higher the filler content, the higher the modulus and subsequently greater deformation resistance [48]. On the other hand, filler content is inversely proportional with polymerization shrinkage. Highly filled composites associated with less volumetric 
shrinkage [49]. Stress development in composite restorations is influenced by the material's stiffness and flowability, both of them are affected by the fillers type, size, shape and their surface treatment [50]. Ilie et al. [51] reported that filler weight $\%$ has the strongest influence on the mechanical properties of composites while filler volume's effect was less pronounced. However, low correlation was found between filler weight and fracture toughness. On the other hand, matrix-filler interaction in composites seems to play an important role in increasing the material's toughness especially with smaller filler size such as in nanohybrid composites.

The microstructure of nanocomposites has a great influence on their mechanical properties. Nanoparticle volume fraction, aspect ratio and the interface between nanoparticle and matrix affect the composite behavior. The resin matrix molecular structure could be altered at the interface due to interaction with nanoparticles [52]. The C-factor (configuration factor) of the cavity is defined as the ratio of the bonded to unbonded surfaces of the filling. It is an essential factor that contributes to stress contraction and gap formation in composite restorations $[53,54]$. Placing the restoration in an incremental technique is a common clinical approach to minimize the contraction stress associated with C-factor. Furthermore, applying a flowable composite lining underneath the main filling could be effective in reducing shrinkage stress [55].

\subsubsection{Dynamic Young's modulus (E)}

Dynamic Young's modulus is a term that describes a material's stiffness. Along with the adhesive properties, elastic modulus is an important factor in terms of microleakage, recurrent caries and dislodgement of restoration [56]. In other words, elastic modulus has 
a direct relationship with a restorative material's reliability [57]. Also, higher filler content would improve strength, hardness and elastic moduli of resin materials [58]. Materials with different elastic moduli are required for different dental applications. Composites with low elastic moduli are required for class V restorations to allow their flexure with the tooth. In contrast, composites with higher elastic moduli are more suitable for class I and class II restorations in order to withstand higher occlusal forces and to avoid deformation and cusp fracture [56].

Few methods have been described for measuring dynamic and static elastic moduli. Three-point bending test $[56,59]$ and tension $[56,60]$ are the most common methods for static moduli measurements. However, dynamic mechanical thermal analysis (DMTA) [61] and ultrasonic pulse method [62] are used to measure the dynamic modulus of elasticity.

In this thesis, we used a nondestructive ultrasonic pulse method to measure the dynamic Young's moduli. Measuring dynamic elastic properties gives an idea about the micro-structural rigidity and the extent of inter-phase adhesion within the composite materials [62]. The ultrasonic waves have the ability to propagate in elastic bodies by means of vibration or oscillation of their particles. This oscillatory motion could be in longitudinal or transverse directions. The main idea of this technique is to analyze the time required for ultrasonic wave propagation by using following components; a pulse function generator, transmitting and receiving piezoelectric crystals (lithium niobate crystals), amplifier, and oscilloscope. The pulse generator applies a high-frequency pulse that causes an ultrasonic mechanical vibration to be emitted by piezoelectric transducers. These transducers convert the electrical pulses into mechanical vibration. This 
piezoelectric effect is reversible. As the ultrasonic wave reaches the piezoelectric element, it also generates a similar frequency pulse at its electrodes, which can be delivered and recorded on the oscilloscope screen. Therefore, two lithium niobate crystals were attached to the two parallel surfaces of the specimens. One crystal emits an ultrasonic wave through the material while the other crystal receives the wave and converts it into an electrical signal. Both the transmitting and receiving signals were recorded in oscilloscope and the wave's travel time was determined from the receiving signal recorded in the oscilloscope. The ultrasonic pulse method is considered to be one of the most convenient techniques in evaluating the materials elastic properties. This technique has the following advantages: it can be used to measure the material's rigidity and it gives a qualitative reflection of the interfacial adhesion between the reinforcing fillers and matrix of the composite [62]. Furthermore, this method has a very low coefficient of variation [63] and is therefore a very valuable for testing new materials.

\subsubsection{Fracture toughness $\left(\mathrm{K}_{\mathrm{IC}}\right)$}

Fracture toughness is defined as the energy absorbed by the material prior to crack propagation. In other word, it is a measurement of the amount of energy required for fracture. It is a standard test used for studying fracture behavior of orthopedic and dental composite materials. Fracture due to crack propagation occurs in three different loading conditions; modes I, II and III [64] (Fig. 1.2). In mode I (opening mode), crack propagates under tension due to pulling its surfaces apart. In mode II (sliding mode), the body is loaded by shear forces perpendicular to the crack front and parallel to the crack surfaces causing their sliding over each other. Mode III (tearing mode) occurs when the 
body is loaded by shear forces parallel to the crack front, causing sliding of the crack surfaces [65].

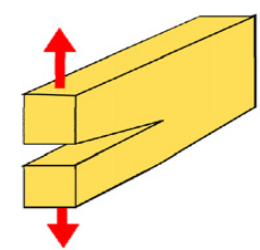

(a)

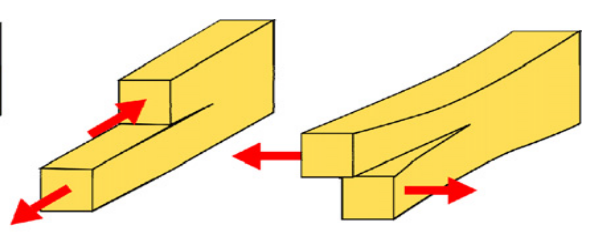

(b)

(c)

Fig 1.2: Fracture modes due to crack propagation. (a) mode I, (b) mode II and (c) mode III. Reproduced with permission (Appendix A) from the journal of dental materials 2010;26(2):63-77 [64].

Many studies have been conducted to understand the fracture mechanics. Researchers suggested that under stress conditions, failure starts from the highly stressed peripheral areas of the bonded surfaces towards the center [64, 66]. Griffith et al. [67] studied the mechanism of composite restorations failure. Their results are in line with the previous ones. They concluded that polymerization shrinkage takes place after curing of composite. This shrinkage pulls the walls of the cavity towards the center.

Different testing methods have been described for $\mathrm{K}_{\mathrm{IC}}$ measurement. Fracture toughness is an intrinsic property of materials. Therefore, its values should be independent on the measurement method. However, different $\mathrm{K}_{\mathrm{IC}}$ values were reported for same materials measured with different methods. This variation could be related either to difficulties in producing appropriate specimens or difficulties in conducting the test $[64,68]$.

Fujishima and Ferracane [68] compared the $\mathrm{K}_{\mathrm{IC}}$ values of dental composites using 
four different methods including single-edge notched, compact tension, chevron-notched short rod (CNSR) and double torsion. In the single-edge notched method, a notched bar specimen was subjected to three-point bending. The compact tension method applies load to a notched plate in uniaxial tension. A cylinder with a chevron-shaped notch is loaded in tension in the CNSR method. The specimen preparation for this method was difficult as it requires cutting a chevron notch which is hard to control especially with small samples [69]. In the double torsion method, a notched and grooved plate was loaded in four-point bending.

Both the single-edge notched and the compact tension methods were described for metallic materials. They require crack propagation from a fatigue produced pre-crack which is difficult in dental composite specimens because of their small size. Thus, these two methods are less commonly used for composites. In contrast, the double torsion method does not require a pre-crack to initiate the facture. Instead, the first crack produced in the test causes propagation of subsequent cracks. Similarly, the CNSR test produces a stable crack region, which acts as a pre-crack for crack propagation. It is one of the most common methods for testing $\mathrm{K}_{\mathrm{IC}}$ of dental composites $[70,71]$.

Among these four tests, the double torsion test was the most difficult one because of its demanding requirements in preparation and alignment of the samples. Specimen failure in this test was associated with fracture out of the crack's plane. Similarly, failure of the CNSR specimens was also due to deviation of the crack fracture plane from the plane of the notch. However, the single-edge notched and compact tension methods showed flat fracture planes with no evidence of deviation. [68]

Ruse et al. [69] described the use of notchless triangular prism (NTP) for $\mathrm{K}_{\mathrm{IC}}$ 
measurement to overcome the difficulties associated with CNSR method. The NTP specimen $(6 \times 6 \times 6 \times 12 \mathrm{~mm})$ was fitted in a holder and secured with screws. A crack (0.1 $\mathrm{mm}$ in depth) was created. The holder including the specimen was then mounted on an Instron machine and tested at a crosshead speed of $0.1 \mathrm{~mm} / \mathrm{min}$ under tension until fracture (Fig. 1.3, 1.4). The maximum load at fracture and displacement were recorded.

Earlier studies of fracture toughness suggested that crack freezing could occur in dental composites when crack is stopped from propagation due to fillers or molecular chains [72]. Other investigators proposed crack bowing effect as a result of pinning by the fillers. Other researchers reported crack branching due to increasing the crack surface area with increasing the filler content [73].

(a)

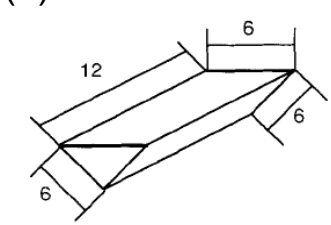

(b)

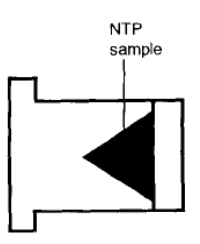

Fig. 1.3: (a) Notchless triangular prism (NTP) used for fracture toughness test. (b) Diagram NTP specimen mounted in holder. Adapted with permission (Appendix A) from the J Biomed Mater Res. 1996; 31(4): 457-63 [69]. 

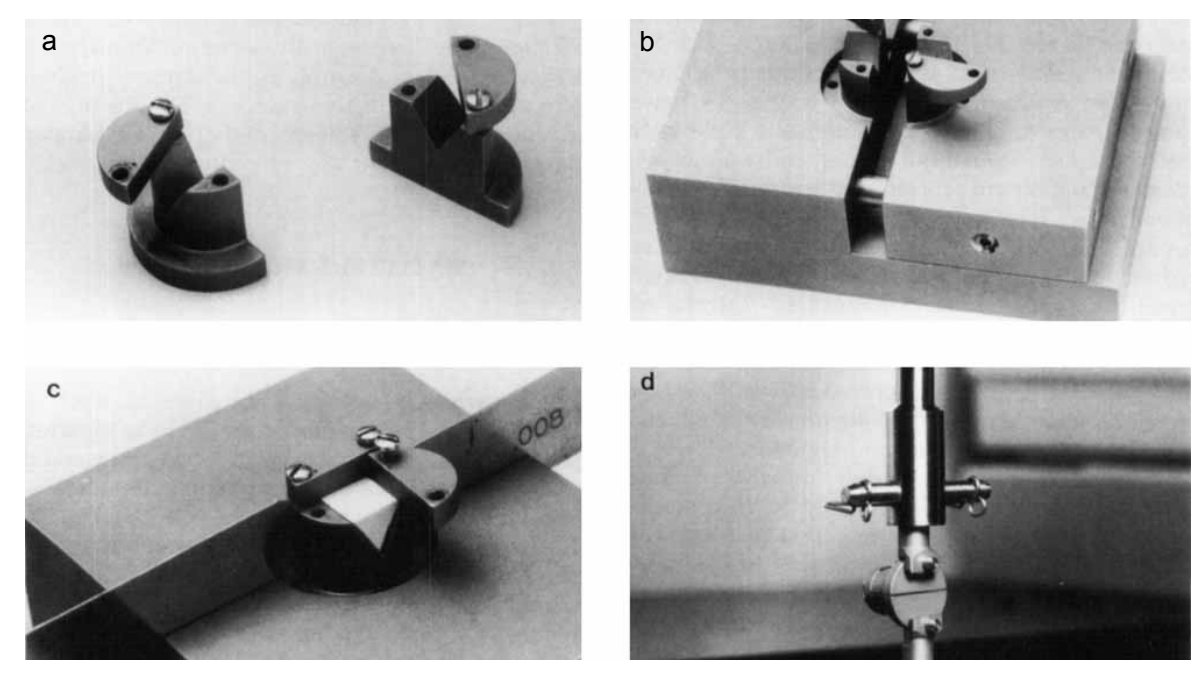

Fig. 1.4: (a) Holder for the NTP specimen, (b) Mounting block with specimen holder, (c) Mounting block with specimen holder, NTP sample, and spacer blade, and (d) Customdesigned grips securing the holder and an NTP specimen. Adapted with permission (Appendix A) from the J Biomed Mater Res. 1996;31(4):457-63[69].

\subsection{Radiopacity of dental composites}

Radiopacity of dental restorations is a critical parameter for accurate diagnosis and treatment planning. It is crucial to use materials with adequate radiopacity in order to distinguish them from the natural tooth structures. Moreover, dental restorations should be radiopaque enough to detect recurrent caries, overhanging margins, proximal contacts and restoration contour [74]. As specified by the International Standards Organization (ISO 4049), the radiopacity of dental materials should be equal to or greater than the same thickness of aluminum wedge and should not be less than $0.5 \mathrm{~mm}$ of any value claimed by the manufacturer [75]. Radiopacity of composite materials should exceed that of dentin. However, no definitive maximum limit has been identified.

Radiopacity is a quantitative measure for dental restorations against a standard dental X-ray source. Three methods are known to measure the radiopacity of dental materials including transmission densitometry, direct digital radiography, or indirect 
digital radiography. Measuring the optical density (OD) of the X-ray image with a densitometer is a common technique for evaluating radiopacity. OD is calculated as a logarithm of the ratio of light transmitted through the film to the incident light according to the following formula: $\mathrm{OD}=\log _{10}\left(\mathrm{I} / \mathrm{I}_{0}\right)$ where $(\mathrm{I})$ is transmitted light and $\left(\mathrm{I}_{0}\right)$ is incident light. The OD is correlated with the absorption of X-rays by the radiopacifiers. Higher OD associated with lower radiopacity [76, 77]. Direct digital method utilizes certain image sensor to provide a direct electronic reading. On the other hand, indirect digital method works by digitizing chemically processed radiographs followed by the use of specific digital color meter to identify the grey values [78]. In the work presented in this thesis, we used the indirect digital method to evaluate the radiopacity of $\mathrm{n}-\mathrm{TiO}_{2}$ reinforced composites.

\subsection{Cytotoxicity}

All synthetic materials inserted in the human body must be tested for biocompatibility. Biocompatibility is the material's ability to function in a host tissue without causing any adverse reaction [79]. Cytotoxicity describes the cascade of molecular events that causes either cellular or functional damage [80]. In case of dental restorations, adverse reactions could be dentin sensitivity, gingival inflammation or loss of pulp vitality.

Previous studies have argued that dental composite resins cause adverse reactions. These studies reported that un-polymerized monomers might leach into saliva [81, 82]. Residual monomers or polymerization products could be released after composite setting into the oral cavity or adjacent tissues [83, 84]. Imazato et al. [85] reported that $20-25 \%$ of monomers remained unreacted after polymerization. Given the fact that flowable 
composites have more monomers and less filler content as compared to hybrid ones, more leaching components could be associated with these composites [83].

The International Organization for Standardization (ISO) guidelines for testing new materials include (ISO 7405: Preclinical evaluation of biocompatibility of medical devices used in Dentistry) [86] and (ISO 10993: Biological evaluation of medical devices) [87]. These guidelines recommend standard practices for evaluating dental materials biologically including the following. (i) It is incumbent upon the dental material manufacturer to select the appropriate tests, based on the intended use of the material, and known and assumed toxicity profile of the material or its components. (ii) A manufacturer may select one of three cytotoxicity tests in preference to another because of cost, experience or other reasons. (iii) Overall, there are four levels of testing. New materials should be evaluated using initial cytotoxicity and secondary tissue screening tests prior to extensive animal testing and clinical trials. (iv) The test result should always be evaluated and interpreted with consideration for the manufacturer's stated use for the material.

Fibroblasts are the most commonly used cells in testing the biocompatibility of new dental materials [88]. They can be isolated from patients easily and they can grow in regular culture media, although cell lines such as L-929 and 3T3 mouse fibroblasts are used frequently [79]. Many in vitro tests can be conducted to evaluate the cytotoxicity. However, the 3-(4,5-dimethylthiazol-2-yl)-2,5-diphenyl tetrazolium bromide (MTT) assay was found to be one of the most sensitive [89]. It is the most commonly used test to evaluate dental material cytotoxicity because it is an easy, fast and inexpensive test [82, 90, 91]. The MTT assay was described by Mossmann (1983) in order to detect the 
viability and proliferation of mammalian cells [92]. It depends on MTT yellow tetrazolium salt cleavage to purple formazan crystals utilizing mitochondrial dehydrogenase in metabolic active cells. The formed purple formazan crystals accumulate in healthy cells as they are insoluble and do not cross the cell membrane. The optical absorbance is directly proportional to the amount of dissolved formazan and the number of viable cells [93]. Issa et al. [90] tested different dental monomers and their toxic effect on human gingival fibroblast using two different cytotoxicity tests. MTT was used to measure fibroblasts metabolism and the cytosolic enzyme lactate dehydrogenase (LDH) was used as a measure of cell integrity. The effects of tested monomers on gingival fibroblast mitochondrial activity found to be reproducible and dose dependent when tested with MTT.

\subsection{Thesis motivation, objectives and hypothesis}

The demand for flowable dental composites with reasonable mechanical properties, excellent flowability and easy handling properties motivated us to work on this project. From the literature, $\mathrm{n}-\mathrm{TiO}_{2}$ were identified as promising reinforcing fillers for composites. The objectives of this study were to: (i) introduce $\mathrm{n}-\mathrm{TiO}_{2}$ as reinforcing fillers into a flowable dental composite, (ii) evaluate the effect of $\mathrm{n}-\mathrm{TiO}_{2}$ content on flowability, (iii) measure the dynamic Young's modulus (E) and fracture toughness ( $\left.\mathrm{K}_{\mathrm{Ic}}\right)$ of the control and reinforced composites, and (iv) evaluate radiopacity and potential cytotoxicity in vitro. We hypothesized that using $\mathrm{n}-\mathrm{TiO}_{2}$ as reinforcing fillers in flowable dental composites would significantly improve their mechanical properties without altering their flowability. 


\section{Chapter 2}

\section{Materials and Methods}




\subsection{Chapter outline}

In this chapter, we describe the experimental setup used for the synthesis of $\mathrm{n}-\mathrm{TiO}_{2}$, their functionalization and chemical characterization. Also explained are the preparation of reinforced flowable composites, assessment of their flowability, and testing of their mechanical properties, radiopacity and cytotoxicity.

The synthesis of $\mathrm{n}-\mathrm{TiO}_{2}$ took place using an autoclave bomb. Functionalization of the synthesized $\mathrm{n}-\mathrm{TiO}_{2}$ was done either by using a rotary evaporator for silane functionalization or by using a reflux condenser for MA functionalization. The reinforced flowable composite samples were prepared by manual incorporation of functionalized n$\mathrm{TiO}_{2}$ into commercially available flowable composites followed by light curing according to standard clinical procedures. A few methods of characterization were employed to examine the synthesized and functionalized $\mathrm{n}-\mathrm{TiO}_{2}$ including X-ray diffraction (XRD), energy dispersive X-ray spectroscopy (EDX), Fourier transform infrared spectroscopy (FTIR), scanning electron microscopy (SEM) and transmission electron microscopy (TEM). The Dynamic Young's moduli (E) and fracture toughness $\left(\mathrm{K}_{\mathrm{IC}}\right)$ of composite specimens were measured.

\subsection{Nanotube synthesis}

Synthesis of $\mathrm{n}-\mathrm{TiO}_{2}$ was carried out in a Teflon-lined stainless steel autoclave (a $125 \mathrm{~mL}$ acid digestion bomb (Parr 4748, Parr Instrument Company, Illinois, USA). The temperature was controlled using a $\mathrm{T}$-thermocouple and a temperature controller (Omega HRC5A). Samples of $\mathrm{n}-\mathrm{TiO}_{2}$ were synthesized using the alkaline hydrothermal technique described earlier by Kasuga et al. [28]. Basically, the experiment was started by 
dispersing $0.24 \mathrm{~g}$ strontium acetate powder in $30 \mathrm{~mL}$ of $10 \mathrm{M} \mathrm{NaOH}$ solution and stirring for $24 \mathrm{~h}$, followed by addition of $2 \mathrm{~g}$ of commercially available $\mathrm{TiO}_{2}$ nanopowder and stirring for another $24 \mathrm{~h}$. The mixture was transferred to a Teflon-lined stainless steel autoclave for hydrothermal treatment. This reaction was maintained at $160^{\circ} \mathrm{C}$ for $20 \mathrm{~h}$. Afterwards, the reaction product was centrifuged and washed with deionized water until the $\mathrm{pH}$ dropped to 10.0 then washed with $0.1 \mathrm{~N} \mathrm{HCl}$ until the $\mathrm{pH}$ dropped to 6.0 at room temperature. The resulting product was dried in a vacuum oven at $80^{\circ} \mathrm{C}$ overnight and then calcined at $400^{\circ} \mathrm{C}$ for $2 \mathrm{~h}$.

\subsection{Nanotube functionalization}

\subsubsection{Silane functionalization}

This reaction was started by dispersing the $\mathrm{n}-\mathrm{TiO}_{2}$ in $20 \mathrm{~mL}$ cyclohexane and $0.028 \mathrm{~mL}$ n-propylamine. The silane mixture of 3-(trimethoxysilyl) propyl methacrylate (MPS) and trimethoxy (octyl) silane (OTMS) was added (7.5\% MPS \& 2.5\% OTMS). The reacting materials were kept under constant stirring at room temperature for $24 \mathrm{~h}$ then at $60^{\circ} \mathrm{C}$ for $30 \mathrm{~min}$. The mixture was placed in a rotary evaporator and the temperature elevated to $95^{\circ} \mathrm{C}$ for $1 \mathrm{~h}$ to evaporate the solvent. Afterwards, the reaction product was subjected to vacuum drying at $80^{\circ} \mathrm{C}$ overnight. Earlier studies suggested that using $10 \%$ silane is more than enough to coat the filler surfaces completely. The amount of silane required to coat the filler was calculated using the following equation [38]: $\mathrm{X}=(\mathrm{A} / \omega) f$, where $\mathrm{X}$ is the amount of silane $(\mathrm{g})$ needed to coat the fillers, A is the surface area of the filler $\left(\mathrm{m}^{2} / \mathrm{g}\right), \omega$ is the surface area coverage per gram of silane $\left(\mathrm{m}^{2} / \mathrm{g}\right)$, and $f$ is the amount of filler $(\mathrm{g})$. In the case of $\mathrm{n}-\mathrm{TiO}_{2}$ used in this study, the surface area $\mathrm{A}=330 \mathrm{~m} / \mathrm{g}$ and the surface area 
coverage per gram of silane $\omega=2525 \mathrm{~m}^{2} / \mathrm{g}$ [38]. Therefore, the amount of silane used to coat $1 \mathrm{~g}$ of $\mathrm{n}-\mathrm{TiO}_{2}$ in this work was $0.13 \mathrm{~g}$. As we used dual-silanization with $10 \%$ silanes, we mixed 7.5\% MPS with 2.5\% OTMS.

\subsubsection{Methacrylic acid (MA) functionalization}

The MA functionalization reaction was carried out under a reflux condenser at $85^{\circ} \mathrm{C}$ for $24 \mathrm{~h}$. The reaction was started by dispersing $0.1 \mathrm{~g} \mathrm{n}-\mathrm{TiO}_{2}$ in $35 \mathrm{~mL}$ of 2-propanol then $3 \mathrm{~mL}$ MA was added. The $\mathrm{pH}$ was adjusted to 5.0 by adding drops of $0.3 \mathrm{~N} \mathrm{KOH}$. The reaction product was subjected to vacuum drying at $80^{\circ} \mathrm{C}$ overnight [25].

\subsection{Characterization of $\mathbf{n}-\mathrm{TiO}_{2}$}

\subsubsection{X-ray diffraction (XRD)}

$\mathrm{XRD}$ was carried out using $\mathrm{CuK} \alpha$ radiation $(30 \mathrm{kV}, 10 \mathrm{~mA})$ in order to examine the $\mathrm{n}$ $\mathrm{TiO}_{2}$ crystalline phase following the alkaline hydrothermal method and calcination at $400^{\circ} \mathrm{C}$. The samples were prepared for XRD by gentle grinding $0.1 \mathrm{~g}$ of the calcined powder using a mortar and pestle. The powder was placed evenly on a plastic XRD flat plate and placed in the XRD machine. Data were collected at a scattering angle of $2 \theta$ from $2^{\circ}$ to $82^{\circ}$ with $0.05^{\circ}$ step size and $10^{\circ} / \mathrm{min}$ scan speed (BRUKER AXS D2 phaser, Karlsruhe, Germany). $2 \theta$ for equivalent $\mathrm{CuK} \alpha$ radiation was calculated using Bragg's Law [94].

\subsubsection{Energy dispersive X-ray spectroscopy (EDX)}

The atomic proportions of $\mathrm{Ti}, \mathrm{O}$ and $\mathrm{Sr}$ atoms in $\mathrm{n}-\mathrm{TiO}_{2}$ were determined using $\mathrm{FIB} / \mathrm{SEM}$ 
LEO 1540XB microscope equipped with an EDX spectrometer (Carl Zeiss, Jena, Germany).

\subsubsection{Fourier transform infrared spectroscopy (FTIR)}

$\mathrm{TiO}_{2}$ functionalized surfaces were investigated by FTIR using the $\mathrm{KBr}$ pellet method (Bruker Vector 22 FT-IR Spectrometer, Bruker Optic Inc., Ettlingen, Germany). Sample preparation was done by adding $0.2 \mathrm{~g}$ anhydrous $\mathrm{KBr}$ to $2 \mathrm{mg}$ of either silane or MA functionalized $\mathrm{n}-\mathrm{TiO}_{2}$ powder (after gentle grinding with mortar and pestle). The prepared powder was pressed at 10 tons for $10 \mathrm{~min}$. using stainless steel die and bolts. Finally, the sample was placed into a sample holder for analysis. Data were collected at wavenumbers ranging between 1000 and $4000 \mathrm{~cm}^{-1}$. The resulting absorbance peaks and their corresponding functional groups were identified.

\subsubsection{Scanning (SEM) and transmission electron microscopy (TEM)}

SEM was used to evaluate both the morphology of $\mathrm{n}-\mathrm{TiO}_{2}$ and fractured composite surfaces following the fracture toughness test (SEM, LEO (Zeiss) 1540XB). TEM was used to confirm the $\mathrm{n}-\mathrm{TiO}_{2}$ structure (TEM, Philips CM10). Samples were prepared for SEM by placing a small amount of fine $\mathrm{n}-\mathrm{TiO}_{2}$ powder on SEM stubs followed by coating with osmium in order to prevent charging of the sample and to reduce the nanotube damage from the electron beam during imaging. TEM sample preparation was done by adding a small amount of $\mathrm{n}-\mathrm{TiO}_{2}$ powder to an Eppendorf tube containing filtered deionized water. A drop of suspension was placed on a carbon grid and left to dry in air for 2 min then examined by TEM. 


\subsection{Preparation of composite specimens}

Commercially available composite was used as control (Filtek ${ }^{\mathrm{TM}}$ Supreme Ultra Flowable Restorative, 3M ESPE). Composites were reinforced by incorporating different weight percentages $(0.5,1,1.5,2,3,5 \%)$ of $\mathrm{n}-\mathrm{TiO}_{2}$. Four different groups of composite were prepared. Group A: control flowable composite (no n- $\mathrm{TiO}_{2}$ added); Group B: flowable composite reinforced with nonfunctionalized (NF) n- $\mathrm{TiO}_{2}$; Group C: flowable composite reinforced with silane-functionalized $\mathrm{n}-\mathrm{TiO}_{2}$; Group $D$ : flowable composite reinforced with MA-functionalized $\mathrm{n}-\mathrm{TiO}_{2}$. Composite disc specimens $(5 \mathrm{~mm}$ diameter, $2 \mathrm{~mm}$ thickness) were prepared for ultrasonic, radiopacity, and cytotoxicity tests. Notchless triangular prisms (NTP, $6 \times 6 \times 6 \times 12 \mathrm{~mm}$ ) were prepared for fracture toughness tests. Composite discs were prepared by loading $1.2 \mathrm{~g}$ of each group of composite into $1 \mathrm{cc}$ disposable syringes followed by light curing for $90 \mathrm{~s}$ (Dentacolor xs, KULZER). A microtome was used to cut the composite discs. NTP specimens were prepared by using a triangular prism Teflon mold. A small amount of composite $(0.6 \mathrm{~g})$ of each group was dispensed into the mold and a microscope glass slide was pressed against it to remove excess material. Afterwards, the composite was light cured and removed from the mold. Samples were soaked at $37^{\circ} \mathrm{C}$ in deionized water for 1 week prior to mechanical testing. The total number of composite specimens was 125 including 93 discs and 32 NTP specimens.

\subsection{Assessment of flowability}

The flowability testing method used in this study was according to ADA guidelines for evaluation of endodontic sealing materials [46]. To evaluate the flowability of the 
reinforced composites, a simple test was done using the Gillmore needle apparatus (modified ADA approach). Different weight percentages of $\mathrm{NF}$ n- $\mathrm{TiO}_{2}(0.5,1,1.5,2,3$ and $5 \%$ ) were incorporated to a commercial flowable composite (Filtek ${ }^{\mathrm{TM}}$ Supreme Ultra Flowable Restorative, 3M ESPE). The quantity of $0.1 \mathrm{~mL}$ of control and each reinforced composite was dispensed between two thin microscopic cover glasses $50 \times 50 \mathrm{~mm}$ (KODAK slide cover glass, Eastman Kodak Comp, NY, USA). These coverslips were then placed under a constant weight using $1 \mathrm{~mm}$ diameter needle weighing $454 \mathrm{~g}$ (Gillmore needle) for $30 \mathrm{~s}$ (i.e. compressive loading force of $4.45 \mathrm{~N}$ ). As a result, the composite spreads forming an expanding disc (Fig. 2.1). The composite discs were subjected to light curing for $30 \mathrm{~s}$ and their diameters were measured and compared (the larger the diameter, the greater the flowability). The thickness of the cover glass that we used in this test was measured by a digital micrometer and found to be $0.62 \mathrm{~mm}$. This thickness is substantially greater than the standard thickness of microscope cover glasses $(0.12 \mathrm{~mm})$ and hence was unlikely to deform during the test.

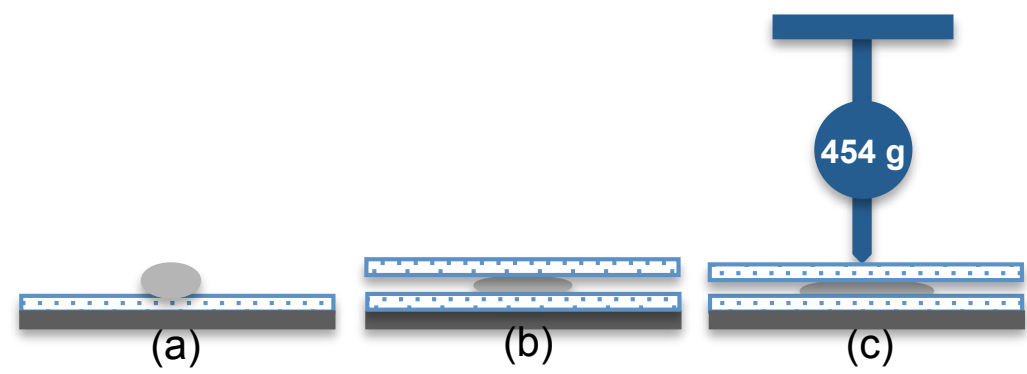

Fig. 2.1: Evaluation of flowability. Flowability was determined by measuring the diameters of composite discs between two microscope coverslips (a) Flowable composite dispensed on a coverglass on a flat platform, (b) covered with another coverslip, and (c) placed under a constant load for $30 \mathrm{~s}$. 


\subsection{Mechanical testing of composites}

\subsubsection{Dynamic Young's moduli (E)}

Dynamic Young's modulus was evaluated using a non-destructive ultrasound technique described elsewhere $[62,63]$. The main idea of this technique is to analyze the time required for ultrasonic wave propagation. The instrument set up has the following components: a pulse generator, transmitting and receiving piezoelectric crystals (lithium niobate), amplifier, and oscilloscope (Fig. 2.2). During the test, a high-frequency pulse $(10 \mathrm{MHz})$ is triggered by pulse function generator causing an ultrasonic mechanical vibration to be emitted by piezoelectric transducers. When the ultrasonic wave reaches the receiving piezoelectric element, it generates a similar frequency pulse at its electrodes which is recorded on the oscilloscope.

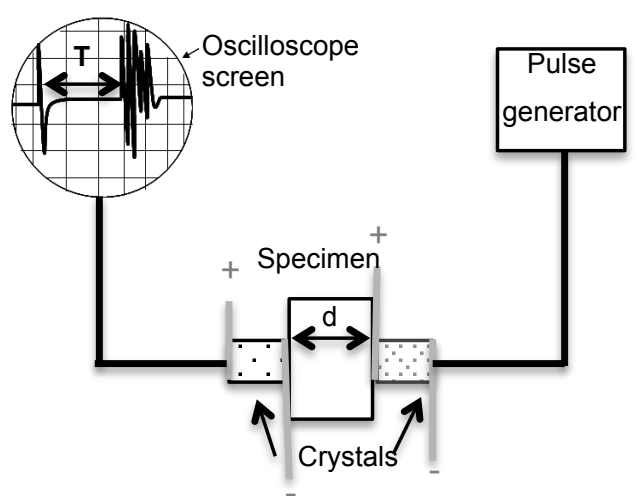

Fig. 2.2: Ultrasonic method setup. $\mathrm{T}$ is the time for ultrasonic wave to travel across the specimen and receiving crystal and $\mathrm{d}$ is the thickness of the specimen.

The specimen thickness $(\mathrm{d})(\mathrm{mm})$ was measured using a digital wrench micrometer. The ultrasonic wave velocity was determined using the following equation: $C=d / t$ where $C$ 
is the velocity of sound $(\mathrm{m} / \mathrm{s}), t=\mathrm{T}-\Delta \mathrm{t}$ where $\mathrm{T}$ is the total travelling time of the ultrasonic wave across the sample and the receiving crystal $(\mu \mathrm{s})$, and $\Delta \mathrm{t}$ is the travelling time of the ultrasonic wave through the receiving crystal ( $\mu \mathrm{s})$.

Poisson's ratio (v) and Dynamic Young's modulus (E) were calculated using the following equations:

Poisson's ratio $(v)$ (dimensionless)

$$
v=\frac{\left(\frac{1}{2}\right)\left(\frac{C_{l}}{C_{s}}\right)^{2}-1}{\left(\frac{C_{l}}{C_{s}}\right)^{2}-1}
$$

where $C_{l}=$ longitudinal wave velocity $(\mathrm{m} / \mathrm{s})$

$$
C_{S}=\text { shear wave velocity }(\mathrm{m} / \mathrm{s})
$$

Dynamic Young's modulus, E (GPa)

$$
\mathrm{E}=\frac{(1+v)(1-2 v)}{(1-v)}\left(\rho C_{l}^{2}\right)
$$

Where $\rho=$ density of specimen $\left(\mathrm{kg} / \mathrm{m}^{3}\right)$

The density of each specimen ( $\rho$ ) was determined using the Archimedes method.

\subsubsection{Fracture toughness $\left(K_{I C}\right)$ :}

Fracture toughness tests were performed on an Instron 3345 materials testing machine at a crosshead speed of $0.1 \mathrm{~mm} / \mathrm{min}$ using NTP specimens [69]. The typical total test time was an average of $15 \mathrm{~min} / \mathrm{specimen}$. The NTP method uses small notchless triangular prism samples $(6 \times 6 \times 6 \times 12 \mathrm{~mm})$. The $\mathrm{K}_{\mathrm{IC}}$ value was obtained using the standard 
formula [95], $\mathrm{K}_{\mathrm{IC}}=\mathrm{P}_{\max } \gamma_{\text {min }}^{*} / \mathrm{DW}^{1 / 2}$, where $\mathrm{P}_{\max }$ is the maximum load recorded at fracture $(\mathrm{N})$; D is the specimen diameter $(\mathrm{mm}), \mathrm{W}$ is the specimen length $(\mathrm{mm})$, and $\gamma^{*}{ }_{\text {min }}$ is the dimensionless stress intensity factor coefficient minimum. Ruse et al. [69] reported these values for NTP specimens. $\mathrm{D}=12 \mathrm{~mm}, \mathrm{~W}=10.5 \mathrm{~mm}$ and $\gamma^{*}{ }_{\text {min }}=28$.

\subsection{Radiopacity}

Composite disc specimens of each group A, B, C and D were placed on size 4 occlusal film (KODAK INSIGHT Dental Film, F speed) together with 3 pieces of lead and an aluminum (Al) step wedge (10-step wedge, $0.5 \mathrm{~mm} / \mathrm{step})$. The film was exposed to an Xray beam using a dental X-ray machine (Gendex GX 770) at $70 \mathrm{kV}$ and $7 \mathrm{~mA}$ for $0.47 \mathrm{~s}$. The distance between X-ray source and the film was $50 \mathrm{~cm}$. Lead backing was placed under the film to minimize backscatter radiation. Following the exposure, the film was processed using an automatic processor. The radiograph was scanned (Epson V700) for radiopacity evaluation. A digital color meter (Apple computer, Power Mac G5) was used to measure the $\%$ RGB scale of the scanned radiographic images. The aluminum step wedge was used as an internal standard for measuring the equivalent radiopacity of different materials as compared to the thickness of the Al step wedge. A correction factor (CF) for background radiation was considered in the calculation of the corrected \% RGB $(\% \mathrm{cRGB}) . \mathrm{CF}=$ white $_{\% \mathrm{RGB}}-$ lead $_{\mathrm{RGB}}=100-88.5=11.5$. Thus, $\% \mathrm{cRGB}=(\% \mathrm{RGB}+$ CF) - background. Linear regression analysis was conducted between the logarithm of $(\%$ cRGB $)$ and the logarithm of aluminum thickness. Significant correlation was obtained ( $\mathrm{r}=0.9723)$ (Fig. 2.3). The linear regression equation is: 


$$
\begin{gathered}
\log (\% \mathrm{cRGB})=0.4778 \log (\mathrm{Al})+1.2212 \\
\log (\mathrm{Al})=(\log (\% \mathrm{cRGB})-1.2212) / 0.4778
\end{gathered}
$$

The radiopacity of each composite specimen in $\mathrm{mm}$ Al thickness was divided by the specimen thickness to obtain the value in terms of mm Al equivalent.

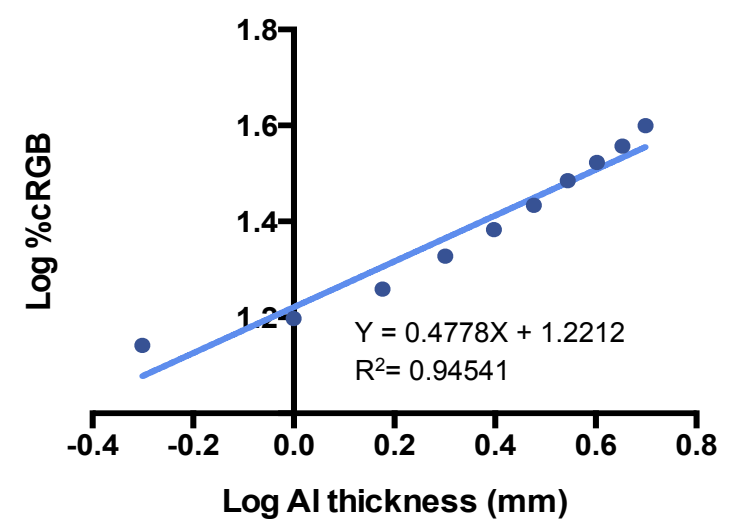

Fig. 2.3: Linear regression curve for Log $\% \mathrm{cRGB}$ versus Log Al thickness.

\subsection{In vitro cytotoxicity}

All composite specimens were sterilized in low-temperature, radio-frequency glow discharge (RFGD) argon plasma using a PDC-32G plasma cleaner (Harrick Plasma, Ithaca, NY). The samples were placed on a sterile plate, the plate was placed inside the plasma cleaner. The samples were flushed twice with argon gas for $30 \mathrm{~s}$ followed by 3 min of rest to establish a full vacuum. Plasma cleaning was done by turning the plasma RF value to medium and opening the argon tank halfway for 4 min. Finally, the vacuum was stopped and samples were removed into sterile culture dishes. 
Cytotoxicity assays were performed on NIH/3T3 mouse fibroblast cells using 3(4,5-dimethylthiazol-2-yl)-2,5-diphenyl tetrazolium bromide (MTT) (cell proliferation kit I MTT, Roche). Culture media was Dulbecco's Modified Eagle Medium (DMEM; Gibco, Catalog \# 11995 Invitrogen) supplemented with 10\% fetal bovine serum (FBS; Gibco, Catalog \# 12483, Lot \# 586696) and 1\% antibiotic (Antibiotic-Antimycotic; Gibco, Catalog \# 14040). A set of triplicate specimens for four different groups was used for plating different cell densities: $10 \times 10^{3}, 20 \times 10^{3}, 30 \times 10^{3} \mathrm{cells} / \mathrm{cm}^{2}$ in a 96-well culture plate. The plates were incubated at $37^{\circ} \mathrm{C}$ in $5 \% \mathrm{CO}_{2}$ for $24 \mathrm{~h}$. Subsequently, $10 \mu \mathrm{L}$ of MTT labeling reagent was added and incubated for $4 \mathrm{~h}$. Finally, $100 \mu \mathrm{L}$ solubilizing solution was added and left overnight. The colorimetric absorbance was recorded using a microplate reader (Tecan, Durham, NC).

\subsection{Statistical analysis}

We used one-way analysis of variance (ANOVA) followed by Tukey's multiple comparison tests at a significance level of $P<0.05$ to analyze differences among groups. 
Chapter 3

Results 


\subsection{Chemical characterization of titanium dioxide nanotubes}

We first used powder X-ray diffraction (XRD) to investigate the crystalline phase of n$\mathrm{TiO}_{2}$. The test was repeated twice. The same diffraction peaks were observed. A prominent diffraction peak was observed at $25.1^{\circ}$, in addition to other peaks at $37.6^{\circ}$, $43.2^{\circ}, 47.8^{\circ}$ and $53.7^{\circ}$ (Fig. 3.1). These diffraction peaks represent the anatase crystal phase of $\mathrm{TiO}_{2}$ [96]. The peak at $31.9^{\circ}$ represents sodium trititanate $\left(\mathrm{Na}_{2} \mathrm{Ti}_{3} \mathrm{O}_{7}\right)$ [97].

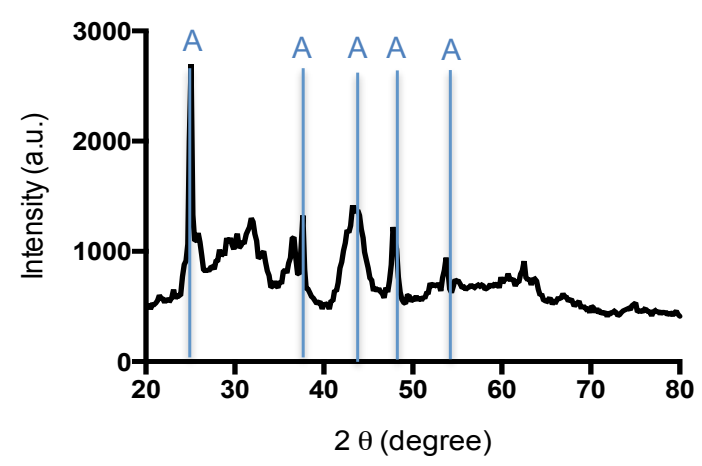

Fig. 3.1: XRD signal intensity (arbitrary units) versus diffraction angle $2 \theta$ (degrees). Letter A represents diffraction peaks corresponding to anatase crystal phase of $\mathrm{TiO}_{2}$.

EDX was also performed after the alkaline hydrothermal reaction and calcination of the $\mathrm{n}-\mathrm{TiO}_{2}$ sample to determine the atomic proportions of $\mathrm{Ti}, \mathrm{O}$ and $\mathrm{Sr}$ atoms. Four EDX images were captured at different sites of the same n- $\mathrm{TiO}_{2}$ sample and the average weight percent of each element was calculated. It was found that $\mathrm{Ti}$ and $\mathrm{O}$ had the highest weight percent. These two elements correspond to $\mathrm{TiO}_{2}$. Lower percentages of $\mathrm{C}$ and $\mathrm{Na}$ were found in the sample. A trace amount of $\mathrm{Sr}$ and $\mathrm{Ni}$ were also detected. Table 3.1 summarizes the weight $\%$ of each element. 


\begin{tabular}{|c|c|}
\hline \multicolumn{2}{|c|}{$\begin{array}{c}\text { Table 3.1: Elemental analysis of } \\
\text { n-TiO }\end{array}$ sample using EDX } \\
\hline Element & Weight (\%) \\
\hline $\mathrm{Ti}$ & $39.85(2.43)$ \\
\hline $\mathrm{O}$ & $35.05(1.90)$ \\
\hline $\mathrm{Sr}$ & $0.32(0.15)$ \\
\hline $\mathrm{Na}$ & $3.65(0.50)$ \\
\hline $\mathrm{C}$ & $20.95(3.55)$ \\
\hline $\mathrm{Ni}$ & $0.15(0.12)$ \\
\hline $\mathrm{Total}$ & $100(0.004)$ \\
\hline
\end{tabular}

Data are mean $\pm(\mathrm{SD})$ of weight $\%$ of each element measured by EDX

Following $\mathrm{n}-\mathrm{TiO}_{2}$ functionalization, FTIR was conducted to investigate the chemical bonds formed between $\mathrm{n}-\mathrm{TiO}_{2}$ and the coupling agents. In case of silane functionalization, FTIR spectra exhibited a strong absorbance peak at $1725 \mathrm{~cm}^{-1}$ and two more peaks at 2935 and $3477 \mathrm{~cm}^{-1}$ (Fig. 3.2a). The absorbance peak at $1725 \mathrm{~cm}^{-1}$ corresponds to the carbonyl group stretching mode in MPS suggesting its chemisorption on n- $\mathrm{TiO}_{2}$ surface [44]. Both $\mathrm{CH}_{3}$ and $\mathrm{OH}$ groups are corresponding to alkoxy group of MPS [98]. On the other hand, FTIR spectra of MA functionalized n- $\mathrm{TiO}_{2}$ showed absorbance bands at 1381 and $1633 \mathrm{~cm}^{-1}$ in Fig. $3.2(\mathrm{~b})$. These peaks are due to the presence of $\mathrm{CH}_{3}$ groups and the vinyl $(\mathrm{C}=\mathrm{C})$ bond of methacrylic acid coordinated to the n- $-\mathrm{TiO}_{2}$ respectively [25]. The absorbance peak at $2355 \mathrm{~cm}^{-1}$ corresponds to the carboxylic group [99], while the broad peak at $3412 \mathrm{~cm}^{-1}$ is due to hydrogen bonded $\mathrm{OH}$ stretch [100]. The FTIR was conducted twice using two different samples for both silane 
and MA functionalized $\mathrm{n}-\mathrm{TiO}_{2}$. The results of both samples were the same.

(a)

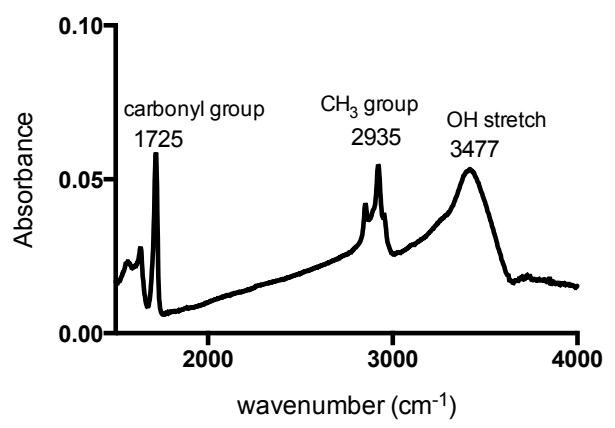

(b)

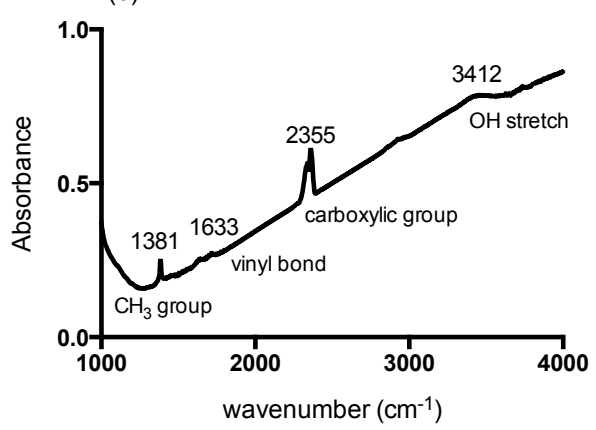

Fig. 3.2: FTIR absorbance peaks and their corresponding functional groups for (a) $\mathrm{n}-\mathrm{TiO}_{2}$ functionalized with silane, (b) $\mathrm{n}-\mathrm{TiO}_{2}$ functionalized with MA.

\subsection{Morphological characterization of titanium dioxide nanotubes}

The morphology of $\mathrm{n}-\mathrm{TiO}_{2}$ was examined by SEM and TEM after hydrothermal reaction and calcination. SEM images revealed the presence of elongated tubular structures (Fig. 3.3a). TEM images confirmed the multi-walled hollow tubular structure of n- $\mathrm{TiO}_{2}$. Inner and outer diameters were measured at three different samples $(n=3)$. The average inner and outer diameters were $12.4( \pm 0.59) \mathrm{nm}$ and $25.5( \pm 1.46) \mathrm{nm}$ respectively (Fig. 3.3b). 

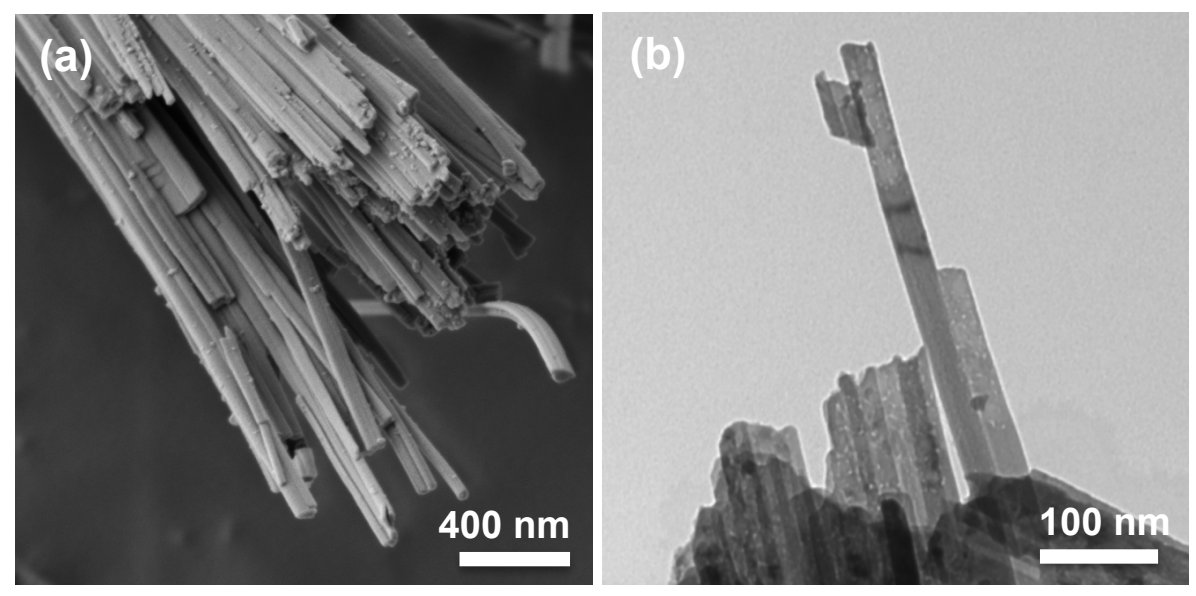

Fig. 3.3: (a) SEM, (b) TEM of $\mathrm{n}-\mathrm{TiO}_{2}$ following alkaline hydrothermal reaction and calcination.

\subsection{Flowability of reinforced and control composites}

Flowability was evaluated by comparing the composite disc diameters after they have been sandwiched between two glass coverslips, subjected to constant weight ( $454 \mathrm{~g})$ for $30 \mathrm{~s}$ and light cured for $30 \mathrm{~s}$. Measuring the composite discs diameters was repeated 10 times at different points on the same sample (Figs. 3.4 and 3.5). Composite flowability decreased slightly with increasing amounts of $\mathrm{NF}$ n- $\mathrm{TiO}_{2}$ fillers. 

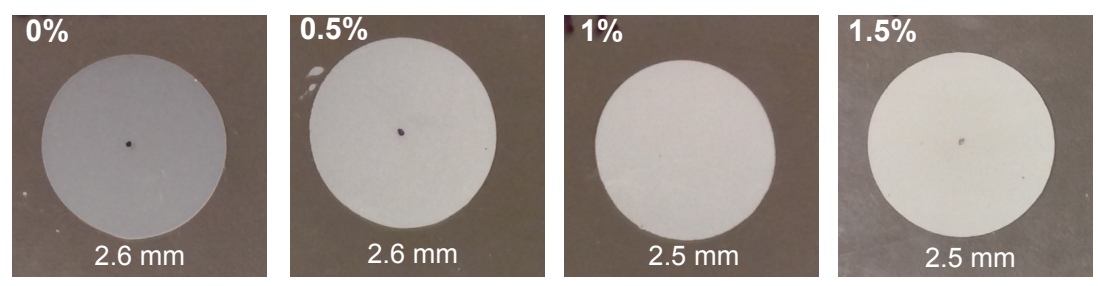

control
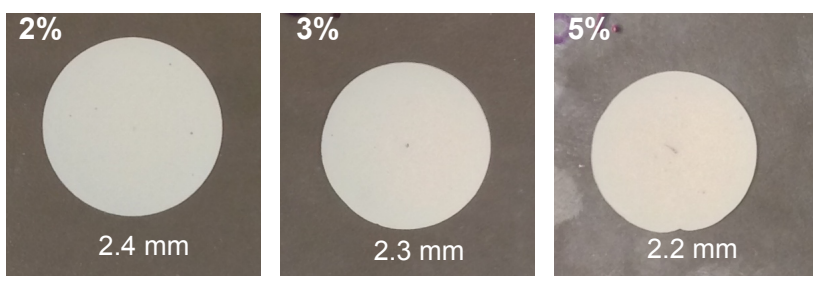

$\mathrm{NF}$ n- $\mathrm{TiO}_{2}$

Fig. 3.4: Changes in composite discs diameter with different amounts of $\mathrm{NF} n-\mathrm{TiO}_{2}$ fillers. Disc diameters and flowability decreased slightly with increasing $\mathrm{NF} n-\mathrm{TiO}_{2}$ content.

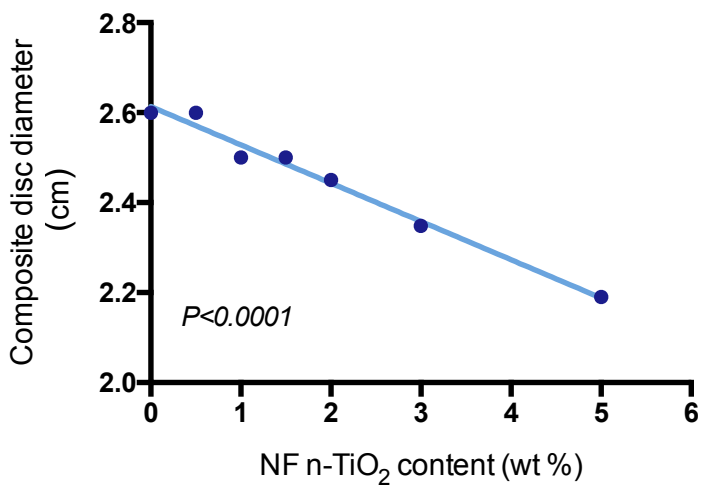

Fig. 3.5: Flowability of control and reinforced composites was evaluated by measuring composite disc diameter. Data are disc diameters (measured 10 times at different points on the same sample). Line was fit by linear regression. $P$ value indicates a significant linear correlation. 


\subsection{Mechanical characterization of reinforced and control composites}

\subsubsection{Dynamic Young's moduli (E)}

The dynamic Young's modulus (E) of control and reinforced composites was determined using a non-destructive ultrasonic pulse method $(n=3)$. Three specimens of each filler weight $\%(0.5$ to $5 \%)$ for each group $(A, B, C$, and $D)$ were used. Composites reinforced with $3 \%$ MA functionalized $\mathrm{n}-\mathrm{TiO}_{2}$ exhibited the greatest elastic moduli of $16.8 \mathrm{GPa}$. $\mathrm{E}$ of composites reinforced with $\mathrm{n}-\mathrm{TiO}_{2}$ functionalized with $3 \%$ silane was $16.1 \mathrm{GPa}$. Both of them were significantly higher than that of control composite $(10.6 \mathrm{GPa})$ at $P<0.05$. However, composites reinforced with 3\% $\mathrm{NF}$ n- $\mathrm{TiO}_{2}$ showed lower E values (15.5 GPa) than those of the functionalized ones (Fig. 3.6). These results established that the largest Young's moduli were obtained when composite was reinforced with $3 \% \mathrm{n}-\mathrm{TiO}_{2}$. Moreover, these data confirmed the successful effect of functionalization.

(a) $\mathrm{NFTiO}_{2}$ nanotubes

(b) $\mathrm{TiO}_{2}$ nanotubes + silane

(c) $\mathrm{TiO}_{2}$ nanotubes $+\mathrm{MA}$
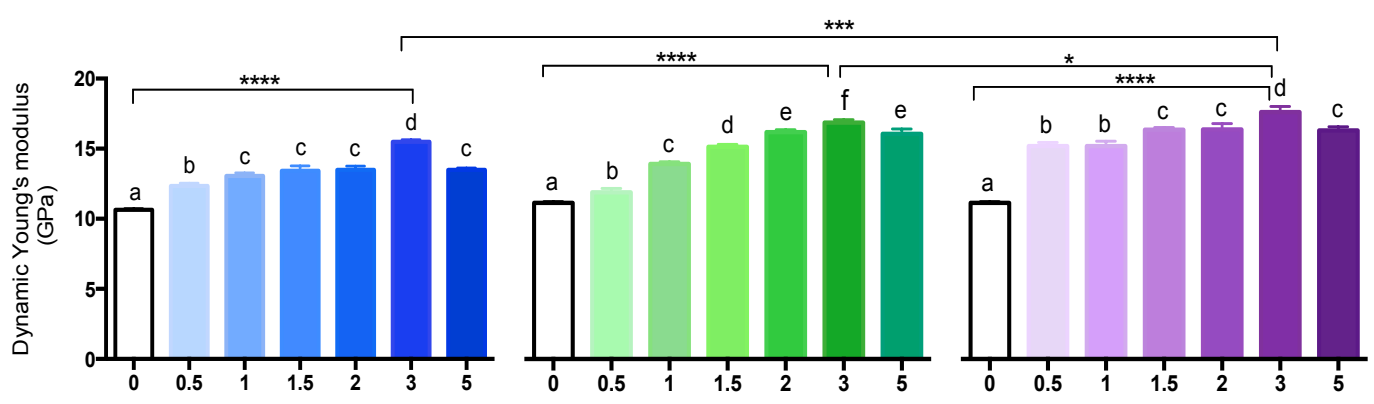

Filler content (wt \%)

Fig. 3.6: Dynamic Young's moduli of reinforced composites as compared to control $(0 \%$ filler content). (a) $\mathrm{NF} n-\mathrm{TiO}_{2}$, (b) $n-\mathrm{TiO}_{2}$ functionalized with silane, and (c) $n-\mathrm{TiO}_{2}$ functionalized with MA. Data are means $\pm \operatorname{SEM}(n=3)$ for each filler weight $\%$ in each group of composite. The same lower case letters indicate values that are not significantly different from each other $(P>0.05) .{ }^{* * * *}$ and $* * *$ show significant differences at $(P<0.0001)$ and $(P<0.001)$ respectively. ${ }^{*}$ shows significant differences at $(P<0.05)$. 


\subsubsection{Fracture toughness $\left(\mathrm{K}_{\mathrm{IC}}\right)$}

Fracture toughness $\left(\mathrm{K}_{\mathrm{IC}}\right)$ and the maximum load applied to each specimen at fracture were determined using an Instron testing machine by applying tension $(n=8)$. NTP specimens were used for this test. Eight specimens of control composite and $3 \% \mathrm{n}-\mathrm{TiO}_{2}$ reinforced composite (3\% NF, 3\% silane, and 3\% MA) were tested. Composite reinforced with $3 \% \mathrm{MA}$ achieved the highest value of $\mathrm{K}_{\mathrm{IC}}$, being statistically different from control and NF groups $(P<0.05)$. The maximum load value is the maximum force that the material can withstand prior to fracture due to crack propagation. Table 3.2 shows the measured maximum load values and $\mathrm{K}_{\mathrm{IC}}$ values of control and reinforced composites.

Table 3.2: Fracture toughness $\left(K_{I C}\right)$ of control and reinforced flowable composites

\begin{tabular}{|l|c|c|c|c|}
\hline & $\begin{array}{c}\text { Control } \\
\text { composite }\end{array}$ & \multicolumn{3}{|c|}{ Reinforced composite } \\
\cline { 2 - 5 } & $\mathbf{0} \%$ & $\mathbf{3 \%} \mathbf{N F}$ & $\mathbf{3 \%}$ silane & $\mathbf{3 \%}$ MA \\
\hline Maximum load (N) $^{*}$ & $30(1.3)$ & $41(2.4)$ & $46(2.3)$ & $52(3.5)$ \\
\hline K $_{\text {IC }}\left(\mathbf{M P a}^{\mathbf{0 . 5}}\right)^{-}$ & $0.87(0.03)^{\mathrm{a}}$ & $0.93(0.05)^{\mathrm{a}}$ & $1.05(0.05)^{\mathrm{ab}}$ & $1.18(0.08)^{\mathrm{b}}$ \\
\hline
\end{tabular}

Data are means (SEM). The same superscript letters indicate values that are not significantly different form each other $(P>0.05)$.

SEM was used to evaluate fracture surfaces of composites after fracture toughness testing. Spherical nanoparticles were observed in control composite (Fig. 3.7a). Composites reinforced with $\mathrm{NF}$ n- $\mathrm{TiO}_{2}$ had nanotubes distributed throughout the composite matrix (Fig. 3.7b). However, composites reinforced with silane and MA functionalized $\mathrm{n}-\mathrm{TiO}_{2}$ showed evidence of nanotubes intimately embedded in the 
composite matrix (Fig. 3.7c and d, respectively).
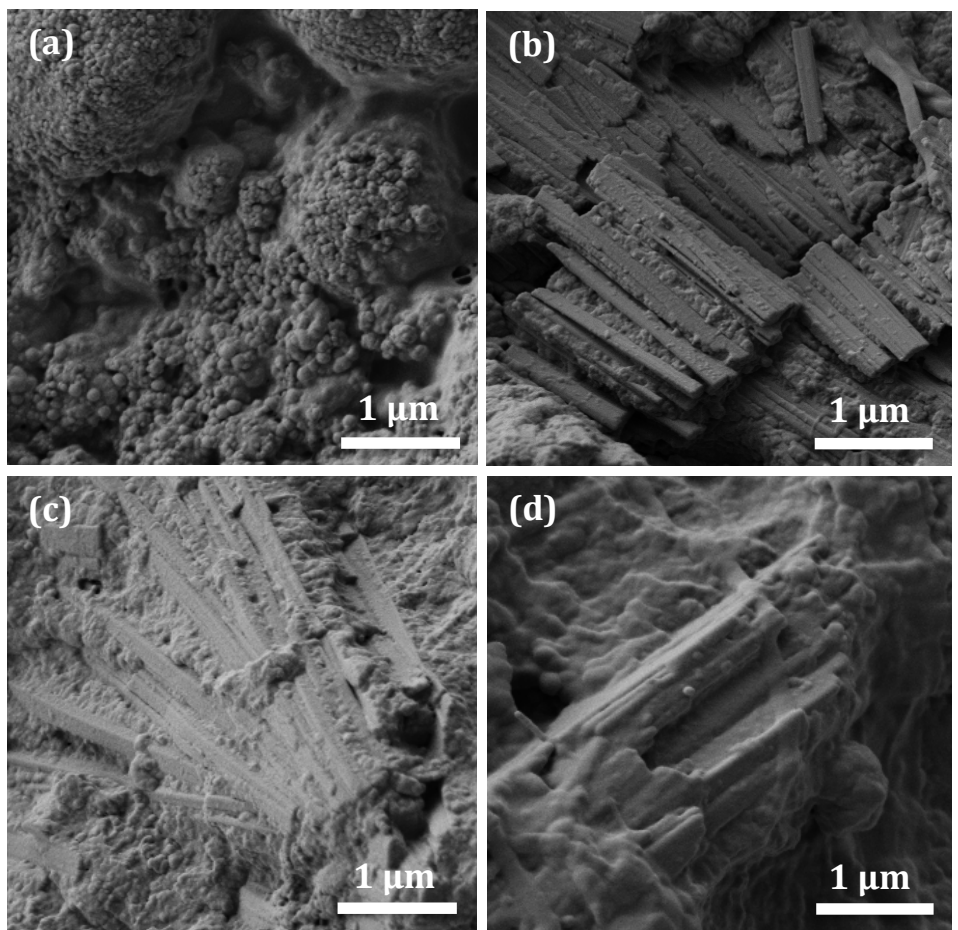

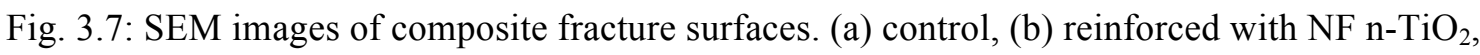
(c) reinforced with n- $\mathrm{TiO}_{2}+$ silane, and (d) reinforced with n- $\mathrm{TiO}_{2}+\mathrm{MA}$.

\subsection{Radiopacity of reinforced and control composites}

Radiopacity of composites was measured in terms of mm aluminum equivalent $(n=3)$.

Three specimens of control and each group of reinforced composite (at 3\%) were used (Fig 3.8). 


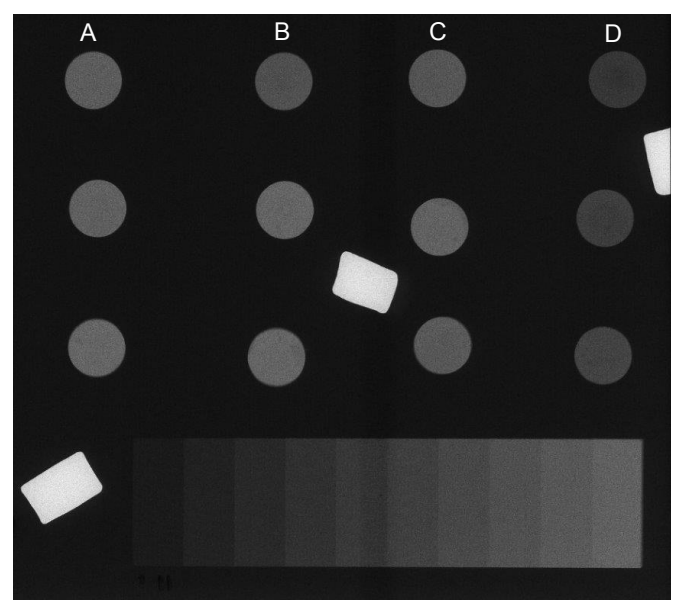

Fig. 3.8: Radiopacity of flowable composite specimens, leads and Al step wedge. (A) Control composite, (B) composite reinforced with $\mathrm{NF}$ n- $-\mathrm{TiO}_{2},(\mathrm{C})$ composite reinforced with $\mathrm{n}-\mathrm{TiO}_{2}+$ silane and (D) composite reinforced with $n-\mathrm{TiO}_{2}+\mathrm{MA}$.

We evaluated the radiopacity by using the digital color meter method in which the $\%$ RGB was used to calculate the radiopacity ( $\mathrm{mm} \mathrm{Al} \mathrm{thickness).} \mathrm{To} \mathrm{calculate} \mathrm{the}$ radiopacity in terms of the $\mathrm{Al}$ equivalent, radiopacity values were divided by each specimen thickness. Fig. 3.9 displays the radiopacity of the control and reinforced flowable composites. It can be seen that the control composite exhibited the highest radiopacity value of $2.62 \mathrm{~mm} \mathrm{Al}$. NF and silane groups are comparable to control (2.19 $\mathrm{mm} \mathrm{Al})$. However, the radiopacity of MA group (1.64 mm Al) was significantly lower than that of control $(P<0.05)$. 


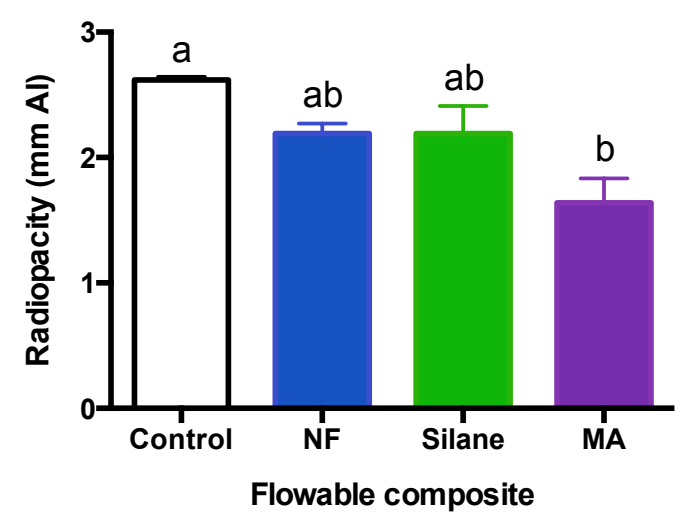

Fig. 3.9: Radiopacity of flowable composites (mm Al). Data are means $\pm \operatorname{SEM}(n=3)$. The same lower case letters indicate values that are not significantly different from each other $(P>0.05)$.

\subsection{Biocompatibility of reinforced and control composites}

NIH/3T3 fibroblasts were plated on composite specimens for each group. Three independent experiments were done at three different points of time, each with a triplicate set of specimens for control, NF, silane and MA groups $(n=3)$. The fibroblasts were plated in three different cell densities $\left(10 \times 10^{3}, 20 \times 10^{3}\right.$ and $\left.30 \times 10^{3} \mathrm{cells} / \mathrm{cm}^{2}\right)$ and cultured for $24 \mathrm{~h}$. Fibroblast viability was then assessed using the MTT assay. In this assay, cell viability is directly proportional to colorimetric absorbance of the MTT dye. The results showed comparable numbers of cells on control and reinforced composites (no significant differences, $P>0.05$ ), indicating that these composites are biocompatible in vitro (Fig. 3.10). 


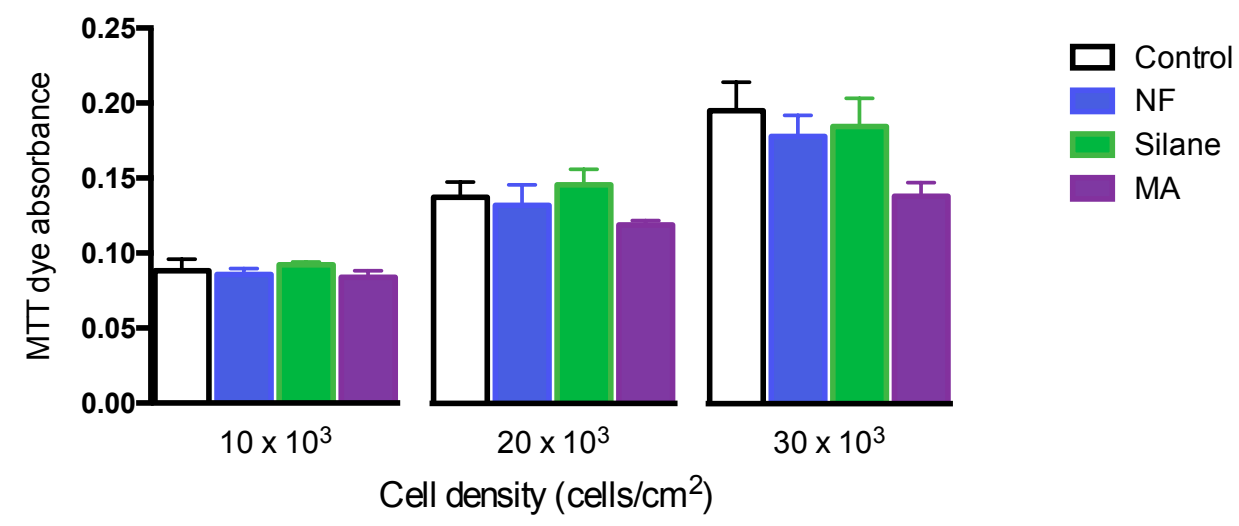

Fig. 3.10: MTT cytotoxicity test. NIH/3T3 fibroblasts were plated at different densities $(10,20$, $30 \times 10^{3}$ cells $/ \mathrm{cm}^{2}$ ) on control, NF, silane- and MA-reinforced composites and incubated for $24 \mathrm{~h}$. The MTT dye absorption is directly proportional to the viability of the cells. No significant differences were found in cell viability among each cell plating density. Three independent experiments were done at three different points of time, each with a triplicate set of specimens for control, NF, silane and MA groups $(n=3)$. 
Chapter 4

Discussion 


\subsection{Nanocomposite fillers}

Nanocomposite materials continue to be investigated for their potential roles in restorative dentistry - for their qualities associated with handling properties, mechanics, biocompatibility and esthetics. They are an interesting topic for research in the field of dental materials. Many studies are being done in order to understand their properties and how they differ from other composites. Different nanofillers have been introduced to dental composites.

Hua et al. [52] studied the effect of incorporating $\mathrm{TiO}_{2}$ nanoparticles in dental composites. They concluded that Young's modulus showed much more rapid increase by adding nanoparticles than by adding glass fibers. Increasing Young's modulus by $30 \%$ required $3 \%$ volume fraction of nanoparticles, whereas $6 \%$ of glass fibers were needed to achieve the same increase in stiffness. This is likely due to the large specific surface area of nanoparticles, which could greatly facilitate load transfer from resin matrix to nanoparticles resulting in better mechanical properties of nanocomposites than microcomposites.

Composite reinforcement with nanofibers was studied by Tian et al. [101] in which nanofibers (containing fibrillar silicate crystals) were added to BisGMA/TEGDMA composite. The average diameter of the nanofibers was $250 \mathrm{~nm}$. Their results revealed that adding small mass fractions of nanofibers (1-2\%) improved the mechanical properties of the composite including elastic modulus, fracture toughness and flexural strength; whereas, larger fractions of $4-8 \%$ resulted in inferior mechanical properties. Our results are in line with these. We found that by incorporating small weight fractions of nanotubes (up to $3 \%$ ) to a flowable dental composite improved its dynamic 
Young's modulus (E). However, at $5 \mathrm{wt} \% \mathrm{n}-\mathrm{TiO}_{2}$, E started to decrease, likely as a result of agglomeration.

Another study tried to improve the mechanical properties of dental composites by reinforcing them with $\mathrm{TiO}_{2}$ nanoparticles $(<20 \mathrm{~nm})$ functionalized with allytriethoxysilane (ATES) [40]. The mechanical properties of these composites were compared to those of composites reinforced with non-functionalized (NF) $\mathrm{TiO}_{2}$ nanoparticles and to composites with no $\mathrm{TiO}_{2}$ nanoparticles. It was reported that $\mathrm{TiO}_{2}$ nanoparticles functionalized with ATES improved the composite flexure strength. However, the NF nanoparticles had a limited effect on the mechanical properties of dental composites because of their agglomeration.

\subsection{Synthesis of n- $\mathrm{TiO}_{2}$ using the alkaline hydrothermal reaction}

Formation of $\mathrm{n}-\mathrm{TiO}_{2}$ during alkaline hydrothermal reaction takes place due to formation of nanosheets with high curling tendency [102]. As described by Kasuga et al. [30] these sheets are formed due to the reaction between the acid and $\mathrm{Ti}-\mathrm{O}-\mathrm{Na}$ with a decrease in Ti-O-Ti bond length. They suggested that the residual electrostatic repulsion of Ti-O$\mathrm{Na}$ bonds may have an influence in connecting $\mathrm{Ti}-\mathrm{O}-\mathrm{Ti}$ sheets followed by their closure and nanotubes formation (Fig. 4.1).

Many studies were conducted to understand the effect of hydrothermal temperature. Yuan and Su [103] studied nanostructures at different hydrothermal temperatures. They concluded that hydrothermal reaction temperature of $100-160^{\circ} \mathrm{C}$ results in nanotube formation, whereas higher temperature of $180-250^{\circ} \mathrm{C}$ leads to formation of nanoribbons. Ribbon-like structures were obtained from hydrothermal 
reactions at $200^{\circ} \mathrm{C}[104]$. Our results are in agreement with these results. In our work, the hydrothermal reaction was carried out at $160^{\circ} \mathrm{C}$ and resulted in nanotube formation.

As reported earlier by Kasuga et al. [30], SEM images showed needle-shaped structures of $\mathrm{HCl}$-treated samples following alkaline hydrothermal method. They also reported that the specific surface area of $n-\mathrm{TiO}_{2}$ greatly increased after washing with distilled water and $\mathrm{HCl}$. In agreement with that, Liu et al. [105] found that the surface area of $\mathrm{n}-\mathrm{TiO}_{2}$ was $78 \mathrm{~m}^{2} / \mathrm{g}$ following the alkaline hydrothermal reaction. However, the surface area was increased to $330 \mathrm{~m}^{2} / \mathrm{g}$ after washing with $\mathrm{HCl}$. This confirms the fact that this reaction has a remarkable effect on the surface area of nanotubes. Moreover, Kasuga and coworkers [30] reported TEM images that indicated the presence of wide lattice stripes at both ends of the needle-shaped structures. They reported nanotubes with inner and outer diameters of $5 \mathrm{~nm}$ and $8 \mathrm{~nm}$, respectively. In our study, the nanotubes had greater inner and outer diameters, $12 \mathrm{~nm}$ and $25 \mathrm{~nm}$, respectively. This may have been due to the higher temperature $\left(160^{\circ} \mathrm{C}\right)$ that we applied during the alkaline hydrothermal reaction.

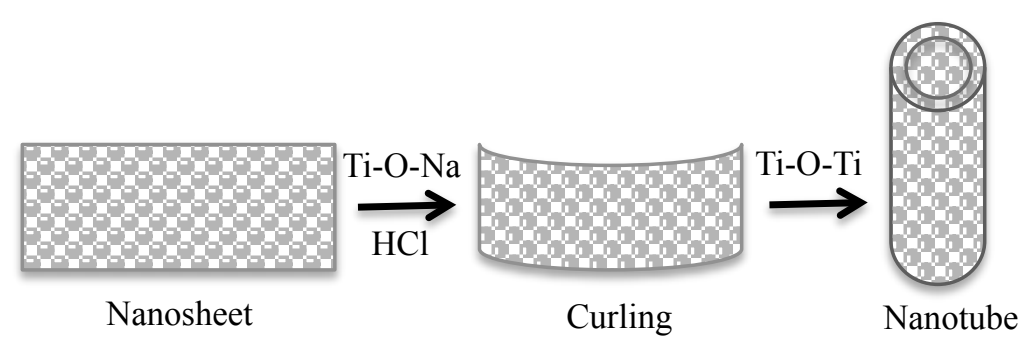

Fig. 4.1: $\mathrm{TiO}_{2}$ Nanotube formation scheme. 


\subsection{Filler functionalization}

\subsubsection{Purpose of functionalization}

Functionalization of fillers is important in composites to provide a link between the polymer matrix and fillers [4]. In the case of nanofillers, functionalization is crucial to avoid nanofiller agglomeration because of their small size. Silane has been used frequently as a coupling agent in dental composites. In the studies reported in this thesis, we used two different methods for functionalizing $\mathrm{n}-\mathrm{TiO}_{2}$. We used a dual-silanization method and methacrylic acid method. The latter has been reported to be a functionalization agent for $\mathrm{n}-\mathrm{TiO}_{2}$ in bone cements [25].

\subsubsection{Functionalization with silane}

Wilson et al. [38] described the dual-silanization method using MPTS and OTMS. This method resulted in improved composite handling properties, lower polymerization shrinkage and improved durability in the oral environment. These effects are more prominent in the case of nanocomposites than in conventional composites that have higher filler content. This is likely due to the fact that nanofillers have a much larger surface area per unit mass [34].

Another study was carried out by Karebela et al. [106] to compare the absorption of water or ethanol/water solution in dental nanocomposites containing silica nanoparticles silanized with different silanes including urethane dimethacrylate silane (UDMS), MPTS, and OTMS. Composite absorption of water or ethanol/water solution was found to be influenced by the structure of silane. Composites with UDMS, which has a hydrophilic urethane group, showed the highest amount of water absorption. On the other hand, composite with OTMS that does not have a methacrylate moiety (i.e, can not 
react with dimethacrylate monomers) was found to have highest solubility, while the MPTS composite was found to absorb the lowest amount. They concluded that the structure of silane affects the solubility of composites.

In other studies, nanosilica particles functionalized with glycidoxypropyltrimethoxy-silane (GPS) were found to be well-dispersed in resin matrix without aggregation. In contrast, $\mathrm{SiO}_{2}$ nanoparticles without GPS aggregated to form macrosized clusters [8]. In our studies, FTIR of $\mathrm{n}-\mathrm{TiO}_{2}$ functionalized with silane showed a peak at $1725 \mathrm{~cm}^{-1}$ due to the $\mathrm{C}=\mathrm{O}$ vibration band in addition to other peaks corresponding to alkoxy group. The $\mathrm{C}=\mathrm{O}$ vibration band is associated with carbonyl group from MPS. The other peaks at 2934 and $3477 \mathrm{~cm}^{-1}$ are due to $\mathrm{CH}_{3}$ and $\mathrm{OH}$ stretches corresponding to alkoxy group of MPS, which is able to bind with the hydroxyl group on the surface of n-TiO 2 . Fig. 4.2 shows a schematic for binding between MPS and n- $\mathrm{TiO}_{2}$. $\mathrm{R}-\mathrm{Si}\left(\mathrm{OCH}_{3}\right)_{3}$ represents a general silane molecule where $\mathrm{R}$ is an organic functional group (such as methacrylate) that forms a covalent bond with the organic resin matrix [107, 108]. 


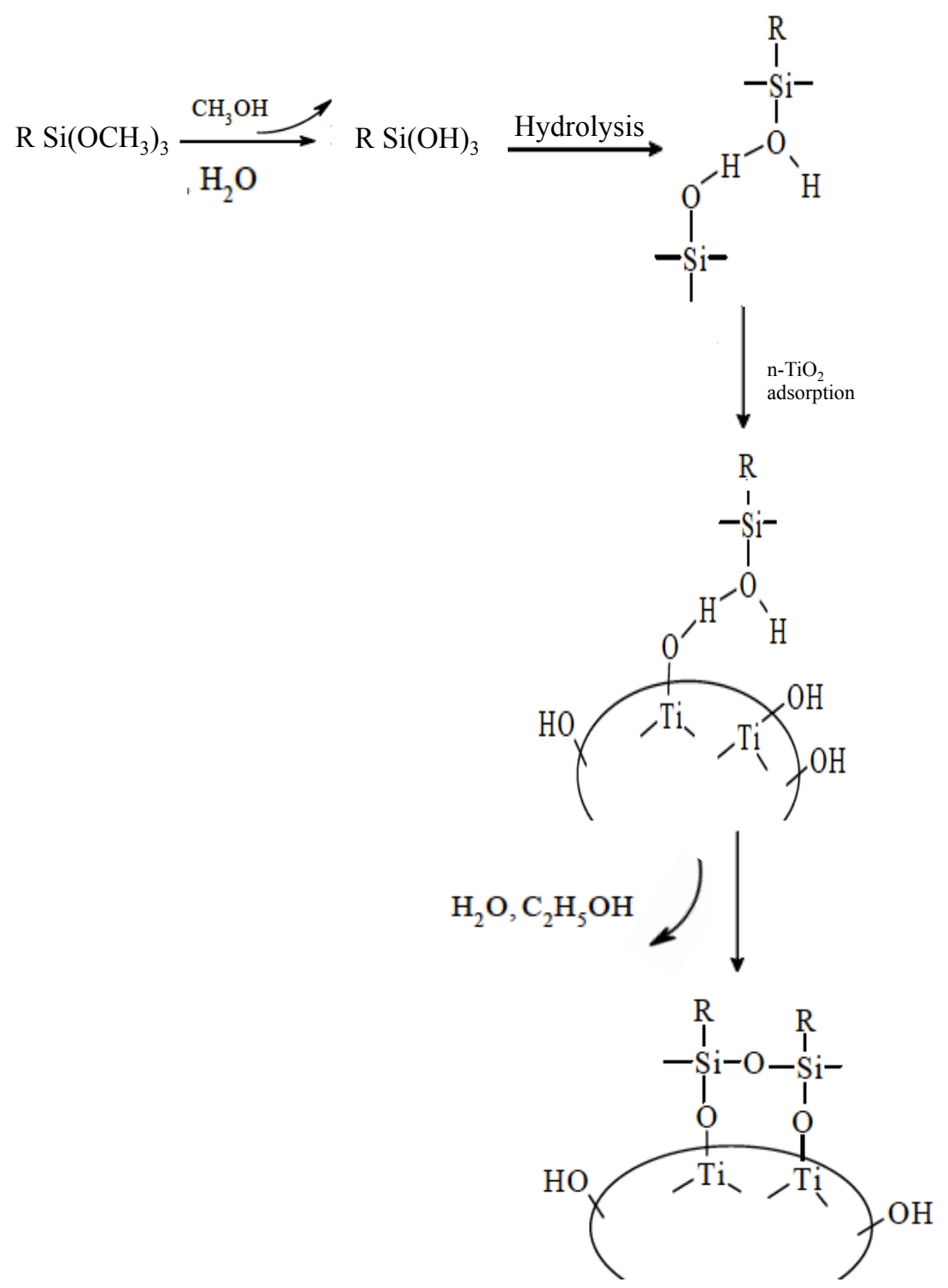

Fig. 4.2: Deposition of MPS on $\mathrm{n}-\mathrm{TiO}_{2}$. This reaction takes place via hydrolysis followed by polycondensation.

\subsubsection{Functionalization with methacrylic acid (MA)}

MA is a bifunctional agent, which is able to form a chemical link between n- $\mathrm{TiO}_{2}$ and the polymer matrix through a Ti-carboxylic coordination bond [25]. In our studies, FTIR for $\mathrm{n}-\mathrm{TiO}_{2}$ functionalized with MA showed an absorbance peak at $1633 \mathrm{~cm}^{-1}$ due to the vinyl bond of methacrylic acid. Another peak at $2355 \mathrm{~cm}^{-1}$ corresponds to carboxylic groups of 
MA coordinated with Ti atoms. The peaks at 1381 and $3412 \mathrm{~cm}^{-1}$ are due to $\mathrm{CH}$ and $\mathrm{OH}$ stretches respectively. They also act as functional sites for further copolymerization, Fig. 4.3 [109]. The presence of these peaks that represent the functional groups and bond formation between $\mathrm{n}-\mathrm{TiO}_{2}$ and $\mathrm{MA}$ provide evidence of chemical bond formation between these functionalized fillers and the resin matrix.

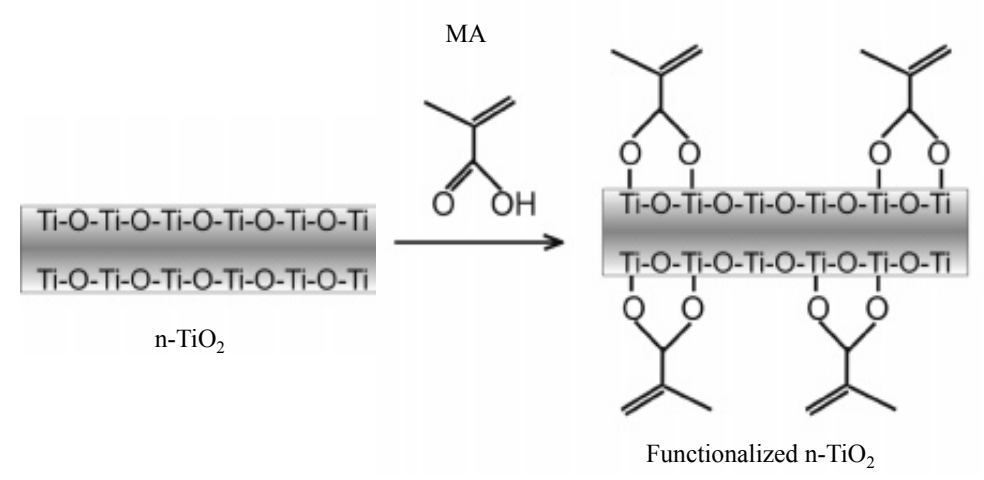

Fig. 4.3: Schematic of MA functionalization of $\mathrm{TiO}_{2}$. Adapted with permission (Appendix A) from the Langmuir. 2007;23:3988-95. [109]

\subsection{Chemical characterization of $\mathrm{n}-\mathrm{TiO}_{2}$}

Our XRD results confirmed that titania nanotubes prepared by alkaline hydrothermal technique and calcined at $400^{\circ} \mathrm{C}$ exhibit the anatase phase of $\mathrm{TiO}_{2}[110,111]$. Sodium trititanate $\left(\mathrm{Na}_{2} \mathrm{Ti}_{3} \mathrm{O}_{7}\right)$ was detected in $\mathrm{TiO}_{2}$ samples. This could be a transition phase between hydrothermal treatment and $\mathrm{HCl}$ washing. Similar results were reported in previous studies. Jiang et al. [110] found anatase diffraction peaks corresponding to $\mathrm{TiO}_{2}$ calcined at $400^{\circ} \mathrm{C}$. $\mathrm{Yu}$ and coworkers [112] reported anatase phase of $\mathrm{TiO}_{2}$ for samples calcined at $300-600^{\circ} \mathrm{C}$. However, at the higher temperature of $700^{\circ} \mathrm{C}$, anatase and rutile phases were found. At the higher calcination temperature of $800^{\circ} \mathrm{C}$, only the rutile phase was seen [113]. 
EDX was done for $\mathrm{n}-\mathrm{TiO}_{2}$ following alkaline hydrothermal reaction and calcination. It is clearly seen that $\mathrm{Ti}$ and $\mathrm{O}$ have the highest weight per cent. These two elements correspond to $\mathrm{TiO}_{2}$. A small percentage of $\mathrm{Na}$ was found in the sample indicating that a small portion of $\mathrm{Na}$ ions (from $\mathrm{NaOH}$ used during the alkali treatment step of $\mathrm{n}-\mathrm{TiO}_{2}$ synthesis) remained after washing. A trace amount of $\mathrm{Sr}$ was also detected. However, C and Ni likely came from the coating and grids that were used to mount the samples.

\subsection{Flowability}

Flowability testing method used in this study was described earlier by Bayne et al. [19] to compare different dental flowable composites. They concluded that the ideal flowable composite should not flow because of its own weight; instead, it should require a force to start to flow. Lee et al. [45] studied the rheological properties of flowable and other composites. They concluded that composite viscosity increases with increasing amounts of fillers, but no direct linear relation was found. Instead, there is a weak relationship between filler volume $\%$ and composite viscosity. In accordance with these results, Beun and coauthors [114] confirmed no correlation between the viscosity of flowable dental composites and the filler weight fraction. They suggested that adding nanoparticles could have a positive effect on flowable composites in terms of mechanical properties and better flow. This is applicable to our titania nanotubes. Previous studies reported that it is possible to increase the nanofiller content due to their small particle sizes. This will result in significant reduction in polymerization shrinkage as well as improvement in the physical properties of the nanocomposites [8]. 


\subsection{Mechanical properties of composites}

\subsubsection{Dynamic Young's modulus (E)}

Dynamic Young's modulus plays an important role in the stresses generated during polymerization shrinkage of resin composite. This phenomenon is critical in terms of the success or failure of adhesive restorations because shrinkage results in marginal gap formation, discoloration, recurrent caries and post-operative sensitivity [115].

To measure E, we used the ultrasonic pulse method. This technique has the advantage of being non-destructive, permits the use of small sample size, and it can be used to measure the material's rigidity. E is an important parameter to assess the effect of nanotube functionalization, as it gives an idea about the adhesion between functionalized $\mathrm{n}-\mathrm{TiO}_{2}$ and composite matrix [62]. Basically, the method works by applying an ultrasonic pulse through the composite sample in both longitudinal and transverse waves and then measuring their velocities [116]. We found that composite reinforced with $3 \% \mathrm{MA}$ functionalized nanotubes has the highest Young's modulus $(16.8 \mathrm{GPa})$, which is significantly higher than that of control composite (10.6 GPa).

The E value of control composite measured in our work is in the range of other commercial flowable composites studied by Sabbagh et al. [56]. They measured the dynamic elastic moduli for composite specimens after incubation in distilled water at room temperature for $7 \mathrm{~d}$. They reported $\mathrm{E}$ values for flowable composites ranging between 4.6 - 10.9 GPa. E for packable composites were found to be in the range of $8.3-$ 20.3 GPa. However, E of amalgam was reported to be $30 \mathrm{GPa}$ [2]. According to Jones et al. [62], the higher magnitude of Young's moduli reflects the stronger adhesion between $\mathrm{n}-\mathrm{TiO}_{2}$ and composite matrix with a higher extent of functionalization. 
Understanding the mechanical properties of human teeth is important for the development of restorations with characteristics closer to those of natural teeth $[56,117]$. When replacing a tissue, the ideal material for replacement should have a modulus of elasticity similar to that of replaced tissue. In terms of dental restorations, they should have a modulus of elasticity similar to that of dentin (the most abundant mineralized tissue in teeth). However, an optimal restoration should mimic both dentin and enamel in structural, mechanical and physical properties. This is impossible to achieve unless different restorative materials are used in combination [115]. Less marginal breakdown is expected with smaller differences in the elasticity $[118,119]$.

Many studies have reported E values for enamel and dentin. Xu et al. [117] measured elastic modulus of human enamel and dentin. They found that Young's modulus of enamel ranges between 80-94 GPa depending on tooth orientation. However, Young's modulus of dentin found to be $19 \mathrm{GPa}$. Craig and Peyton [49] reported $18 \mathrm{GPa}$ elastic modulus value for dentin in human. Elastic modulus values of $15 \mathrm{GPa}$ for dentin and 40-80 GPa for enamel were reported by Rees and Jacobsen [120]. McCabe [2] reported $\mathrm{E}$ values of $50 \mathrm{GPa}$ and $12 \mathrm{GPa}$ for enamel and dentin respectively.

Braga et al. [121] studied the effect of composite modulus of elasticity on stress distribution at the tooth-restoration interface. They concluded that stress concentration decreased with composites that have a modulus value of $12 \mathrm{GPa}$ due to less modulus mismatch between dentin and composite. It is clearly seen that the E values of our reinforced composite samples are comparable to that of human dentin. Furthermore, applying a flowable composite lining underneath the main filling could be effective in reducing shrinkage stress [55]. The lower elastic moduli and the higher flowability of 
composites might allow stress concentration relaxation and possible reduction of marginal breakdown and debonding [56]. Our reinforced flowable composite could be ideal for this purpose as the reinforcing nanotubes may greatly reduce its polymerization shrinkage.

\subsubsection{Fracture toughness $\left(K_{I C}\right)$}

Fracture toughness is one of the most important mechanical properties for dental materials. It is defined as the energy absorbed by the material prior to fracture due to crack propagation. In case of poor adhesion between fillers and matrix, debonding will occur during tensile loading resulting in the formation of microvoids within the matrix with subsequent crack propagation [25]. In our study, this was investigated by SEM of composite fracture surfaces. The covalent bond formed between functionalized $\mathrm{n}-\mathrm{TiO}_{2}$ and the composite matrix appeared to influence their adhesion and embedding in the composite matrix.

Schultz et al. [122] compared $\mathrm{K}_{\mathrm{IC}}$ of a few commercial highly filled composites with their corresponding flowable ones. They reported a highly filled (Nanopaq) composite to have the highest $\mathrm{K}_{\mathrm{IC}}$ value of $3.64 \mathrm{MPa} \cdot \mathrm{m}^{0.5}$. On other hand, Dyract flowable composite showed the lowest $\mathrm{K}_{\mathrm{IC}}$ value of $0.82 \mathrm{MPa} \cdot \mathrm{m}^{0.5}$. Generally, all the tested flowable composites showed significantly lower $\mathrm{K}_{\mathrm{IC}}$ values as compared to their corresponding highly filled ones. In case of the $\mathrm{n}-\mathrm{TiO}_{2}$ we used in this study, $\mathrm{K}_{\mathrm{IC}}$ were 0.93, 1.05 and $1.18 \mathrm{MPa} . \mathrm{m}^{0.5}$ for composites reinforced with $\mathrm{NF}$ n- $-\mathrm{TiO}_{2}$, composites reinforced with $\mathrm{n}-\mathrm{TiO}_{2}+$ silane and composites reinforced with $\mathrm{n}-\mathrm{TiO}_{2}+\mathrm{MA}$, respectively. Soderholm [64] reviewed the $\mathrm{K}_{\mathrm{IC}}$ values for enamel, dentin and different 
dental materials. He reported the $\mathrm{K}_{\mathrm{IC}}$ values ranging from $0.65-2.5 \mathrm{MPa} \cdot \mathrm{m}^{0.5}$ for enamel and 1.0 - 4.0 MPa.m ${ }^{0.5}$ for dentin. $\mathrm{K}_{\mathrm{IC}}$ values of dental amalgam were found to be in the range of 1.4 to $2.4 \mathrm{MPa} \cdot \mathrm{m}^{0.5}$, while $\mathrm{K}_{\mathrm{IC}}$ value for composites ranged between 0.7 and 1.9 MPa.m ${ }^{0.5}$. In another study, $\mathrm{K}_{\mathrm{IC}}$ values for enamel were between 0.6 and $1.8 \mathrm{MPa} \cdot \mathrm{m}^{0.5}$ and 3.1 MPa.m ${ }^{0.5}$ for dentin [51].

Table 4.1 summarizes the $\mathrm{E}$ and $\mathrm{K}_{\mathrm{IC}}$ values for enamel, dentin and different dental materials. Previous studies found that reinforcing fillers could distribute the force propagation into several components causing crack curving or dissipation between particles. This will create conditions unfavourable for growth of the crack. However, the relationship between the filler content and $\mathrm{K}_{\mathrm{IC}}$ seems to be complicated [51].

\begin{tabular}{|l|c|c|}
\hline \multicolumn{3}{|c|}{ Table 4.1: Summary for E and K $\begin{array}{c}\text { IC values for enamel, dentin } \\
\text { and different dental materials }\end{array}$} \\
\hline & E (GPa) & K $_{\text {IC }}$ (MPa.m ${ }^{\mathbf{0 . 5}}$ ) \\
\hline Enamel & $40-94$ & $0.65-2.5$ \\
\hline Dentin & $12-19$ & $1.0-4.0$ \\
\hline Amalgam & 30 & $1.4-2.4$ \\
\hline Packable composites & $8.3-20.3$ & $0.7-1.9$ \\
\hline Flowable composites & $4.6-10.9$ & 0.82 \\
\hline Our n-TiO ${ }_{2}$ flowable composite & $15.5-16.8$ & $0.93-1.2$ \\
\hline
\end{tabular}




\subsection{Radiopacity}

The radiopacity of a restorative material is an important parameter for accurate diagnosis and treatment planning. Evaluating long term success or failure of the restoration is highly dependent on radiographs. Composite restorations radiopacity has an important role in detecting recurrent caries and distinguishing the restorations from the natural tooth structures [78]. The radiopacity of dental composites according to the ISO standard 4049 should be equal to dentin, and equal or greater than $1 \mathrm{~mm} \mathrm{Al} \mathrm{equivalent} \mathrm{[75].}$

Previous studies suggested that the composite first increment should have a sufficient radiopacity to clearly evaluate the tooth-restoration interface. This is important when flowable composite is used as an intermediate layer between the restoration and the tooth [123]. Other studies recommended that the composite radiopacity should be equal to or greater than that of the enamel $[17,76,78,123]$. However, materials with much higher radiopacity than enamel (such as amalgam) may lead to under or over estimation of secondary caries and marginal defects. Thus, materials with slightly higher radiopacity than enamel are preferred $[74,124]$. The amalgam is too radiopaque as compared to the tooth. This is associated with the risk of undiagnosed caries and adjacent defects, which are hidden in the shadow of amalgam [125].

Matsumura et al. [125] reported the radiopacity values of different dental materials as examples; enamel $(1.77-2 \mathrm{~mm} \mathrm{Al})$, dentin $(0.98-1.01 \mathrm{~mm} \mathrm{Al})$ and amalgam $(9.74-11.47 \mathrm{~mm} \mathrm{Al})$. Flowable composites were found to have lower radiopacity as compared to hybrid composite due to their lower filler content [126]. Sabbagh and others reported linear correlation between the filler weight percent and radiopacity [127]. The atomic number of the elements is the most important factor 
affecting the radiopacity of dental materials [128]. Radiopacity of dental composites can be increased by incorporating a higher percentage of fillers with high atomic numbers such as barium, strontium and ytterbium [127].

Furtos and co-authors [129] evaluated the radiopacity of 17 different flowable composites. The radiopacity values ranged between 1.14 and $3.57 \mathrm{~mm}$ Al. Dukic and coworkers [130] reported the radiopacity for 32 dental composites (including both microfilled and nanohydrid). The radiopacity ranged from 0.61 to $4.78 \mathrm{~mm} \mathrm{Al}$. In our study, the radiopacity of $\mathrm{n}-\mathrm{TiO}_{2}$ reinforced flowable composites ranged between 1.64 and $2.19 \mathrm{~mm} \mathrm{Al}$. The control composite showed a higher value of radiopacity $(2.62 \mathrm{~mm} \mathrm{Al})$. However, all of these composites (control, $\mathrm{NF} \mathrm{n}$ - $\mathrm{TiO}_{2}$-reinforced composites, composites reinforced with $\mathrm{n}-\mathrm{TiO}_{2}+$ silane and composites reinforced with $\left.\mathrm{n}-\mathrm{TiO}_{2}+\mathrm{MA}\right)$ met the ISO standard for dental materials radiopacity. All of them had radiopacity greater than dentin. Table 4.2 summarizes the radiopacity values of enamel, dentin and different dental materials.

\begin{tabular}{|l|c|}
\hline \multicolumn{2}{|c|}{$\begin{array}{c}\text { Table 4.2: Radiopacity of enamel, dentin } \\
\text { and restorative materials }\end{array}$} \\
\hline \multicolumn{1}{|c|}{ Tissue/ Material } & Radiopacity (mm Al) \\
\hline Enamel & $1.77-2.00$ \\
\hline Dentin & $0.98-1.01$ \\
\hline Amalgam & $9.74-11.47$ \\
\hline Packable composites & $0.61-4.78$ \\
\hline Flowable composites & $1.14-3.57$ \\
\hline $\begin{array}{l}\text { Our n-TiO } \\
\text { composites }\end{array}$ & $1.64-2.19$ \\
\hline
\end{tabular}




\subsection{Biocompatibility}

All dental materials, including resin composites, are required to be tested in vitro and in vivo to evaluate the biocompatibility. In our study, we evaluated possible cytotoxicity using the MTT assay to evaluate fibroblast viability. Fibroblasts are an approved cell type for cytotoxicity testing by ISO. In addition, they are the most dominant cell type in the pulp that can be affected by the leaching components from composite restorations [83]. The MTT cytotoxicity assay is a rapid, sensitive, colorimetric test [131]. This assay utilizes mitochondrial dehydrogenase activity that results in cleavage of a yellow tetrazolium salt (MTT) to form purple formazan crystals [132]. MTT dye reduction appears to take place only in viable cells; in contrast, nonviable cells cannot reduce the dye [133].

Our MTT assay results showed no significant difference in the viability of cells cultured on pure and reinforced composites. These data indicate that our reinforced composites have excellent biocompatibility. Assessment of biocompatibility using dye uptake methods provides an idea only about cell death caused by biomaterials. However, biomaterials may show different mechanisms of cytotoxicity. Therefore, biocompatibility should be assessed using a number of quantitative measures. Ciapetti et al. [134] recommended a model proposed in xenobiotic research. It utilizes the LDH assay for evaluation of membrane integrity, ${ }^{3} \mathrm{H}$-thymidine uptake to quantify DNA synthesis, neutral red uptake to evaluate the efficiency of lysosomes, the Lowry method for protein assessment, and the MTT assay to test mitochondrial activity. Using such a system to study cell-biomaterial interactions will be valuable in future studies. 


\section{Chapter 5}

\section{Conclusions and Future Directions}




\subsection{Summary and conclusions}

A flowable dental composite was successfully reinforced with $\mathrm{n}-\mathrm{TiO}_{2}$. Incorporation of small weight percentages of this nanofiller exhibited a marked improvement in the mechanical properties. The flowability of the reinforced composites was slightly reduced, but was acceptable for clinical applications. Our research findings are summarized as follows:

- $\mathrm{n}-\mathrm{TiO}_{2}$ powder was successfully synthesized by alkaline hydrothermal reaction at $160^{\circ} \mathrm{C}$ to act as a reinforcing phase for a flowable dental composite.

- Three different groups of $\mathrm{n}-\mathrm{TiO}_{2}$ were prepared - i) nonfunctionalized (NF) $\mathrm{n}-\mathrm{TiO}_{2}$, ii) $\mathrm{n}-\mathrm{TiO}_{2}$ functionalized with silane, and iii) $\mathrm{n}-\mathrm{TiO}_{2}$ functionalized with methacrylic acid (MA) - to evaluate the reinforcing effect of each group.

- Chemical characterization of $n-\mathrm{TiO}_{2}$ was conducted using XRD, EDX and FTIR. XRD showed anatase diffraction peaks of $\mathrm{n}-\mathrm{TiO}_{2}$. EDX showed $\mathrm{Ti}$ and $\mathrm{O}$ had the highest weight \%. FTIR revealed that both silane and MA were successful coupling agents for $\mathrm{n}-\mathrm{TiO}_{2}$ fillers. FTIR absorption spectra showed the presence of functional groups corresponding to binding between $\mathrm{n}-\mathrm{TiO}_{2}$ and the functionalizing agent. Bond formation between silane and $\mathrm{n}-\mathrm{TiO}_{2}$ was primarily through alkoxy group. However, carboxylic group resulted in bond formation between $\mathrm{MA}$ and $\mathrm{n}-\mathrm{TiO}_{2}$.

- SEM and TEM images of n- $\mathrm{TiO}_{2}$ exhibited the tubular morphology with no evidence of agglomeration. SEM of composite surfaces following fracture toughness test shows gaps at the interfaces between $\mathrm{NF} n-\mathrm{TiO}_{2}$ and the resin matrix. On the other hand, functionalized $\mathrm{n}-\mathrm{TiO}_{2}$ (both silane and $\mathrm{MA}$ ) were embedded within the 
composite resin matrix. However, SEM images of fracture surfaces of control composite showed only spherical nanoparticles embedded into the resin matrix.

- $\mathrm{n}-\mathrm{TiO}_{2}$ were successfully incorporated into a flowable composite. Nanotubes were incorporated in small weight fractions as they have a high surface area.

- Flowability evaluation of composites showed a minimum decrease in composite fluidity with increasing $\mathrm{n}-\mathrm{TiO}_{2}$ content.

- Mechanical properties of the reinforced composites were significantly higher than those of control composite. Flowable composites reinforced with MA-functionalized $\mathrm{n}-\mathrm{TiO}_{2}$ exhibited the highest values of elastic moduli. Both silane- and MAfunctionalized $\mathrm{n}-\mathrm{TiO}_{2}$ had $\mathrm{E}$ values significantly greater than that of control composite. E values of flowable composites reinforced with $\mathrm{n}-\mathrm{TiO}_{2}$ are comparable to that of human dentin. Moreover, these reinforced flowable composites showed higher resistance to crack propagation. Composite reinforced with 3\% MA achieved the highest value of $\mathrm{K}_{\mathrm{IC}}$, significantly greater than the control and NF groups.

- Although the radiopacity of the MA-reinforced composite was significantly less than that of the control composite, all composites met the ISO standard for radiopacity of dental restorative materials.

- In vitro cytotoxicity testing using MTT showed excellent biocompatibility of $\mathrm{n}-\mathrm{TiO}_{2}$ reinforced composites. The viability of cells grown on the reinforced composites was comparable to that of cells grown on the control composite.

- A reduction in polymerization shrinkage of flowable composites is expected with the incorporation of $\mathrm{n}-\mathrm{TiO}_{2}$ fillers, due to their high surface area to volume ratio. 
- Improved mechanical properties, acceptable handling characteristics and excellent biocompatibility of flowable composites reinforced with $\mathrm{n}-\mathrm{TiO}_{2}$ make them promising materials for future applications in restorative dentistry.

\subsection{Future directions}

Although $\mathrm{n}-\mathrm{TiO}_{2}$ reinforced flowable dental composites could result in successful restorations, it is recommended to conduct the following tests to predict their long-term performance.

- Wear resistance and surface polish of $n-\mathrm{TiO}_{2}$ reinforced composites should be evaluated.

- As the polymerization shrinkage is expected to decrease in composites reinforced with $\mathrm{n}-\mathrm{TiO}_{2}$, these restorations could be tested in extracted teeth. Histologic sections can be done afterwards to evaluate marginal leakage at the tooth-restoration interface.

- Our reinforced composites showed excellent biocompatibility in vitro. Future studies should examine their biocompatibility in vivo. Animal model for dental materials biocompatibility testing includes rats, rabbits, dogs and non-human primates [79, 135]. Favorable outcomes in animal models could then lead to an application to Health Canada to undertake clinical trials in humans.

It is also recommended to reinforce other dental resins with $\mathrm{TiO}_{2}$ nanofillers in order to improve their physical and mechanical properties as the following:

- Changing the temperature and $\mathrm{pH}$ of the hydrothermal reactions could produce different $\mathrm{TiO} 2$ nanofillers. We suggest incorporating $\mathrm{TiO}_{2}$ nanoribbons (can be 
fabricated at $180-250^{\circ} \mathrm{C}$ hydrothermal temperature) and ribbon-like structures (can be fabricated at $200^{\circ} \mathrm{C}$ under hydrothermal conditions) to flowable dental composite and compare their effects to that of the $n-\mathrm{TiO}_{2}$.

- Incorporation of a small weight fraction of $\mathrm{n}-\mathrm{TiO}_{2}$ fillers to dentin bonding agents to render them radiopaque. The dentin bonding agents are known to be radiolucent or have lower radiopacity than dentin. This makes the radiographic examination and diagnosis challenging in terms of recurrent caries detection. Addition of n- $\mathrm{TiO}_{2}$ doped with Sr to dentin bonding agents could facilitate their detection in radiographs. 
Chapter 6

References 
1. Albers. Tooth-colored restoratives: Principles and techniques. Oral Dis. 2004;10(1):61.

2. McCabe JF, Walls A. Applied dental materials. 8th ed. Malden, MA: Blackwell Science; 1998.

3. Knock FE GJ. Dental materials and methods. US Patent No 2558139.

4. Bowen RL. Properties of a silica-reinforced polymer for dental restorations. J Am Dent Assoc. 1963;66:57-64.

5. Lindberg A. Resin composites : Sandwich restorations and curing techniques Umeå: Odontologi; 2005.

6. Hervas-Garcia A, Martinez-Lozano MA, Cabanes-Vila J, Barjau-Escribano A, FosGalve P. Composite resins. A review of the materials and clinical indications. Med Oral Patol Oral Cir Bucal. 2006;11(2):215-20.

7. Dart EC, Cantwell JB, Traynor JR, Franciszek JJ, Nemeck J. Method of repairing teeth using a composition which is curable by irradiation with visible light. US Patent 4089 763.1978.

8. Chen M-. Critical reviews in oral biology \& medicine: Update on dental nanocomposites. J Dent Res. 2010;89(6):549-60.

9. Ferracane JL. Current trends in dental composites. Crit Rev Oral Biol Med, 1995;6(4):302-18.

10. Lee SY, Chui CH, Boghosian A, Greener EH. Radiometric and spectroradiometric comparison of power outputs of five visible light-curing units. J Esthet Dent. 1999;11(6):340-41.

11. Ferracane JL. Resin composite - State of the art. Dental Materials. 2011;27(1):29-38.

12. Bonsor S. and Pearson GA. clinical guide to applied dental materials. 1st ed. Elsevier. $2012 ; 70$.

13. Mitra SB, Wu D, Holmes BN. An application of nanotechnology in advanced dental materials. The J of the Am Dent Ass. 2003;134(10):1382-90.

14. Wagner HD, Vaia RA. Nanocomposites: Issues at the interface. Materials Today. 2004;7(11):38-42.

15. Ilie N, Hickel R, Watts DC. Spatial and cure-time distribution of dynamic-mechanical properties of a dimethacrylate nano-composite. Dental Materials. 2009;25(3):411-18. 
16. Ilie N, Hickel R. Macro-, micro- and nano-mechanical investigations on silorane and methacrylate-based composites. Dental Materials. 2009;25(6):810-19.

17. Attar N, Tam LE, McComb D. Flow, strength, stiffness and radiopacity of flowable resin composites. J Can Dent Assoc. 2003;69(8):516-21.

18. Cadenaro M, Marchesi G, Antoniolli F, Davidson C, De Stefano Dorigo E, Breschi L. Flowability of composites is no guarantee for contraction stress reduction. Dental Materials. 2009;25(5):649-54.

19. Bayne SC, Thompson JY, Swift EJ,Jr, Stamatiades P, Wilkerson M. A characterization of first-generation flowable composites. J Am Dent Assoc. 1998;129(5):567-77.

20. Sarrett DC. Clinical challenges and the relevance of materials testing for posterior composite restorations. Dental Materials. 2005;21(1):9-20.

21. Brunthaler A, König F, Lucas T, Sperr W, Schedle A. Longevity of direct resin composite restorations in posterior teeth: A review. Clin Oral Invest. 2003;7(2):6370 .

22. Kotha SP, Li C, Schmid SR, Mason JJ. Fracture toughness of steel-fiber-reinforced bone cement. J Biomed Mater Res. 2004;70A(3):514-21.

23. Xu HHK, Quinn JB, Smith DT, Giuseppetti AA, Eichmiller FC. Effects of different whiskers on the reinforcement of dental resin composites. Dental Materials. 2003;19(5):359-67.

24. Marrs B, Andrews R, Rantell T, Pienkowski D. Augmentation of acrylic bone cement with multiwall carbon nanotubes. J Biomed Mater Res. 2006;77A(2):269-76.

25. Khaled SMZ, Miron RJ, Hamilton DW, Charpentier PA, Rizkalla AS. Reinforcement of resin based cement with titania nanotubes. Dental Materials. 2010;26(2):169-78.

26. Ding,Yong, Wang Z,Lin. Structure analysis of nanowires and nanobelts by transmission electron microscopy. J. Phys. Chem B .2004;108(33):12280-91.

27. Jung J, Kobayashi H, Bommel K, Shinkai S, Shimizu T. Creation of novel helical ribbon and double-layered nanotube $\mathrm{TiO} 2$ structures using an organogel template. Chem. Mater. 2002;14(4):1445-1447.

28. Kasuga T, Hiramatsu M, Hoson A, Sekino T, Niihara K. Formation of titanium oxide nanotube. Langmuir. 1998;14(12):3160-63.

29. Gong D, Grimes CA, Varghese OK, Hu W, Singh RS, Chen Z, et al. Titanium oxide nanotube arrays prepared by anodic oxidation. J Mater Res. 2001;16(12):3331-34. 
30. Kasuga T, Hiramatsu M, Hoson A, Sekino T, Niihara K. Titania nanotubes prepared by chemical processing. Adv Mater. 1999;11(15):1307-11.

31. Ou HH, Lo SL. Review of titania nanotubes synthesized via the hydrothermal treatment: Fabrication, modification, and application. Sep Purif Technol. 2007;58(1):179-91.

32. Swami N, Cui Z, Nair LS. Titania nanotubes: Novel nanostructures for improved osseointegration. J. Heat Transfer. 2010;133(3):034002-09.

33. Yoshikawa M, Terada Y, Toda T. Setting time and sealing ability of alpha-tricalcium phosphate cement containing titanic oxide. J Osaka Dent Univ. 1998;32(2):67-70.

34. Mohsen N, Craig R. Effect of silanation of fillers on their dispersability by monomer systems. J Oral Rehabil. 1995;22(3):183-89.

35. Plueddemann EP. Silane coupling agents. New York: Plenum Press; 1982.

36. Liu Q, Ding J, Chambers DE, Debnath S, Wunder SL, Baran GR. Filler-coupling agent-matrix interactions in silica/polymethylmethacrylate composites. J Biomed Mater Res. 2001;57(3):384-93.

37. Chen TM, Brauer GM. Solvent effects on bonding organo-silane to silica surfaces. J Dent Res. 1982;61(12):1439-43.

38. Wilson KS, Zhang K, Antonucci JM. Systematic variation of interfacial phase reactivity in dental nanocomposites. Biomaterials. 2005;26(25):5095-103.

39. Khaled SMZ, Charpentier PA, Rizkalla AS. Synthesis and characterization of poly(methyl methacrylate)-based experimental bone cements reinforced with $\mathrm{TiO} 2-$ SrO nanotubes. Acta Biomaterialia. 2010;6(8):3178-86.

40. Xia Y, Zhang F, Xie H, Gu N. Nanoparticle-reinforced resin-based dental composites. J Dent. 2008;36(6):450-55.

41. Langford JI, Lou D. Powder diffraction. Reports on Progress in Physics. Rep. Prog. Phys.1996;59(2):131.

42. Lin YJ, Wang L, Chiu WY. Preparation and characterization of titania nanotubes and hybrid materials derived from them. J. Vac. Sci. Technol. B. 2005;23(6):2398-03.

43. Goldstein J, Newbury D, Joy D, Lyman C, Echlin P, Lifshin E, Sawyer L. Scanning electron microscopy and x-ray microanalysis. 3rd ed. Joseph Michael Kluwer. 2005. 
44. Yang M, Dan Y. Preparation and characterization of poly(methyl methacrylate)/titanium oxide composite particles. Colloid Polym Sci. 2005;284(3):243-50.

45. Lee I, Son H, Um C. Rheologic properties of flowable, conventional hybrid, and condensable composite resins. Dental Materials. 2003;19(4):298-07.

46. ADA Professional Product Review. Laboratory testing methods: Endodontic filling and sealing materials. 2008;3(4).

47. Opdam NJ, Roeters JJ, Peters TC, Burgersdijk RC, Kuijs RH. Consistency of resin composites for posterior use. Dent Mater. 1996;12(6):350-54.

48. Braem M, Finger W, Van Doren VE, Lambrechts P, Vanherle G. Mechanical properties and filler fraction of dental composites. Dent Mater. 1989;5(5):346-48.

49. Watts D, Vogel K, Marouf A. Shrinkage stress reduction in resin-composites of increasing particle concentration. J Dent Res. 2002;81(A):308.

50. Tjandrawinata R, Irie M, Suzuki K. Flexural properties of eight flowable light-cured restorative materials, in immediate vs 24-hour water storage. Oper Dent. 2005;30(2):239-49.

51. Ilie N, Hickel R, Valceanu A, Huth K. Fracture toughness of dental restorative materials. Clin Oral Invest. 2012;16(2):489-98.

52. Hua Y, Gu L, Watanabe H. Micromechanical analysis of nanoparticle-reinforced dental composites. Int J Eng Sci. 2013 8;69:69-76.

53. Choi KK, Condon JR, Ferracane JL. The effects of adhesive thickness on polymerization contraction stress of composite. J Dent Res. 2000;79(3):812-17.

54. Feilzer A, de Gee AJ, Davidson CL. Setting stress in composite resin in relation to configuration of the restoration. J Esthet Dent. 2000;12(1):52.

55. Yahagi C, Takagaki T, Sadr A, Ikeda M, Nikaido T, Tagami J. Effect of lining with a flowable composite on internal adaptation of direct composite restorations using allin-one adhesive systems. Dent Mater J. 2012;31(3):481-88.

56. Sabbagh J, Vreven J, Leloup G. Dynamic and static moduli of elasticity of resinbased materials. Dental Materials. 2002;18(1):64-71.

57. Braem M, Lambrechts P, Van Doren V, Vanherle G. The impact of composite structure on its elastic response. J Dent Res. 1986;65(5):648-53. 
58. Taylor DF, Kalachandra S, Sankarapandian M, McGrath JE. Relationship between filler and matrix resin characteristics and the properties of uncured composite pastes. Biomaterials. 1998;19(1-3):197-204.

59. ISO-4049, Resin based filling materials. 1998.

60. Kildal KK and Ruyter IE. How different curing methods affect mechanical properties for inlays when tested in dry and wet conditions. Eur J Oral Sc. 1997;105:353-61.

61. Jacobsen PH, Darr AH. Static and dynamic moduli of composite restorative materials. The J Oral Rehabil. 1997;24(4):265-73.

62. Jones DW, Rizkalla AS. Characterization of experimental composite biomaterials. J Biomed Mater Res. 1996;33(2):89-100.

63. Rizkalla AS, Jones DW. Indentation fracture toughness and dynamic elastic moduli for commercial feldspathic dental porcelain materials. Dental Materials. 2004;20(2):198-206.

64. Soderholm K. Review of the fracture toughness approach. Dental Materials. 2010;26(2):63-77.

65. Irwin GR. Fracture. encyclopedia of physics (handbuch der physic). Springer Verlag, Berlin. 1958:551-90.

66. Gdoutos EE. Fracture mechanics. 2nd ed. Springer; 2005.

67. Griffith AA. The phenomena of rupture and flow in solids. Philosophical Transactions of the Royal Society of London.Series A. 1921;221:163-98.

68. Fujishima A, Ferracane JL. Comparison of four modes of fracture toughness testing for dental composites. Dental Materials. 1996;12(1):38-43.

69. Ruse ND, Troczynski T, MacEntee MI, Feduik D. Novel fracture toughness test using a notchless triangular prism (NTP) specimen. J Biomed Mater Res. 1996;31(4):45763.

70. Ferracane JL, Antonio RC, Matsumoto H. Variables affecting the fracture toughness of dental composites. J Dent Res. 1987;66(6):1140-45.

71. Kovarik RE, Fairhurst CW. Effect of griffith precracks on measurement of composite fracture toughness. Dental Materials. 1993;9(4):222-28.

72. Williams JG, Cawood MJ. European group on fracture: Kc and gc methods for polymers. Polym Test. 1990;9(1):15-26. 
73. Kim KH, Park JH, Imai Y, Kishi T. Microf racture mechanisms of dental resin composites containing spherically-shaped filler particles. J Dent Res. 1994;73(2):499-04.

74. Tveit AB, Espelid I. Radiographic diagnosis of caries and marginal defects in connection with radiopaque composite fillings. Dental Materials. 1986;2(4):159-62.

75. International Standard 4049 Geneva. International organization for standardization dentistry- polymer based filings, restorative and luting materials. 2000.

76. Amirouche A, Mouzali M, Watts DC. Radiopacity evaluation of bisGMA/TEGDMA/opaque mineral filler dental composites. J Appl Polym Sci. 2007;104(3):1632-39.

77. Toyooka H, Taira M, Wakasa K, Yamaki M, Fujita M, Wada T. Radiopacity of 12 visible-light-cured dental composite resins. J Oral Rehabil. 1993;20(6):615-22.

78. Oztas B, Kursun S, Dinc G, Kamburoglu K. Radiopacity evaluation of composite restorative resins and bonding agents using digital and film $\mathrm{x}$-ray systems. Eur $\mathbf{J}$ Dent. 2012;6(2):115-22.

79. Moharamzadeh K, Brook IM, Van Noort R. Biocompatibility of resin-based dental materials. Materials. 2009;2(2):514-48.

80. Aldridge WN. The biochemical principles of toxicology. Exp. Toxicol. 1993;5:56-78.

81. Lee, Huang, Lin, Shih. Leached components from dental composites in oral simulating fluids and the resultant composite strengths. J Oral Rehabil. 1998;25(8):575-88.

82. Michelsen VB, Lygre H, Skålevik R, Tveit AB, Solheim E. Identification of organic eluates from four polymer-based dental filling materials. Eur $\mathbf{J}$ Oral Sci. 2003;111(3):263-71.

83. Al-Hiyasat AS, Darmani H, Milhem MM. Cytotoxicity evaluation of dental resin composites and their flowable derivatives. Clin Oral Invest. 2005;9(1):21-25.

84. Schmalz G. The biocompatibility of non-amalgam dental filling materials. Eur J Oral Sci. 1998;106(2):696-70.

85. Imazato S, McCabe JF, Tarumi H, Ehara A, Ebisu S. Degree of conversion of composites measured by DTA and FTIR. Dental Materials. 2001;17(2):178-83.

86. ISO 7405. Dentistry - preclinical evaluation of biocompatibility of medical devices used in dentistry - test methods for dental materials. International Standards Organization. 1996. 
87. ISO 10993. Biological evaluation of dental devices. International Standards Organization. 1992.

88. Willershausen B, Schafer D, Pistorius A, Schulze R, Mann W. Influence of resinbased restoration materials on cytotoxicity in gingival fibroblasts. Eur J Med Res. 1999;4(4):149-55.

89. Fotakis G, Timbrell JA. In vitro cytotoxicity assays: Comparison of LDH, neutral red, MTT and protein assay in hepatoma cell lines following exposure to cadmium chloride. Toxicol Lett. 2006;160(2):171-77.

90. Issa Y, Watts DC, Brunton PA, Waters CM, Duxbury AJ. Resin composite monomers alter MTT and LDH activity of human gingival fibroblasts in vitro. Dental Materials. 2004;20(1):12-20.

91. Geurtsen W, Lehmann F, Spahl W, Leyhausen G. Cytotoxicity of 35 dental resin composite monomers/additives in permanent $3 \mathrm{~T} 3$ and three human primary fibroblast cultures. J Biomed Mater Res. 1998;41(3):474-80.

92. Mosmann T. Rapid colorimetric assay for cellular growth and survival: Application to proliferation and cytotoxicity assays. J Immunol Methods. 1983;65(1-2):55-63.

93. Lupu AR, Popescu T. The noncellular reduction of MTT tetrazolium salt by $\mathrm{TiO} 2$ nanoparticles and its implications for cytotoxicity assays. Toxicol in Vitro. 2013;27(5):1445-50.

94. Fultz B, Howe J. Transmission electron microscopy and diffractometry of materials. 4th ed. Springer Berlin Heidelberg; 2013:1-59.

95. Busse G. Non-destructive polymer testing. in: Grellmann W, seidler S, editors. polymer testing. munich:Hanser. . 2007:454-55.

96. Busani T, Devine RAB. Dielectric and infrared properties of $\mathrm{TiO} 2$ films containing anatase and rutile. Semicond Sci Technol. 2005;20(8):870-75.

97. Morgado E, de Abreu MAS, Pravia ORC, Marinkovic BA, Jardim PM, Rizzo FC. A study on the structure and thermal stability of titanate nanotubes as a function of sodium content. Solid State Sci. 2006;8(8):888-900.

98. Innocenzi P. Infrared spectroscopy of sol-gel derived silica-based films: A spectramicrostructure overview. J Non Cryst Solids. 2003;316(2-3):309-19.

99. Cervantes-Uc JM, Cauich-Rodriguez JV, Vazquez-Torres H, Licea-Claverie A. TGA/FTIR study on thermal degradation of polymethacrylates containing carboxylic groups. Polym Degrad Stab. 2006;91(12):3312-21. 
100. A.K. Pahari BSC. Engineering chemistry.2nd ed. 2008:25.

101. Tian M, Gao Y, Liu Y, Liao Y, Xu R, Hedin NE. Bis-GMA/TEGDMA dental composites reinforced with electrospun nylon 6 nanocomposite nanofibers containing highly aligned fibrillar silicate single crystals. Polymer. 2007;48(9):272028 .

102. Chen Q, Zhou W, Du GH, Peng L-. Trititanate nanotubes made via a single alkali treatment. Adv Mater. 2002;14(17):1208-11.

103. Yuan Z, Su B. Titanium oxide nanotubes, nanofibers and nanowires. Colloids Surf Physicochem Eng Aspects. 2004;241(1-3):173-78.

104. Yuan Z, Colomer J, Su B. Titanium oxide nanoribbons. Chemical Physics Letters. 2002;363(3-4):362-66.

105. Wen Liu, Jianqin Gao, Fengbao Zhang and Guoliang Zhang. Preparation of TiO2 nanotubes and their photocatalytic properties in degradation methylcyclohexane. Materials Transactions. 2007;48(9):2464-66.

106. Karabela MM, Sideridou ID. Effect of the structure of silane coupling agent on sorption characteristics of solvents by dental resin-nanocomposites. Dental Materials. 2008;24(12):1631-39.

107. Rong Y, Chen H-, Wu G, Wang M. Preparation and characterization of titanium dioxide nanoparticle/polystyrene composites via radical polymerization. Mater Chem Phys. 2005;91(2-3):370-74.

108. Zhu M, Xing Q, He H, Zhang Y, Chen Y, Pötschke P Adler HJ. Preparation of PA6/nano titanium dioxide (TiO2) composites and their spinnability. Macromol. Symp. 2004;210(1):251-61.

109. Khaled SM, Sui R, Charpentier PA, Rizkalla AS. Synthesis of TiO(2)-PMMA nanocomposite: Using methacrylic acid as a coupling agent. Langmuir. 2007;23(7):3988-95.

110. Jiang F, Zheng S, An L, Chen H. Effect of calcination temperature on the adsorption and photocatalytic activity of hydrothermally synthesized $\mathrm{TiO} 2$ nanotubes. Appl Surf Sci. 2012;258(18):7188-94.

111. Mankad V, Gupta SK, Jha PK. Low frequency raman scattering of anatase titanium dioxide nanocrystals. Physica E: Low-dimensional Systems and Nanostructures. 2011;44(3):614-17. 
112. Yu J, Yu H, Cheng B, Trapalis C. Effects of calcination temperature on the microstructures and photocatalytic activity of titanate nanotubes. J. Mol. Catal. A: Chem. 2006;249(1-2):135-42.

113. Yu GJ, Yu HG, Cheng B, Zhao XJ, Yu JC, Ho WK. The effect of calcination temperature on the surface microstructure and photocatalytic activity of $\mathrm{TiO} 2$ thin films prepared by liquid phase deposition. J. Phys. Chem. B. 2003;107(50):1387179.

114. Beun S, Bailly C, Devaux J, Leloup G. Rheological properties of flowable resin composites and pit and fissure sealants. Dental Materials. 2008 4;24(4):548-55.

115. Helvatjoglu-Antoniades M, Papadogiannis Y, Lakes RS, Dionysopoulos P, Papadogiannis D. Dynamic and static elastic moduli of packable and flowable composite resins and their development after initial photo curing. Dental Materials. 2006;22(5):450-59.

116. Babikov OI. Ultrasonics and its industrial applications.translated from russian. New York: Consultants Bureau; 1960: 14,15.

117. Xu HHK, Smith DT, Jahanmir S, Romberg E, Kelly JR, Thompson VP, et al. Indentation damage and mechanical properties of human enamel and dentin. J Dent Res. 1998;77(3):472-80.

118. Nakayama W, Hall D, Grenoble D, Katz J. Elastic properties of dental resin restorative materials. J Dent Res. 1974;53(5):1121-26.

119. Willems G, Lambrechts P, Braem M, Celis JP, Vanherle G. A classification of dental composites according to their morphological and mechanical characteristics. Dental Materials. 1992;8(5):310-19.

120. Rees JS, Jacobsen PH. The elastic moduli of enamel and dentine. Clin Mater. 1993;14(1):35-39.

121. Braga RR, Meira JBC, Boaro LCC, Xavier TA. Adhesion to tooth structure: A critical review of "macro" test methods. Dental Materials. 2010;26(2):38-49.

122. Schultz S, Rosentritt M, Behr M, Handel G. Mechanical properties and three-body wear of dental restoratives and their comparative flowable materials. Quintessence Int. 2010;41(1):1-10.

123. Bouschlicher MR, Cobb DS, Boyer DB. Radiopacity of compomers, flowable and conventional resin composites for posterior restorations. Oper Dent. 1999;24(1):2025 . 
124. Goshima T, Goshima Y. The optimum level of radiopacity in posterior composite resins. Dentomaxillofac Radiol. 1989;18(1):19-21.

125. Matsumura H, Sueyoshi M, Atsuta M. Radiopacity and physical properties of titanium-polymethacrylate composite. J Dent Res. 1992;71(1):2-6.

126. Labella R, Lambrechts P, Van Meerbeek B, Vanherle G. Polymerization shrinkage and elasticity of flowable composites and filled adhesives. Dental Materials. 1999;15(2):128-37.

127. Sabbagh J, Vreven J, Leloup G. Radiopacity of resin-based materials measured in film radiographs and storage phosphor plate (digora). Oper Dent. 2004;29(6):677-84.

128. Watts DC, McCabe JF. Aluminium radiopacity standards for dentistry: An international survey. J Dent. 1999;27(1):73-78.

129. Furtos G, Baldea B, Silaghi-Dumitrescu L, Bratu D, Moldovan M, Prejmerean C. Measuring the radiopacity of flowable resin composites using scanned radiograph images. Particul Sci Technol. 2012;30(5):391-402.

130. Dukic W, Delija B, Derossi D, Dadic I. Radiopacity of composite dental materials using a digital X-ray system. Dent Mater J. 2012;31(1):47-53.

131. Fotakis G, Timbrell JA. In vitro cytotoxicity assays: Comparison of LDH, neutral red, MTT and protein assay in hepatoma cell lines following exposure to cadmium chloride. Toxicol Lett. 2006;160(2):171-77.

132. Ciapetti G, Cenni E, Pratelli L, Pizzoferrato A. In vitro evaluation of cell/biomaterial interaction by MTT assay. Biomaterials. 1993;14(5):359-64.

133. Green LM, Reade JL, Ware CF. Rapid colorimetric assay for cell viability: Application to the quantitation of cytotoxic and growth inhibitory lymphokines. $\mathbf{J}$ Immunol Methods. 1984;70(2):257-68.

134. Ciapetti G, Cenni E, Pratelli L, Pizzoferrato A. In vitro evaluation of cell/biomaterial interaction by MTT assay. Biomaterials. 1993;14(5):359-64.

135. Murray PE, Garcia-Godoy F. Comparison of the clinical and preclinical biocompatibility testing of dental materials: Are the ISO usage tests meaningful? J Biomed Mater Res. 2007;81A(1):51-58. 


\title{
List of Appendices
}

\author{
Appendix A
}

\section{Copyrights Permissions}

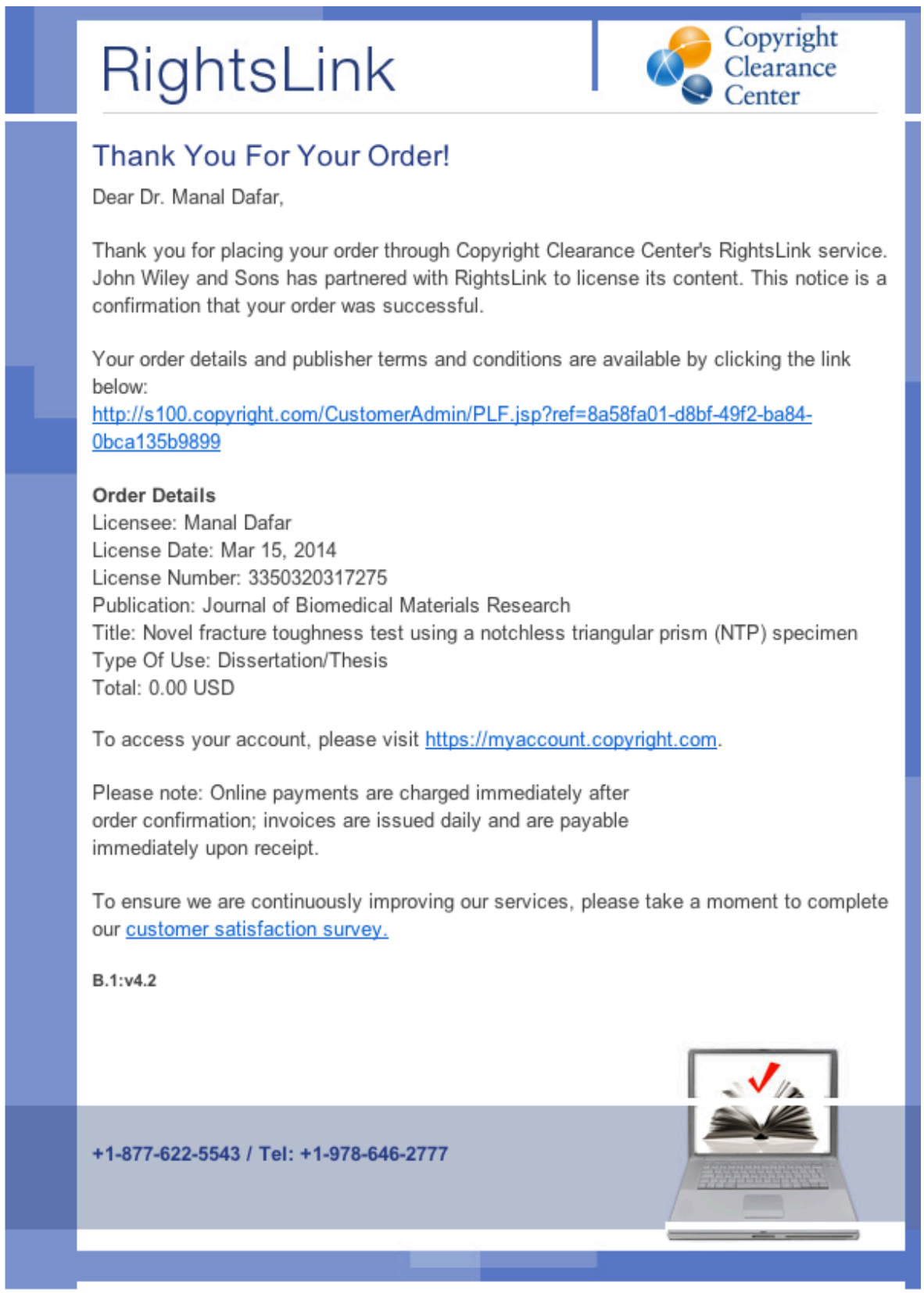


This is a License Agreement between Manal Dafar ("You") and John Wiley and Sons ("John Wiley and Sons") provided by Copyright Clearance Center ("CCC"). The license consists of your order details, the terms and conditions provided by John Wiley and Sons, and the payment terms and conditions.

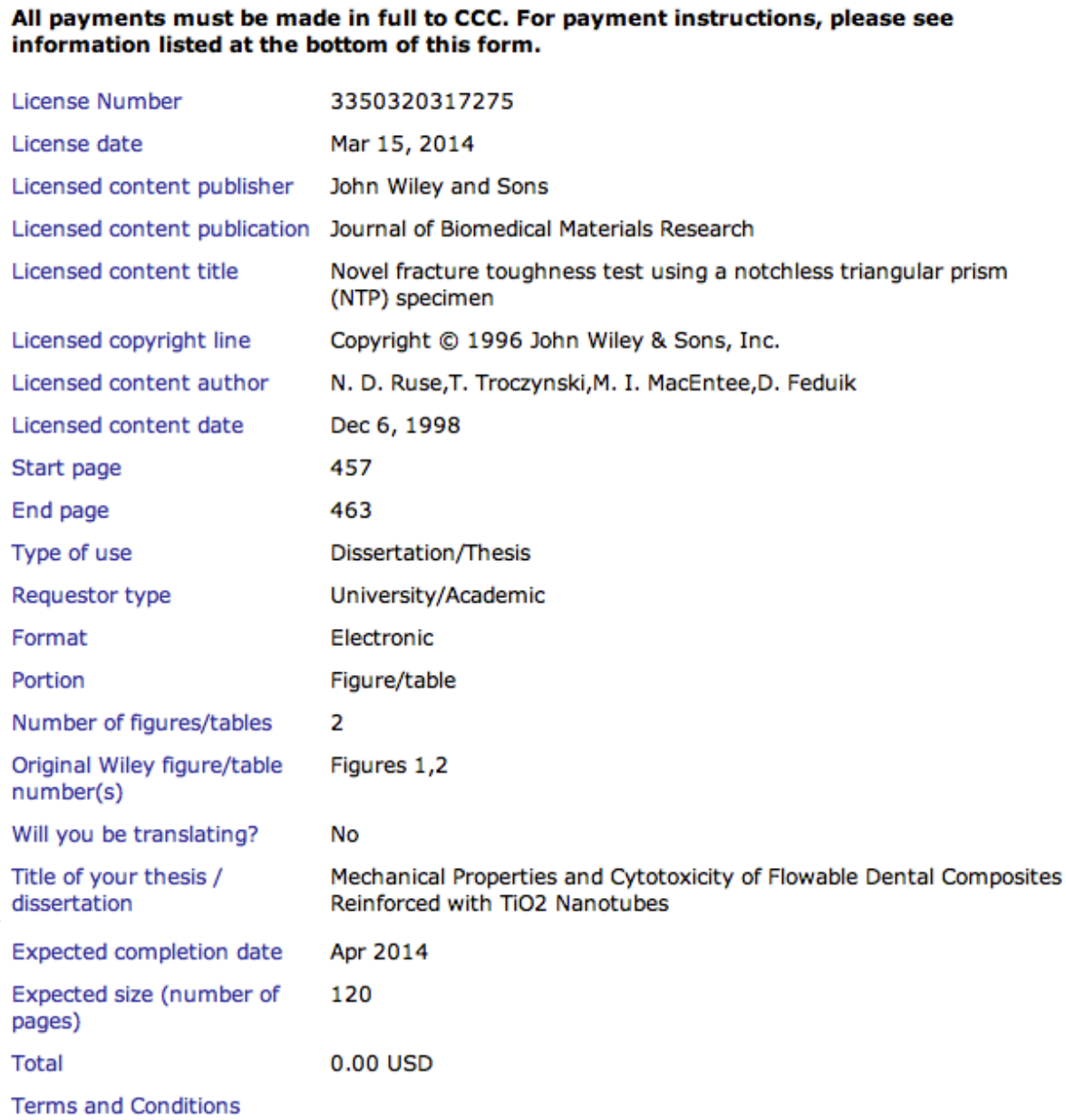

Terms and Conditions

\section{TERMS AND CONDITIONS}

This copyrighted material is owned by or exclusively licensed to John Wiley \& Sons, Inc. or one of its group companies (each a "Wiley Company") or a society for whom a Wiley Company has exclusive publishing rights in relation to a particular journal (collectively "WILEY"). By clicking "accept" in connection with completing this licensing transaction, you agree that the following terms and conditions apply to this transaction (along with the billing and payment terms and conditions established by the Copyright Clearance Center Inc., ("CCC's Billing and Payment terms and conditions"), at the time that you opened your RightsLink account (these are available at any time at http://myaccount.copyright.com).

\section{Terms and Conditions}

1. The materials you have requested permission to reproduce (the "Materials") are protected by copyright. 
2.You are hereby granted a personal, non-exclusive, non-sublicensable, non-transferable, worldwide, limited license to reproduce the Materials for the purpose specified in the licensing process. This license is for a one-time use only with a maximum distribution equal to the number that you identified in the licensing process. Any form of republication granted by this license must be completed within two years of the date of the grant of this license (although copies prepared before may be distributed thereafter). The Materials shall not be used in any other manner or for any other purpose. Permission is granted subject to an appropriate acknowledgement given to the author, title of the material/book/journal and the publisher. You shall also duplicate the copyright notice that appears in the Wiley publication in your use of the Material. Permission is also granted on the understanding that nowhere in the text is a previously published source acknowledged for all or part of this Material. Any third party material is expressly excluded from this permission.

3. With respect to the Materials, all rights are reserved. Except as expressly granted by the terms of the license, no part of the Materials may be copied, modified, adapted (except for minor reformatting required by the new Publication), translated, reproduced, transferred or distributed, in any form or by any means, and no derivative works may be made based on the Materials without the prior permission of the respective copyright owner. You may not alter, remove or suppress in any manner any copyright, trademark or other notices displayed by the Materials. You may not license, rent, sell, loan, lease, pledge, offer as security, transfer or assign the Materials, or any of the rights granted to you hereunder to any other person.

4. The Materials and all of the intellectual property rights therein shall at all times remain the exclusive property of John Wiley \& Sons Inc or one of its related companies (WILEY) or their respective licensors, and your interest therein is only that of having possession of and the right to reproduce the Materials pursuant to Section 2 herein during the continuance of this Agreement. You agree that you own no right, title or interest in or to the Materials or any of the intellectual property rights therein. You shall have no rights hereunder other than the license as provided for above in Section 2 . No right, license or interest to any trademark, trade name, service mark or other branding ("Marks") of WILEY or its licensors is granted hereunder, and you agree that you shall not assert any such right, license or interest with respect thereto.

\section{NEITHER WILEY NOR ITS LICENSORS MAKES ANY WARRANTY OR REPRESENTATION OF ANY KIND TO YOU OR ANY THIRD PARTY, EXPRESS, IMPLIED OR STATUTORY, WITH RESPECT TO THE MATERIALS OR THE ACCURACY OF ANY INFORMATION CONTAINED IN THE MATERIALS, INCLUDING, WITHOUT LIMITATION, ANY IMPLIED WARRANTY OF MERCHANTABILITY, ACCURACY, SATISFACTORY QUALITY, FITNESS FOR A PARTICULAR PURPOSE, USABILITY, INTEGRATION OR NON-INFRINGEMENT AND ALL SUCH WARRANTIES ARE HEREBY EXCLUDED BY WILEY AND ITS LICENSORS AND WAIVED BY YOU.}

6. WILEY shall have the right to terminate this Agreement immediately upon breach of this Agreement by you.

7. You shall indemnify, defend and hold harmless WILEY, its Licensors and their respective directors, officers, agents and employees, from and against any actual or threatened claims, demands, causes of action or proceedings arising from any breach of this Agreement by you.

8. IN NO EVENT SHALL WILEY OR ITS LICENSORS BE LIABLE TO YOU OR ANY OTHER PARTY OR ANY OTHER PERSON OR ENTITY FOR ANY SPECIAL, CONSEQUENTIAL, INCIDENTAL, INDIRECT, EXEMPLARY OR PUNITIVE DAMAGES, HOWEVER CAUSED, ARISING OUT OF OR IN CONNECTION WITH THE DOWNLOADING, PROVISIONING, VIEWING OR USE OF THE MATERIALS REGARDLESS OF THE FORM OF ACTION, WHETHER FOR BREACH OF CONTRACT, BREACH OF WARRANTY, TORT, NEGLIGENCE, INFRINGEMENT OR OTHERWISE (INCLUDING, WITHOUT LIMITATION, DAMAGES BASED ON LOSS OF PROFITS, DATA, FILES, USE, BUSINESS OPPORTUNITY OR CLAIMS OF THIRD PARTIES), AND WHETHER OR NOT THE PARTY HAS BEEN ADVISED OF THE POSSIBILITY OF SUCH DAMAGES. THIS LIMITATION SHALL APPLY NOTWITHSTANDING ANY FAILURE OF ESSENTIAL PURPOSE OF ANY LIMITED REMEDY PROVIDED HEREIN. 
9. Should any provision of this Agreement be held by a court of competent jurisdiction to be illegal, invalid, or unenforceable, that provision shall be deemed amended to achieve as nearly as possible the same economic effect as the original provision, and the legality, validity and enforceability of the remaining provisions of this Agreement shall not be affected or impaired thereby.

10. The failure of either party to enforce any term or condition of this Agreement shall not constitute a waiver of either party's right to enforce each and every term and condition of this Agreement. No breach under this agreement shall be deemed waived or excused by either party unless such waiver or consent is in writing signed by the party granting such waiver or consent. The waiver by or consent of a party to a breach of any provision of this Agreement shall not operate or be construed as a waiver of or consent to any other or subsequent breach by such other party.

11. This Agreement may not be assigned (including by operation of law or otherwise) by you without WILEY's prior written consent.

12. Any fee required for this permission shall be non-refundable after thirty (30) days from receipt

13. These terms and conditions together with CCC's Billing and Payment terms and conditions (which are incorporated herein) form the entire agreement between you and WILEY concerning this licensing transaction and (in the absence of fraud) supersedes all prior agreements and representations of the parties, oral or written. This Agreement may not be amended except in writing signed by both parties. This Agreement shall be binding upon and inure to the benefit of the parties' successors, legal representatives, and authorized assigns.

14. In the event of any conflict between your obligations established by these terms and conditions and those established by CCC's Billing and Payment terms and conditions, these terms and conditions shall prevail.

15. WILEY expressly reserves all rights not specifically granted in the combination of (i) the license details provided by you and accepted in the course of this licensing transaction, (ii) these terms and conditions and (iii) CCC's Billing and Payment terms and conditions.

16. This Agreement will be void if the Type of Use, Format, Circulation, or Requestor Type was misrepresented during the licensing process.

17. This Agreement shall be governed by and construed in accordance with the laws of the State of New York, USA, without regards to such state's conflict of law rules. Any legal action, suit or proceeding arising out of or relating to these Terms and Conditions or the breach thereof shall be instituted in a court of competent jurisdiction in New York County in the State of New York in the United States of America and each party hereby consents and submits to the personal jurisdiction of such court, waives any objection to venue in such court and consents to service of process by registered or certified mail, return receipt requested, at the last known address of such party.

\section{Wiley Open Access Terms and Conditions}

Wiley publishes Open Access articles in both its Wiley Open Access Journals program [http://www.wileyopenaccess.com/view/index.html] and as Online Open articles in its subscription journals. The majority of Wiley Open Access Journals have adopted the Creative Commons Attribution License (CC BY) which permits the unrestricted use, distribution, reproduction, adaptation and commercial exploitation of the article in any medium. No permission is required to use the article in this way provided that the article is properly cited and other license terms are observed. A small number of Wiley Open Access journals have retained the Creative Commons Attribution Non Commercial License (CC BY-NC), which permits use, distribution and reproduction in any medium, provided the original work is properly cited and is not used for commercial purposes.

Online Open articles - Authors selecting Online Open are, unless particular exceptions apply, offered a choice of Creative Commons licenses. They may therefore select from the CC BY, the CC BY-NC and the Attribution-NoDerivatives (CC BY-NC-ND). The CC BY-NC-ND is more restrictive than the $\mathrm{CC} B \mathrm{BY}-\mathrm{NC}$ as it does not permit adaptations or modifications without rights holder consent. 
Wiley Open Access articles are protected by copyright and are posted to repositories and websites in accordance with the terms of the applicable Creative Commons license referenced on the article. At the time of deposit, Wiley Open Access articles include all changes made during peer review, copyediting, and publishing. Repositories and websites that host the article are responsible for incorporating any publisher-supplied amendments or retractions issued subsequently.

Wiley Open Access articles are also available without charge on Wiley's publishing platform, Wiley Online Library or any successor sites.

Conditions applicable to all Wiley Open Access articles:

- The authors' moral rights must not be compromised. These rights include the right of "paternity" (also known as "attribution" - the right for the author to be identified as such) and "integrity" (the right for the author not to have the work altered in such a way that the author's reputation or integrity may be damaged).

- Where content in the article is identified as belonging to a third party, it is the obligation of the user to ensure that any reuse complies with the copyright policies of the owner of that content.

- If article content is copied, downloaded or otherwise reused for research and other purposes as permitted, a link to the appropriate bibliographic citation (authors, journal, article title, volume, issue, page numbers, DOI and the link to the definitive published version on Wiley Online Library) should be maintained. Copyright notices and disclaimers must not be deleted.

- Creative Commons licenses are copyright licenses and do not confer any other rights, including but not limited to trademark or patent rights.

- Any translations, for which a prior translation agreement with Wiley has not been agreed, must prominently display the statement: "This is an unofficial translation of an article that appeared in a Wiley publication. The publisher has not endorsed this translation."

\section{Conditions applicable to non-commercial licenses (CC BY-NC and CC BY-NC- ND)}

For non-commercial and non-promotional purposes individual non-commercial users may access, download, copy, display and redistribute to colleagues Wiley Open Access articles. In addition, articles adopting the CC BY-NC may be adapted, translated, and text- and data-mined subject to the conditions above.

\section{Use by commercial "for-profit" organizations}

Use of non-commercial Wiley Open Access articles for commercial, promotional, or marketing purposes requires further explicit permission from Wiley and will be subject to a fee. Commercial purposes include:

- Copying or downloading of articles, or linking to such articles for further redistribution, sale or licensing;

- Copying, downloading or posting by a site or service that incorporates advertising with such content;

- The inclusion or incorporation of article content in other works or services (other than normal quotations with an appropriate citation) that is then available for sale or licensing, for a fee (for example, a compilation produced for marketing purposes, inclusion in a sales pack)

- Use of article content (other than normal quotations with appropriate citation) by for-profit organizations for promotional purposes

- Linking to article content in e-mails redistributed for promotional, marketing or educational purposes; 
- Use for the purposes of monetary reward by means of sale, resale, license, loan, transfer or other form of commercial exploitation such as marketing products

- Print reprints of Wiley Open Access articles can be purchased from: corporatesales@wiley.com

The modification or adaptation for any purpose of an article referencing the $\mathrm{CC}$ BY-NC-ND License requires consent which can be requested from

RightsLink@wiley.com.

Other Terms and Conditions:

BY CLICKING ON THE "I AGREE..." BOX, YOU ACKNOWLEDGE

THAT YOU HAVE READ AND FULLY UNDERSTAND EACH OF THE SECTIONS OF AND PROVISIONS SET FORTH IN THIS AGREEMENT AND THAT YOU ARE IN AGREEMENT WITH AND ARE WILLING TO ACCEPT ALL OF YOUR OBLIGATIONS AS SET FORTH IN THIS AGREEMENT.

$\mathbf{v 1 . 8}$

\begin{abstract}
If you would like to pay for this license now, please remit this license along with your payment made payable to "COPYRIGHT CLEARANCE CENTER" otherwise you will be invoiced within $\mathbf{4 8}$ hours of the license date. Payment should be in the form of a check or money order referencing your account number and this invoice number RLNK501251826.

Once you receive your invoice for this order, you may pay your invoice by credit card. Please follow instructions provided at that time.
\end{abstract}

Make Payment To:

Copyright Clearance Center

Dept 001

P.o. Box 843006

Boston, MA 02284-3006

For suggestions or comments regarding this order, contact RightsLink Customer Support: customercare@copyright.com or +1-877-622-5543 (toll free in the US) or +1978-646-2777.

Gratis licenses (referencing $\$ 0$ in the Total field) are free. Please retain this printable license for your reference. No payment is required. 


\section{RightsLink

\section{Thank You For Your Order!}

Dear Dr. Manal Dafar,

Thank you for placing your order through Copyright Clearance Center's RightsLink service. Elsevier has partnered with RightsLink to license its content. This notice is a confirmation

that your order was successful.

Your order details and publisher terms and conditions are available by clicking the link below:

http://s100. copyright.com/CustomerAdmin/PLF.jsp?ref=7fad952c-6d62-4242-9c33a90caccb5a1b

\section{Order Details}

Licensee: Manal Dafar

License Date: Mar 29, 2014

License Number: 3358360228697

Publication: Dental Materials

Title: Review of the fracture toughness approach

Type Of Use: reuse in a thesis/dissertation

Total: 0.00 USD

To access your account, please visit https://myaccount.copyright.com.

Please note: Online payments are charged immediately after order confirmation; invoices are issued daily and are payable immediately upon receipt.

To ensure that we are continuously improving our services, please take a moment to complete our customer satisfaction survey.

B.1:v4.2

+1-877-622-5543/ Tel: +1-978-646-2777

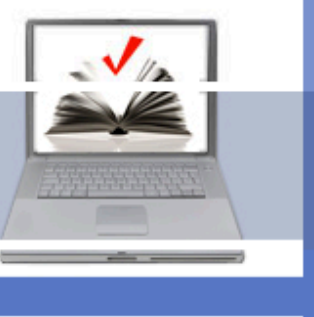


This is a License Agreement between Manal Dafar ("You") and Elsevier ("Elsevier") provided by Copyright Clearance Center ("CCC"). The license consists of your order details, the terms and conditions provided by Elsevier, and the payment terms and conditions.

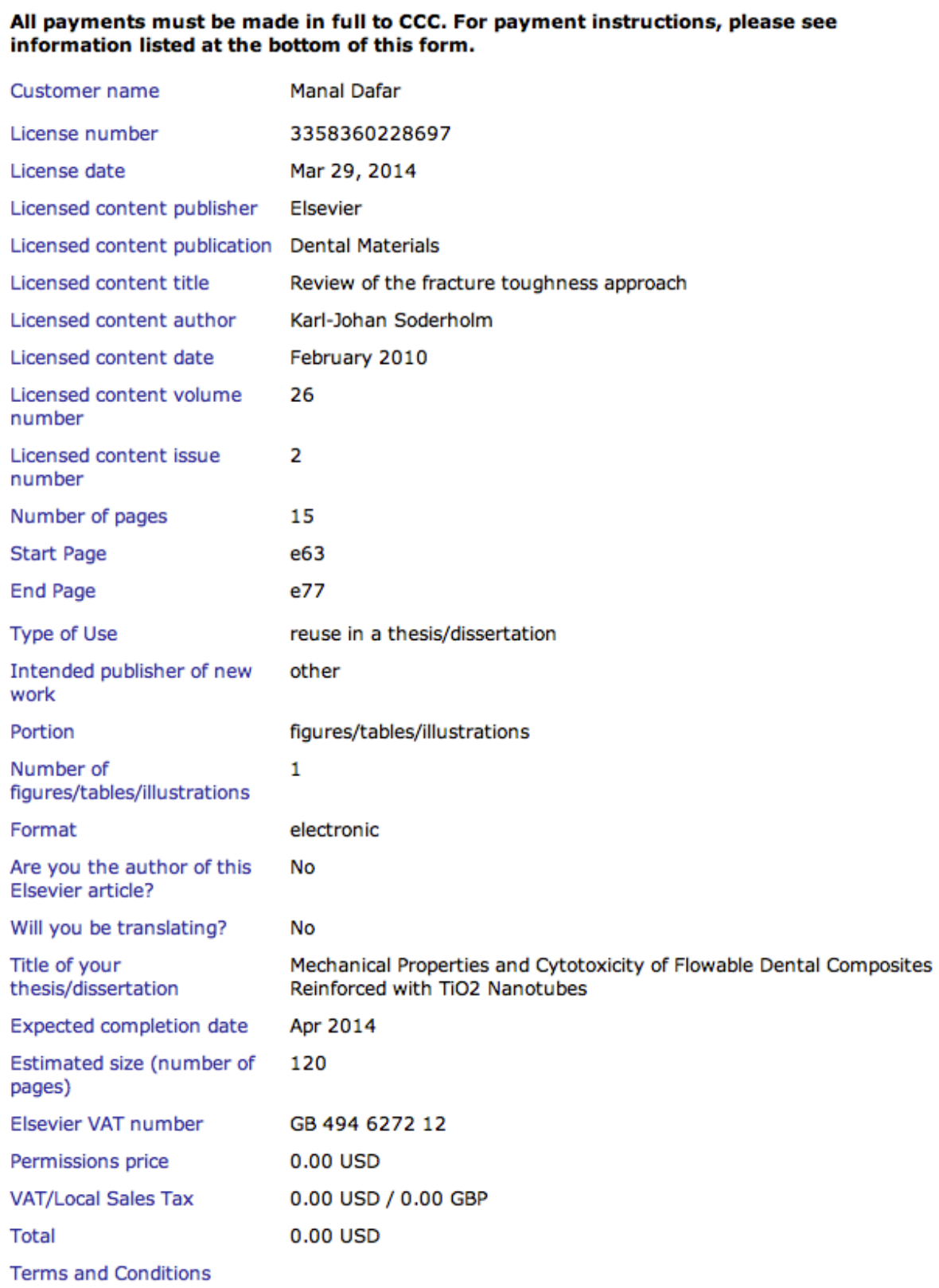

Customer name

License number

License date

Licensed content publisher

Licensed content publication

Licensed content title

Licensed content author

Licensed content date

Licensed content volume number

Licensed content issue

number

Number of pages

Start Page

End Page

Type of Use

Intended publisher of new work

Portion

Number of

figures/tables/illustrations

Format

Are you the author of this

Elsevier article?

Will you be translating?

Title of your

thesis/dissertation

Expected completion date

Estimated size (number of pages)

Elsevier VAT number

Permissions price

VAT/Local Sales Tax

Total

Terms and Conditions

Manal Dafar

3358360228697

Mar 29, 2014

Elsevier

Dental Materials

Review of the fracture toughness approach

Karl-Johan Soderholm

February 2010

26

2

15

e63

e77

reuse in a thesis/dissertation

other

figures/tables/illustrations

1

electronic

No

No

Mechanical Properties and Cytotoxicity of Flowable Dental Composites Reinforced with TiO2 Nanotubes

Apr 2014

120

GB 494627212

0.00 USD

0.00 USD / 0.00 GBP

0.00 USD 


\section{INTRODUCTION}

1. The publisher for this copyrighted material is Elsevier. Byclicking "accept" in connection with completing this licensingtransaction, you agree that the following terms and conditions apply to thistransaction (along with the Billing and Payment terms and conditionsestablished by Copyright Clearance Center, Inc. ("CCC"), at the timethat you opened your Rightslink account and that are available at any time at http://myaccount.copyright.com).

\section{GENERAL TERMS}

2. Elsevier hereby grants you permission to reproduce the aforementionedmaterial subject to the terms and conditions indicated.

3. Acknowledgement: If any part of the material to be used (for example,figures) has appeared in our publication with credit or acknowledgement toanother source, permission must also be sought from that source. If suchpermission is not obtained then that material may not be included in yourpublication/copies. Suitable acknowledgement to the source must be made, eitheras a footnote or in a reference list at the end of your publication, asfollows:

"Reprinted from Publication title, Vol /edition number, Author(s), Title ofarticle / title of chapter, Pages No., Copyright (Year), with permission fromElsevier [OR APPLICABLE SOCIETY COPYRIGHT OWNER]." Also Lancet special credit -"Reprinted from The Lancet, Vol. number, Author(s), Title of article, PagesNo., Copyright (Year), with permission from Elsevier."

4. Reproduction of this material is confined to the purpose and/or media forwhich permission is hereby given.

5. Altering/Modifying Material: Not Permitted. However figures andillustrations may be altered/adapted minimally to serve your work. Any otherabbreviations, additions, deletions and/or any other alterations shall be madeonly with prior written authorization of Elsevier Ltd. (Please contact Elsevierat permissions@elsevier.com)

6. If the permission fee for the requested use of our material is waived inthis instance, please be advised that your future requests for Elseviermaterials may attract a fee.

7. Reservation of Rights: Publisher reserves all rights not specificallygranted in the combination of (i) the license details provided by you andaccepted in the course of this licensing transaction, (ii) these terms andconditions and (iii) CCC's Billing and Payment terms and conditions.

8. License Contingent Upon Payment: While you may exercise the rightslicensed immediately upon issuance of the license at the end of the licensingprocess for the transaction, provided that you have disclosed complete andaccurate details of your proposed use, no license is finally effective unlessand until full payment is received from you (either by publisher or by CCC) asprovided in CCC's Billing and Payment terms and conditions. If fullpayment is not received on a timely basis, then any license preliminarilygranted shall be deemed automatically revoked and shall be void as if nevergranted. Further, in the event that you breach any of these terms andconditions or any of CCC's Billing and Payment terms and conditions, thelicense is automatically revoked and shall be void as if never granted. Use of materials as described in a revoked license, as well as any use of thematerials beyond the scope of an unrevoked license, may constitute copyrightinfringement and publisher reserves the right to take any and all action toprotect its copyright in the materials.

9. Warranties: Publisher makes no representations or warranties with respectto the licensed material. 
10. Indemnity: You hereby indemnify and agree to hold harmless publisher andCCC, and their respective officers, directors, employees and agents, from andagainst any and all claims arising out of your use of the licensed materialother than as specifically authorized pursuant to this license.

11. No Transfer of License: This license is personal to you and may not besublicensed, assigned, or transferred by you to any other person withoutpublisher's written permission.

12. No Amendment Except in Writing: This license may not be amended exceptin a writing signed by both parties (or, in the case of publisher, by CCC onpublisher's behalf).

13. Objection to Contrary Terms: Publisher hereby objects to any termscontained in any purchase order, acknowledgment, check endorsement or otherwriting prepared by you, which terms are inconsistent with these terms andconditions or CCC's Billing and Payment terms and conditions. These termsand conditions, together with CCC's Billing and Payment terms and conditions(which are incorporated herein), comprise the entire agreement between you andpublisher (and CCC) concerning this licensing transaction. In the eventof any conflict between your obligations established by these terms andconditions and those established by CCC's Billing and Payment terms andconditions, these terms and conditions shall control.

14. Revocation: Elsevier or Copyright Clearance Center may deny thepermissions described in this License at their sole discretion, for any reasonor no reason, with a full refund payable to you. Notice of such denialwill be made using the contact information provided by you.

Failure toreceive such notice will not alter or invalidate the denial. In no eventwill Elsevier or Copyright Clearance Center be responsible or liable for anycosts, expenses or damage incurred by you as a result of a denial of yourpermission request, other than a refund of the amount(s) paid by you toElsevier and/or Copyright Clearance Center for denied permissions.

\section{LIMITED LICENSE}

The following terms and conditions apply only to specific license types:

15. Translation: This permission is granted fornon-exclusive world English rights only unless yourlicense was granted for translation rights. If you licensed translation rightsyou may only translate this content into the languages you requested. Aprofessional translator must perform all translations and reproduce the contentword for word preserving the integrity of the article. If this license is tore-use 1 or 2 figures then permission is granted for non-exclusive world rightsin all languages.

16. Posting licensed content on any Website: The followingterms and conditions apply as follows: Licensing material from an Elsevierjournal: All content posted to the web site must maintain the copyright informationline on the bottom of each image; A hyper-text must be included to the Homepageof the journal from which you are licensing at http://www sciencedirect.com/science/journal/xxxxx orthe Elsevier homepage for books at http://www.elsevier.com; CentralStorage: This license does not include permission for a scanned version of thematerial to be stored in a central repository such as that provided byHeron/XanEdu.

Licensing material from an Elsevier book: A hyper-text link must be includedto the Elsevier homepage at http://www.elsevier.com . Allcontent posted to the web site must maintain the copyright information line onthe bottom of each image.

Posting licensed content on Electronic reserve: In addition to the above the following clausesare applicable: The web site must be password-protected and made available onlyto bona fide students registered on a relevant course. This permission isgranted for 1 year only. You may obtain a new license for future websiteposting.

For journal authors: the following clauses are applicable inaddition to the above: Permission granted is limited to the author acceptedmanuscript version* of your paper. 
*Accepted Author Manuscript (AAM) Definition: An accepted authormanuscript (AAM) is the author's version of the manuscript of an article thathas been accepted for publication and which may include any author-incorporatedchanges suggested through the processes of submission processing, peer review, and editor-author communications. AAMs do not include other publishervalue-added contributions such as copy-editing, formatting, technicalenhancements and (if relevant) pagination.

You are not allowed to download and post the published journal article (whetherPDF or HTML, proof or final version), nor may you scan the printed edition tocreate an electronic version. A hyper-text must be included to the Homepage ofthe journal from which you are licensing at http://www.sciencedirect.com/science/journal/xxxxx. As part of our normal production process, you will receive an e-mail noticewhen your article appears on Elsevier's online service ScienceDirect(www.sciencedirect.com). That e-mail will include the article's Digital ObjectIdentifier (DOI). This number provides the electronic link to the publishedarticle and should be included in the posting of your personal version. We askthat you wait until you receive this e-mail and have the DOI to do any posting.

Posting to a repository: Authorsmay post their AAM immediately to their employer's institutional repository forinternal use only and may make their manuscript publically available after thejournal-specific embargo period has ended.

Please also refer to Elsevier'sArticle Posting Policy for further information.

18. For book authors the following clauses are applicable in addition tothe above: Authors are permitted to place a briefsummary of their work online only.. You are notallowed to download and post the published electronic version of your chapter,nor may you scan the printed edition to create an electronic version. Posting to a repository: Authors arepermitted to post a summary of their chapter only in their institution'srepository.

20. Thesis/Dissertation: If your license is for use in athesis/dissertation your thesis may be submitted to your institution in eitherprint or electronic form. Should your thesis be published commercially, pleasereapply for permission. These requirements include permission for the Libraryand Archives of Canada to supply single copies, on demand, of the completethesis and include permission for UMI to supply single copies, on demand, ofthe complete thesis. Should your thesis be published commercially, pleasereapply for permission.

\section{Elsevier Open Access Terms andConditions}

Elsevier publishes Open Access articles in both its Open Access journals andvia its Open Access articles option in subscription journals.

Authors publishing in an Open Access journal or who choose to make theirarticle Open Access in an Elsevier subscription journal select one of thefollowing Creative Commons user licenses, which define how a reader may reusetheir work: Creative Commons Attribution License (CC BY), Creative CommonsAttribution - Non Commercial - ShareAlike (CC BY NCSA) and Creative Commons Attribution - Non Commercial - No Derivatives (CC BYNC ND)

\section{Terms \& Conditions applicable toall Elsevier Open Access articles:}

Any reuse of the article must not represent the author as endorsing theadaptation of the article nor should the article be modified in such a way asto damage the author's honour or reputation.

The author(s) must be appropriately credited.

If any part of the material to be used (for example, figures) has appearedin our publication with credit or acknowledgement to another source it is theresponsibility of the user to ensure their reuse complies with the terms andconditions determined by the rights holder. 
Additional Terms \& Conditionsapplicable to each Creative Commons user license:

CC BY: You may distribute andcopy the article, create extracts, abstracts, and other revised versions,adaptations or derivative works of or from an article (such as a translation),to include in a collective work (such as an anthology), to text or data minethe article, including for commercial purposes without permission from Elsevier

CC BY NC SA: For non-commercialpurposes you may distribute and copy the article, create extracts, abstractsand other revised versions, adaptations or derivative works of or from anarticle (such as a translation), to include in a collective work (such as ananthology), to text and data mine the article and license new adaptations or creationsunder identical terms without permission from Elsevier

CC BY NC ND: For non-commercialpurposes you may distribute and copy the article and include it in a collectivework (such as an anthology), provided you do not alter or modify the article,without permission from Elsevier

Any commercial reuse of Open Access articles published with a CC BY NC SA

CC BY NC NDlicense requires permission from Elsevier and will be subject to a fee.

Commercial reuse includes:

- Promotional purposes (advertising or marketing)

- Commercial exploitation (e.g. a product forsale or loan)

- Systematic distribution (for a fee or free ofcharge)

Please refer to Elsevier'sOpen Access Policy for further information.

21. Other Conditions:

v1.7

If you would like to pay for this license now, please remit this license along with your payment made payable to "COPYRIGHT CLEARANCE CENTER" otherwise you will be invoiced within $\mathbf{4 8}$ hours of the license date. Payment should be in the form of a check or money order referencing your account number and this invoice number RLNK501264180.

Once you receive your invoice for this order, you may pay your invoice by credit card. Please follow instructions provided at that time.

Make Payment To:

Copyright Clearance Center

Dept 001

P.O. Box 843006

Boston, MA 02284-3006

For suggestions or comments regarding this order, contact RightsLink Customer Support: customercare@copyright.com or +1-877-622-5543 (toll free in the US) or +1978-646-2777.

Gratis licenses (referencing $\$ 0$ in the Total field) are free. Please retain this printable license for your reference. No payment is required. 
Copyright Clearance Center

ACS Publications Title:

High quality. High impact.
Structure Analysis of Nanowires and Nanobelts by Transmission Electron Microscopy

Author: Yong Ding and and Zhong Lin Wang*

Publication: The Journal of Physical Chemistry B

Publisher: American Chemical Society

Date: Aug 1, 2004

Copyright (c) 2004, American Chemical Society
Logged in as: Manal Dafar Account \#: 3000762382

\section{LOGOUT}

\section{PERMISSION/LICENSE IS GRANTED FOR YOUR ORDER AT NO CHARGE}

This type of permission/license, instead of the standard Terms \& Conditions, is sent to you because no fee is being charged for your order. Please note the following:

- Permission is granted for your request in both print and electronic formats, and translations.

- If figures and/or tables were requested, they may be adapted or used in part.

- Please print this page for your records and send a copy of it to your publisher/graduate school.

- Appropriate credit for the requested material should be given as follows: "Reprinted (adapted) with permission from (COMPLETE REFERENCE CITATION). Copyright (YEAR) American Chemical Society." Insert appropriate information in place of the capitalized words.

- One-time permission is granted only for the use specified in your request. No additional uses are granted (such as derivative works or other editions). For any other uses, please submit a new request.

If credit is given to another source for the material you requested, permission must be obtained from that source. 
Copyright

Clearance

\section{ACS Publications ritle:}

High quality. High impact.
Synthesis of TiO2-PMMA

Nanocomposite: Using Methacrylic Acid as a Coupling Agent

Author: $\quad$ S. M. Khaled, $t$, Ruohong Sui, + , Paul A. Charpentier, $*,+$ and, and Amin S. Rizkalla†, $\neq$

Publication: Langmuir

Publisher: American Chemical Society

Date: Mar 1, 2007

Copyright (c) 2007, American Chemical Society

Logged in as:

Manal Dafar

Account \#: 3000762382

\section{LOGOUT}

\section{PERMISSION/LICENSE IS GRANTED FOR YOUR ORDER AT NO CHARGE}

This type of permission/license, instead of the standard Terms \& Conditions, is sent to you because no fee is being charged for your order. Please note the following:

- Permission is granted for your request in both print and electronic formats, and translations.

- If figures and/or tables were requested, they may be adapted or used in part.

- Please print this page for your records and send a copy of it to your publisher/graduate school.

- Appropriate credit for the requested material should be given as follows: "Reprinted (adapted) with permission from (COMPLETE REFERENCE CITATION). Copyright (YEAR) American Chemical Society." Insert appropriate information in place of the capitalized words.

- One-time permission is granted only for the use specified in your request. No additional uses are granted (such as derivative works or other editions). For any other uses, please submit a new request.

If credit is given to another source for the material you requested, permission must be obtained from that source. 


\section{Appendix B}

\section{Composition of Filtek ${ }^{\mathrm{TM}}$ Supreme Ultra Flowable Restorative, 3M}

\section{ESPE as Supplied by Manufacturer}

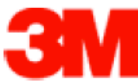

\section{Material Safety Data Sheet}

Copyright, 2013, 3M Company All rights reserved. Copying and/or downloading of this information for the purpose of properly utilizing $3 \mathrm{M}$ products is allowed provided that: (1) the information is copied in full with no changes unless prior written agreement is obtained from $3 \mathrm{M}$, and (2) neither the copy nor the original is resold or otherwise distributed with the intention of earning a profit thereon.

\section{SECTION 1: PRODUCT AND COMPANY IDENTIFICATION}

PRODUCT NAME: 6032/ 6033 3M MM $^{\mathrm{TM}}$ ESPE $^{\mathrm{TM}}$ FILTEK ${ }^{\mathrm{TM}}$ SUPREME ULTRA FLOWABLE RESTORATIVE

MANUFACTURER: $3 \mathrm{M}$

DIVISION: 3M ESPE Dental Products

ADDRESS: 3M Center, St. Paul, MN 55144-1000

\section{EMERGENCY PHONE: 1-800-364-3577 or (651) 737-6501 (24 hours)}

Issue Date: 03/14/13

Supercedes Date： $05 / 04 / 10$

Document Group： 27-9483-2

Product Use:
Intended Use:
Dental product
Limitations on Use:
For use only by dental professionals
Specific Use:
Composite restorative material

\section{SECTION 2: INGREDIENTS}

Ingredient
SILANE TREATED CERAMIC
SUBSTITUTED DIMETHACRYLATE
BISPHENOL A DIGLYCIDYL ETHER DIMETHACRYLATE (BISGMA)
SILANE TREATED SILICA
TRIETHYLENE GLYCOL DIMETHACRYLATE (TEGDMA)
Ytterbium fluoride (YbF3)
FUNCTIONALIZED DIMETHACRYLATE POLYMER
TITANIUM DIOXIDE
ETHYL 4-DIMETHYL AMINOBENZOATE (EDMAB)
BENZOTRIAZOL
DIPHENYLIODONIUM HEXAFLUOROPHOSPHATE

DIPHENYLIODONIUM HEXAFLUOROPHOSPHATE

\begin{tabular}{ll} 
C.A.S. No. & \% by Wt \\
\cline { 2 - 2 } $444758-98-9$ & $50-60$ \\
$27689-12-9$ & $15-25$ \\
$1565-94-2$ & $5-10$ \\
$248596-91-0$ & $5-10$ \\
$109-16-0$ & $5-10$ \\
$13760-80-0$ & $<5$ \\
None & $<5$ \\
$13463-67-7$ & $<0.5$ \\
$10287-53-3$ & $<0.5$ \\
$96478-09-0$ & $<0.5$ \\
$58109-40-3$ & $<0.5$
\end{tabular}




\section{Curriculum Vitae}

Name:

Post-secondary Education and Degrees:

Honours and Awards:

Related Work Experience:
Manal Dafar

M.Sc. candidate, Medical Biophysics Graduate Program Schulich School of Medicine \& Dentistry Western University London, Ontario, Canada $2012-2014$

Bachelor Degree in Dental Medicine and Surgery (B.D.S) King Abdulaziz University Jeddah, Saudi Arabia $2002-2008$

Scholarship for graduate and clinical studies Ministry of Health, Saudi Arabia $2012-2014$

Certificate of achieving second honour degree

School of Dentistry, King Abdulaziz University

Jeddah, Saudi Arabia

2008

Dental resident

King Fahad General Hospital

Jeddah, Saudi Arabia

$2010-2011$

Dental intern

King Abdulaziz University Hospital

Jeddah, Saudi Arabia

$2008-2009$ 


\section{Posters and presentations:}

March 2014: Mechanical properties and cytotoxicity of flowable dental composites reinforced with $\mathrm{TiO}_{2}$ nanotubes. London Health Research Day, London ON, Canada.

June 2013: Flowable dental composites; indications and limitations. UWO, London ON, Canada

March 2012: Dental implant biomaterials, UWO, London ON, Canada

March 2009: Hyperbaric oxygen therapy in dentistry, Department of Maxillofacial Surgery, King Fahad Armed Forces Hospital, Jeddah, Saudi Arabia

Nov 2007: Fracture resistance of all-ceramic restorations, Faculty of Dentistry, King Abdulaziz University, Jeddah, Saudi Arabia 